\begin{abstract}
UNIVERSIDADE DE BRASÍLIA
FACULDADE GAMA / FACULDADE DE TECNOLOGIA PROGRAMA DE PÓS-GRADUAÇÃO EM INTEGRIDADE DE MATERIAIS DA ENGENHARIA
\end{abstract}

\begin{abstract}
OBTENÇÃO E CARACTERIZAÇÃO DE COMPÓSITOS BIODEGRADÁVEIS DE POLIÁCIDO LACTICO (PLA) REFORÇADOS COM FIBRAS DE CURAUÁ
\end{abstract}

JANAÍNE MÔNICA DE OLIVEIRA

ORIENTADORA: Profa Dra ${ }^{\mathrm{a}}$ SANDRA MARIA DA LUZ

DISSERTAÇÃO DE MESTRADO EM INTEGRIDADE DE MATERIAIS DA ENGENHARIA

PUBLICAÇÃO: FGA.DM - 039A/2016

BRASÍLIA/DF: 08/2016 


\begin{abstract}
UNIVERSIDADE DE BRASÍLIA
FACULDADE GAMA / FACULDADE DE TECNOLOGIA PROGRAMA DE PÓS-GRADUAÇÃO EM INTEGRIDADE DE MATERIAIS DA ENGENHARIA.
\end{abstract}

JANAÍNE MÔNICA DE OLIVEIRA

\begin{abstract}
OBTENÇÃO E CARACTERIZAÇÃO DE COMPÓSITOS BIODEGRADÁVEIS DE POLIÁCIDO LÁCTICO (PLA) REFORÇADOS COM FIBRAS DE CURAUÁ
\end{abstract}

DISSERTAČ̃̃o DE MESTRADO SUBMETIDA AO PROGRAMA DE PÓSGRADUAÇẢO EM INTEGRIDADE DE MATERIAIS DA ENGENHARIA DA FACULDADE GAMA E FACULDADE DE TECNOLOGIA DA UNIVERSIDADE DE BRASÍLIA, COMO PARTE DOS REQUISITOS NECESSÁRIOS PARA A OBTENÇÃO DO GRAU DE MESTRA EM INTEGRIDADE DE MATERIAIS DA ENGENHARIA.

ORIENTADORA: Prof ${ }^{a}$ Dra $^{\mathrm{a}}$. SANDRA MARIA DA LUZ

BRASÍLIA/DF 
UNIVERSIDADE DE BRASÍLIA

FACULDADE GAMA / FACULDADE DE TECNOLOGIA

PROGRAMA DE PÓS-GRADUAÇÃO EM INTEGRIDADE DE MATERIAIS DA ENGENHARIA

\section{OBTENÇÃO E CARACTERIZAÇÃO DE COMPÓSITOS BIODEGRADÁVEIS DE POLIÁCIDO LÁCTICO (PLA) REFORÇADOS COM FIBRAS DE CURAUÁ}

\section{JANAÍNE MÔNICA DE OLIVEIRA}

DISSERTAÇÃO DE MESTRADO SUBMETIDA AO PROGRAMA DE PÓS-GRADUAÇÃO EM INTEGRIDADE DE MATERIAIS DA ENGENHARIA DA FACULDADE GAMA E FACULDADE DE TECNOLOGIA DA UNIVERSIDADE DE BRASÍLIA, COMO PARTE DOS REQUISITOS NECESSÁRIOS PARA A OBTENÇÃO DO GRAU DE MESTRA EM INTEGRIDADE DE MATERIAIS DA ENGENHARIA.

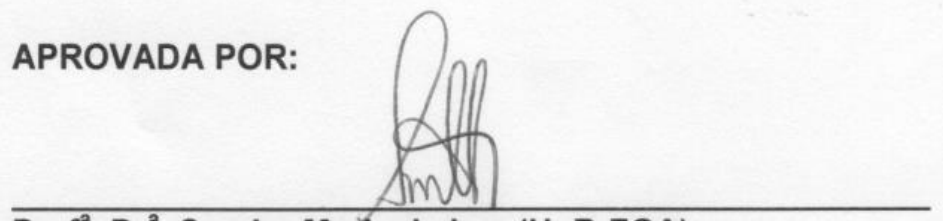

Prof ${ }^{a}$. Dr ${ }^{a}$. Sandra María da Luz (UnB-FGA)

Orientadora

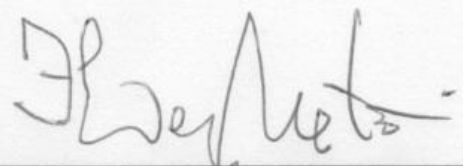

Prof. Dr. Flamínio Levy Neto (UnB-FT)

Examinador externo

Prof. Bra Carla Tatiana Mota Anflor (UnB-FGA)

Examinadora interna 
FICHA CATALOGRÁFICA

Janaíne Mônica de Oliveira

Obtenção e caracterização de compósitos biodegradáveis de Poliácido Láctico (PLA) reforçados com fibras de curauá, Distrito Federal, 2016. 86 f. (FGA/FT/UnB, Mestra, Integridade de Materiais da Engenharia, 2016). Dissertação de Mestrado Universidade de Brasília, Publicação FGA.DM - 039A/2016. Faculdade UnB Gama. Programa de Pós-Graduação em Integridade de Materiais da Engenharia.

1. PLA

3. MERCERIZAÇÃO

I. FGA/FT/UnB
2. CURAUÁ

4. COMPÓSITOS BIODEGRADÁVEIS

II. Mestre (FGA.DM - 039A/2016)

\section{REFERÊNCIA BIBLIOGRÁFICA}

OLIVEIRA, J. M. (2016). Obtenção e caracterização de compósitos biodegradáveis de poliácido láctico (PLA) reforçados com fibras de curauá. Dissertação de Mestrado em Integridade de Materiais da Integridade da Engenharia, Publicação: FGA.DM 039A/2016, Faculdade UnB Gama/FT/Universidade de Brasília, DF, 86 f..

\section{CESSÃO DE DIREITOS}

AUTOR: Janaíne Mônica de Oliveira

TÍTULO: Obtenção e caracterização de compósitos biodegradáveis de poliácido láctico (PLA) reforçados com fibras de curauá.

GRAU: Mestra

ANO: 2016

É concedida à Universidade de Brasília permissão para reproduzir cópias desta dissertação de mestrado e para emprestar ou vender tais cópias somente para propósitos acadêmicos e científicos. O autor reserva outros direitos de publicação e nenhuma parte desta dissertação de mestrado pode ser reproduzida sem a autorização por escrito do autor.

Janaíne Mônica de Oliveira

Rua Cacau, 157 - Vila Operária

CEP: 76350-000 Rubiataba, GO - Brasil.

monica.janaine@gmail.com 
Aos meus pais e ao meu noivo Vítor. 


\section{AGRADECIMENTOS}

À Deus pela plenitude de seu amor, pela perseverança e pela sabedoria.

Aos meus pais Divilmar e Sandra, por todo o apoio, pelas palavras de sabedoria nos momentos difíceis, pela paciência e pelo carinho que sempre me deram.

Ao meu irmão e cunhada, Marcos Henrique e Priscilla, pelo carinho e amizade.

À minha sogra Doralice e cunhada Carla, pelo carinho, respeito e amizade.

À minha orientadora Sandra, pela paciência, carinho, cuidado e orientação em todos os momentos.

Ao meu noivo Vítor, por todo amor, carinho, paciência e companheirismo durante mais esta etapa.

Aos meus amigos, pela compreensão e paciência.

Ao professor Ademir Zattera e sua equipe da Universidade de Caxias do Sul.

Ao professor Sandro Amico e sua equipe da UFRGS, em especial à Tiane e Stephanie 


\section{RESUMO}

Oliveira, J. M. Obtenção e caracterização de compósitos biodegradáveis de poliácido láctico (PLA) reforçados com fibras de curauá, 2016, 86 f., Dissertação (Mestrado em Integridade de Materiais da Engenharia) - Faculdade UnB Gama/Faculdade de Tecnologia, Universidade de Brasília, 2016.

Com o advento da tecnologia moderna, ocorreu um aumento descontrolado no uso das reservas naturais, o que tem causado efeitos negativos ao meio ambiente provocados pela utilização de forma destrutiva dos recursos pelos homens. Nos últimos anos a busca por tecnologias que possibilitem a utilização de produtos com menor impacto ambiental tem crescido significativamente, dentro disto o equilíbrio entre o homem e a natureza passou a ter uma consideração especial no desenvolvimento de produtos. Em busca de solucionar este problema, várias pesquisas e trabalhos foram e estão sendo realizados nesta área, e uma alternativa aos polímeros convencionais são os compósitos poliméricos de matriz biodegradável reforçados com fibras naturais. O presente trabalho estuda as características mecânicas, térmicas e morfológicas de compósitos de PLA reforçados com fibras de curauá. Foram avaliados compósitos com dois teores diferentes de fibra de curauá, 10 e $20 \% \mathrm{~m} / \mathrm{m}$, puras ou tratadas superficialmente. A fim de melhorar a interface entre matriz e reforço, as fibras de curauá foram submetidas a duas rotas de tratamento, a primeira consistiu em uma lavagem da fibra com água a $80^{\circ} \mathrm{C}$ por 2 horas e sua posterior mercerização com solução de $\mathrm{NaOH} 5 \% \mathrm{~m} / \mathrm{v}$. A segunda rota de tratamento consistiu na lavagem da fibra de curauá com $\mathrm{NaClO}$ em temperatura ambiente por 5 horas e sua posterior mercerização em solução de $\mathrm{NaOH} 5 \% \mathrm{~m} / \mathrm{v}$. Os compósitos foram processados em extrusora e os corpos de prova de tração, flexão e impacto foram injetados. Foram produzidos compósitos de PLA/Curauá com a fibra in natura, com a fibra resultante da rota de tratamento com água e mercerização e com a fibra resultante da rota de tratamento com $\mathrm{NaClO}$ e mercerização. As fibras de curauá in natura e após cada etapa de tratamento foram avaliadas quanto aos teores lignocelulósicos, cristalinidade, morfologia e comportamento térmico por meio das técnicas de Termogravimetria (TGA), calorimetria exploratória diferencial (DSC), difração de raio-x (DRX) e microscopia eletrônica de varredura (MEV). O comportamento térmico e cristalinidade dos compósitos foram obtidos por meio das técnicas TGA e DSC e o comportamento 
mecânico avaliado por meio de ensaios de tração, flexão e impacto. Foi determinado o índice de fluidez para o compósito e a seção de ruptura dos corpos de prova de tração foram estudadas por meio de micrografias de MEV. Os resultados mostraram que a lavagem da fibra com água não retira componentes estruturais da fibra de curauá, enquanto que com a lavagem da fibra com $\mathrm{NaClO}$ ocorre a retirada de componentes estruturais. A maior cristalinidade das fibras foi obtida para as fibras lavadas com $\mathrm{NaClO}$. A adição da fibra na matriz de PLA causou uma pequena diminuição na estabilidade térmica do material. O compósito de PLA/curauá lavado com água e mercerizado $(20 \% \mathrm{~m} / \mathrm{m})$ apresentou o melhor resultado no comportamento mecânico, tanto nos ensaios de tração quanto flexão. Este compósito aumentou em $57 \%$ no módulo de elasticidade e $29 \%$ da resistência à tração em relação ao polímero puro.

Palavras chaves: PLA, curauá, compósito biodegradável, mercerização, tratamento superficial. 


\begin{abstract}
With the advent of modern technology, there was an uncontrolled increase in the use of natural resources, which has caused negative effects to the environment by the use of resources in a destructive way by men. In recent years the search for technologies that enable the use of products with less environmental impact has grown considerably within this balance between man and nature have been given special consideration in product development. In seeking to solve this problem, various researches and studies have been and are being conducted in this area, and an alternative to conventional polymers are biodegradable polymeric matrix composites reinforced with natural fibers. This paper studies the mechanical, thermal and morphological properties of PLA composites reinforced with fibers curauá.
\end{abstract} Composites were evaluated with two different curauá fiber content, 10 and $20 \%$ wt pure or surface treated. In order to improve the interface between matrix and reinforcement, the curauá fibers were subjected to two treatment routes, the first consisted of a fiber water wash at $80^{\circ} \mathrm{C}$ for 2 hours and subsequent mercerizing with $\mathrm{NaOH} 5 \% \mathrm{w} / \mathrm{v}$. The second treatment route consisted of curauá fiber washing with $\mathrm{NaClO}$ at room temperature for 5 hours and subsequent mercerization $\mathrm{NaOH}$ solution $5 \% \mathrm{w} / \mathrm{v}$. The composites were processed in twin screw corrotating extruder and tensile, bending and impact test specimens were injection molded into miniinjector. Composites were prepared with the fiber in nature, with the resulting fiber treatment with water and mercerizing and the resulting fiber treatment with $\mathrm{NaClO}$ and mercerizing. The fibers curauá in natura and after each treatment step were evaluated for lignocellulosic content, crystallinity, morphology and thermal behavior by means of Thermogravimetry techniques (TGA), Differential Scanning Calorimetry (DSC), X-ray Diffraction (XRD) and Scanning Electron Microscopy (SEM). The thermal behavior and crystallinity of the composites were obtained by the TGA and DSC techniques and the mechanical behavior evaluated through tensile, bending and impact. It was determined the melt flow index for the composite and the break section of the tensile test specimens were studied by SEM micrographs. The results showed that the fiber of the water wash does not remove structural components of curauá fiber, while with the fiber washing with $\mathrm{NaClO}$ removes structural components. The higher crystallinity of the fibers was obtained for the fibers washed with $\mathrm{NaClO}$, because these showed lower levels of amorphous components. The addition of fiber in the PLA matrix caused a small decrease in thermal stability of the 
material. The composite PLA/curauá washed with water and mercerized $(20 \% \mathrm{w} / \mathrm{w})$ showed the best result in the mechanical behavior, both in tensile and bending tests. All composites showed an improvement in mechanical properties compared to pure polymer. The simplest surface treatment has increased the strength and crystallinity to the composite.

Keywords: PLA, curauá, biodegradable composites, mercerizing, superficial treatment. 


\section{LISTA DE ILUSTRAÇÕES}

Figura 1 - Estrutura química da celulose (a) e da lignina (b). Retirado de Albinante et al. (4). 5

Figura 2 - Classificação das fibras naturais segundo sua origem e exemplos.

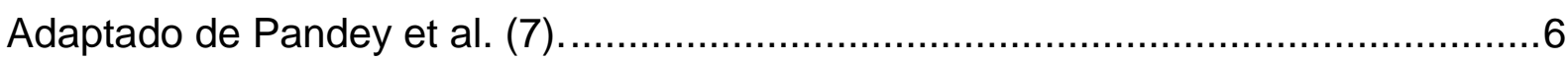

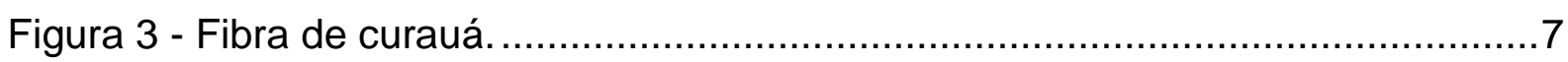

Figura 4 - Classificação dos polímeros biodegradáveis conforme sua origem.

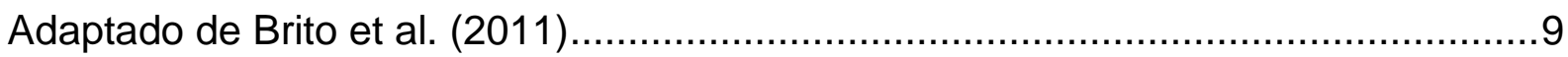

Figura 5 - Produção do PLA a partir do ácido lático e do lactídeo............................

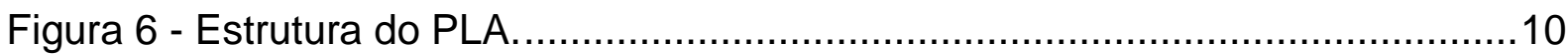

Figura 7 - Classificação dos materiais compósitos de acordo com o mecanismo de reforço utilizado. Elaborado de acordo Jones (21).

Figura 8 - Esquema de mercerização de uma fibra natural com hidróxido de sódio. 14

Figura 9 - Esquema de tratamento superficial das fibras de curauá 19

Figura 10 - Dimensões dos corpos de prova de tração, flexão e impacto. 23

Figura 11 - Esquema do ensaio de flexão mostrando o vão utilizado para o ensaio: $51 \mathrm{~mm}$.

Figura 12 - Fibras de curauá in natura $(A)$, após rota de tratamento com lavagem com água e mercerização com $\mathrm{NaOH} 5 \% \mathrm{~m} / \mathrm{v}$ (B) e após rota de tratamento com lavagem com solução de $\mathrm{NaCLO}(2 \%$ v/v) e mercerização com $\mathrm{NaOH} 5 \% \mathrm{~m} / \mathrm{v}$ (C). 27 Figura 13 - Micrografias MEV do curauá in natura e após processo de lavagem. a) e b) Curauá in natura. c) e d) curauá lavado com água quente. e) e f) curauá lavado com hipoclorito de sódio. .28

Figura 14 - Micrografias das fibras de curauá mercerizadas. a) e b) lavada com água quente e mercerizada. c) e d) lavada com hipoclorito de sódio e mercerizadas.

Figura 15 - Difratogramas para as amostras de fibra de curauá in natura e tratadas.

Figura 16 - Curvas TGA e DTG para as fibras de curauá in natura e tratadas. 35 Figura 17 - Espectros dos gases liberados durante a pirólise da amostra de curauá in natura. 38

Figura 18 - Espectro dos gases liberados pela queima da fibra de curauá para as amostras tratadas. 
Figura 19 - Corpos de prova de tração do PLA e seus compósitos com fibra de curauá. A) PLA puro. B) PLA/curauá in natura $10 \% \mathrm{~m} / \mathrm{m}$. c) PLA/curauá in natura $20 \% \mathrm{~m} / \mathrm{m}$. D) PLA/Curauá água- $\mathrm{NaOH} 10 \% \mathrm{~m} / \mathrm{m}$. E) PLA/Curauá água- $\mathrm{NaOH} 20 \%$ $\mathrm{m} / \mathrm{m}$. F) PLA/curauá NaClO-NaOH 10\% m/m G) PLA/curauá NaClO-NaOH 20\% $\mathrm{m} / \mathrm{m}$.

Figura 20 - Curvas TGA e DTG dos compósitos de PLA/curauá e do poliácido láctico puro. .42

Figura 21 - Curvas de DSC do PLA puro e dos seus compósitos com fibra de curauá.

Figura 22 - Curvas DSC do PLA e de seus compósitos no intervalo de temperaturas de 35 a $190^{\circ} \mathrm{C}$. 45

Figura 23 - Índice de fluidez para as amostras de PLA puro e seus compósitos com fibra de curauá.

Figura 24 - Comportamento tensão vs deformação em tração para o PLA e para os seus compósitos com fibras de curauá.

Figura 25 - Módulo de elasticidade em tração para o PLA e para seus compósitos com fibra de curauá.

Figura 26 - Limite de resistência à tração dos compósitos de PLA/fibra de curauá. .50 Figura 27 - Comportamento tensão vs deformação em flexão para o PLA e compósitos de PLA/fibra de curauá. .52

Figura 28 - módulo de elasticidade em flexão para o PLA e compósitos de PLA/fibra de curauá .52

Figura 29 - Limite de resistência à flexão para o PLA e compósitos de PLA/fibra de curauá. .53

Figura 30 - Resistência ao impacto Izod para o PLA e para os compósitos de PLA/fibra de curauá. .54

Figura 31 - Região fraturada do corpo de prova do ensaio de tração para os compósitos de PLA/fibra de curauá. a) PLA/Curauá in natura $10 \% \mathrm{~m} / \mathrm{m}$, b) PLA/Curauá in natura $20 \% \mathrm{~m} / \mathrm{m}$, c) PLA/Curauá água quente e mercerizado $10 \%$ $\mathrm{m} / \mathrm{m}$, d) PLA/Curauá água quente e mercerizado $20 \% \mathrm{~m} / \mathrm{m}$, e) PLA/Curauá $\mathrm{NaClO}$ e mercerizado $10 \% \mathrm{~m} / \mathrm{m}$ e f) PLA/Curauá $\mathrm{NaClO}$ e mercerizado $20 \% \mathrm{~m} / \mathrm{m}$. .56 Figura 32 - Micrografias da seção de ruptura dos corpos de tração para os compósitos mercerizados. a) PLA/Curauá água quente e mercerizada $10 \% \mathrm{~m} / \mathrm{m}$, b) 
PLA/Curauá água quente e mercerizada $20 \% \mathrm{~m} / \mathrm{m}$, c) PLA/Curauá $\mathrm{NaClO}$ e mercerizada $10 \% \mathrm{~m} / \mathrm{m}$ e d) PLA/Curauá $\mathrm{NaClO}$ e mercerizada $20 \% \mathrm{~m} / \mathrm{m}$..............57 


\section{LISTA DE TABELAS}

Tabela 1 - Composição química em massa de algumas fibras naturais. .5

Tabela 2 - Comparação entre módulo de elasticidade de algumas fibras naturais com a fibra de vidro.

Tabela 3 - Definições sobre as análises térmicas de TGA e DSC.

Tabela 4 - Caracterização lignocelulósica das fibras de curauá in natura e tratadas.

Tabela 5 - Índice de cristalinidade para as fibras de curauá obtidos pelo método de Segal. 34

Tabela 6 - Estabilidade térmica, resíduos, temperatura de início de perda de massa ( $T_{\text {on set }}$ ) e temperatura de pico de perda de massa ( $\left.T_{\text {pico }}\right)$ para as amostras de fibra de curauá in natura e tratadas .37

Tabela 7 - Entalpias de fusão, cristalização a frio e grau de cristalinidade para o PLA puro e para seus compósitos com fibra de curauá. 


\section{LISTA DE ABREVIATURAS E SIGLAS}

ASTM: American Society for Testing and Materials

CEAPAC: Centro de Apoio a Projetos de Ação Comunitária

DRX: difração de raio-X

DSC: calorimetria diferencial exploratória

DTG: análise termogravimétrica derivada

EMBRAPA: Empresa Brasileira de Pesquisa Agropecuária

FGA: Faculdade UnB Gama

FT: Faculdade de Tecnologia

MEV: microscopia eletrônica de varredura

PET: polietileno tereftalato

PHAs: polihidroxialcanoatos

PHB: polihidroxibutirato

PLA: poliácido láctico ou polilactato

PP: polipropileno

TGA: análise termogravimétrica

UFRGS: Universidade Federal do Rio Grande do Sul

UnB: Universidade de Brasília 


\section{LISTA DE SÍMBOLOS}

$\% \mathrm{~m} / \mathbf{m}$ : concentração percentual massa por massa $\% \mathrm{~m} / \mathbf{v}$ : concentração percentual massa por volume $\% \mathbf{v} / \mathbf{v}$ : concentração percentual volume por volume $\% \mathbf{X}_{c}$ : percentual de cristalinidade

$\Delta \mathbf{H}$ : variação de entalpia

$\Delta \mathbf{H}_{\mathrm{f}}$ : entalpia de fusão

$\Delta \mathbf{H}_{\mathrm{f}}^{\circ}$ : entalpia de fusão teórica

$\mu \mathrm{m}$ : micrômetro

${ }^{\circ} \mathbf{C}$ : grau Celsius (unidade de temperatura)

bar: unidade de pressão

$\mathrm{C}_{2} \mathrm{H}_{4}$ : eteno

$\mathrm{C}_{2} \mathrm{H}_{6}$ : etano

$\mathrm{CH}_{4}$ : metano

$\mathbf{c m}^{3}$ : centímetro cúbico (unidade de volume)

$\mathbf{c m}^{-1}$ : número de onda

CO: monóxido de carbono

$\mathrm{CO}_{2}$ : dióxido de carbono

g: grama

g/mol: grama por mol (unidade de peso molecular)

$\mathbf{g} / \mathbf{c m}^{3}$ : grama por centímetro cúbico (unidade de densidade)

GPa: giga pascal

h: hora

$\mathbf{H}_{2}$ : hidrogênio

$\mathrm{H}_{2} \mathrm{SO}_{4}$ : ácido sulfúrico

J: joule

$\mathbf{J} / \mathbf{g}$ : unidade de energia específica

$\mathbf{k N}$ : quilo newton

kV: quilo volt 
L/D: razão comprimento/diâmetro da rosca

mg: miligrama

min: minuto

mL: mililitro

mm: milímetro

MPa: mega pascal

$\mathbf{N}_{\mathbf{2}}$ : gás nitrogênio

NaCIO: hipoclorito de sódio

nm: nanômetro

$\mathrm{NaOH}$ : hidróxido de sódio

O: oxigênio

P.A.: reagente de grau analítico

rpm: rotações por minuto

$\mathbf{T}_{\mathrm{d}}$ : temperatura de degradação

$\mathbf{T}_{\mathbf{g}}$ : temperatura de transição vítrea

$\mathbf{T}_{\mathbf{f}}$ : temperatura de fusão

W: watt 


\section{SUMÁRIO}

1 INTRODUÇÃO

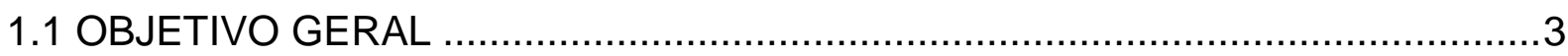

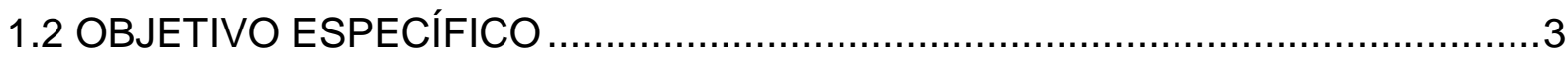

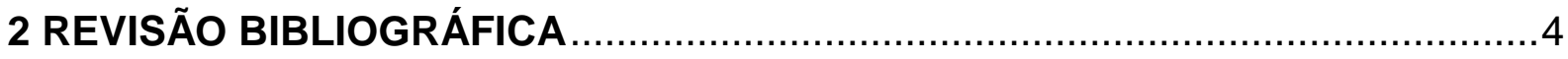

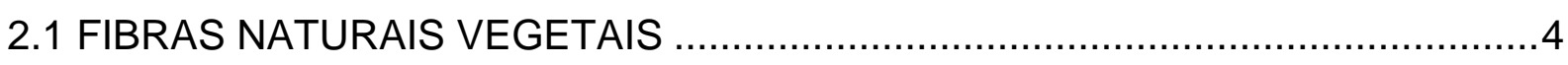

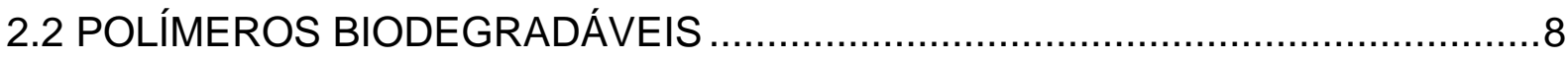

2.3 COMPÓSITOS COM MATRIZ POLIMÉRICA BIODEGRADÁVEL ......................11

2.4 ADESÃO ENTRE REFORÇO E MATRIZ ....................................................13

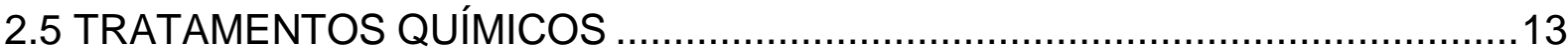

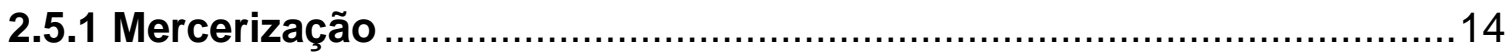

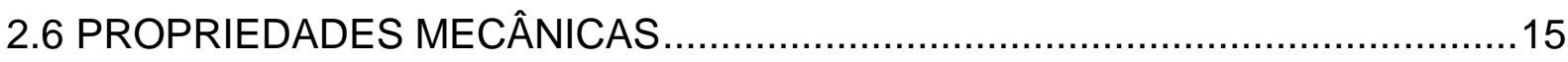

2.7 COMPORTAMENTO TÉRMICO DOS COMPÓSITOS ......................................16

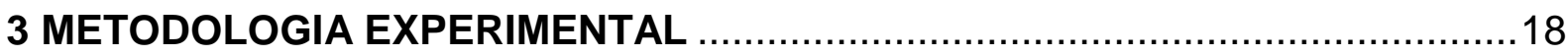

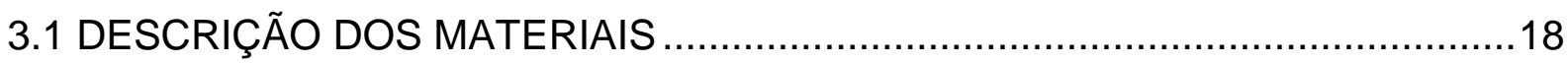

3.2 TRATAMENTO SUPERFICIAL DA FIBRA DE CURAUÁ................................18

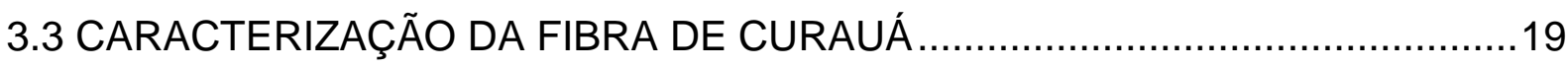

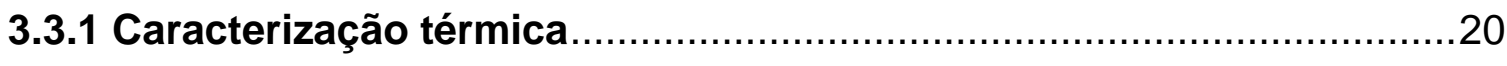

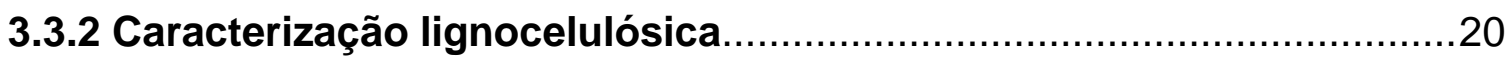

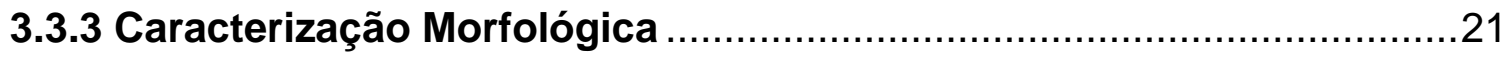

3.3.4 Grau de Cristalinidade das fibras de curauá ....................................22

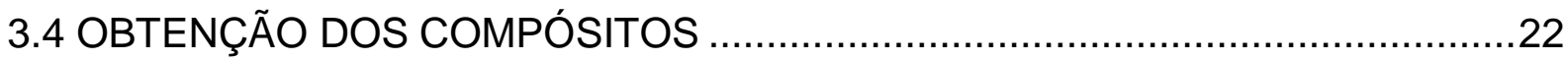

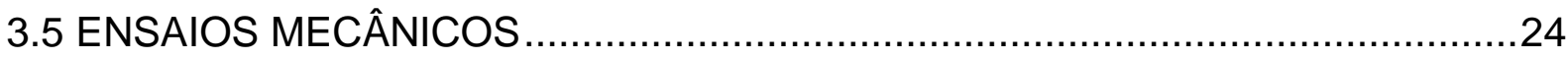

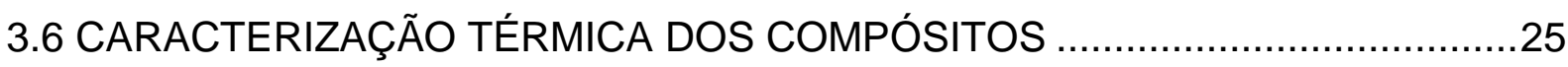

3.7 CARACTERIZAÇÃO DA INTERFACE DO COMPÓSITO …................................25 
4 RESULTADOS E DISCUSSÃO. .26

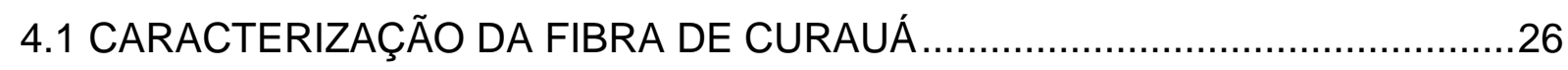

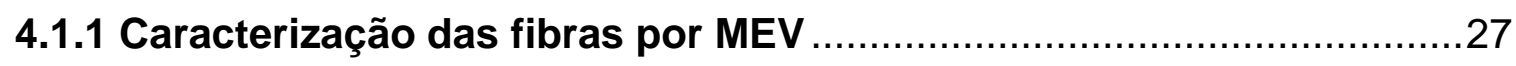

4.1.2 Caracterização lignocelulósica da fibra de curauá ...............................31

4.1.3 Grau de cristalinidade das fibras de curauá ......................................32

4.1.4 Comportamento térmico das fibras de curauá....................................34

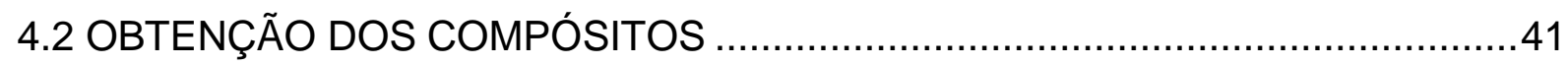

4.3 COMPORTAMENTO TÉRMICO DO COMPÓSITO …..................................... 41

4.4 DETERMINAÇÃO DO ÍNDICE DE FLUIDEZ …..........................................46

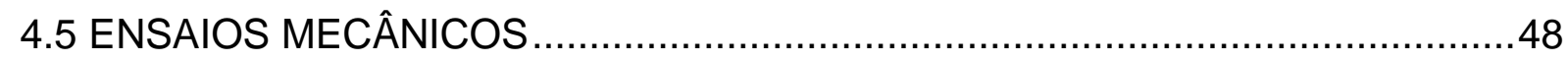

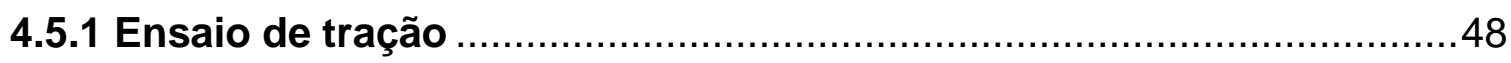

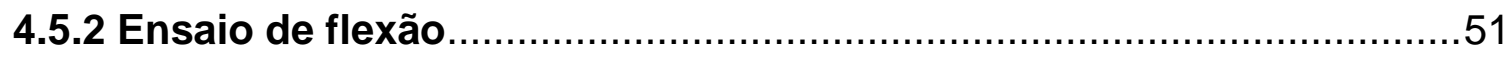

4.5.3 Ensaio de resistência ao impacto Izod. .............................................54

4.6 CARACTERIZAÇÃO DA REGIÃO DA FRATURA........................................55

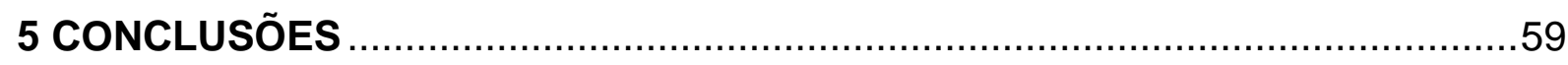

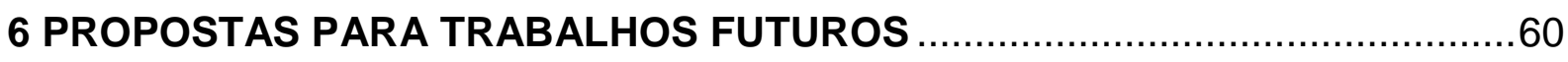

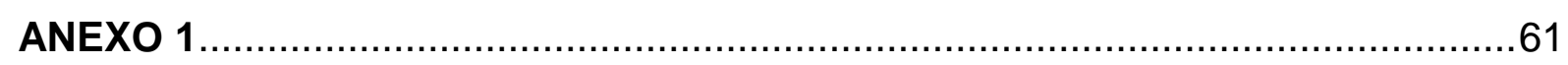

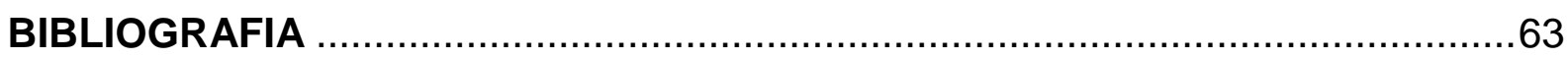




\section{INTRODUÇÃO}

Com o advento da tecnologia moderna, ocorreu um aumento descontrolado no uso das reservas naturais, o que tem causado efeitos negativos ao meio ambiente provocados pela utilização de forma destrutiva dos recursos pelos homens. Nos últimos anos a busca por tecnologias que possibilitem a utilização de produtos com menor impacto ambiental tem crescido bastante, dentro disto o equilíbrio entre o homem e a natureza passaram a ter uma consideração especial no desenvolvimento de produtos. Neste contexto os polímeros sintéticos acabam por receber uma atenção especial, visto que não são biodegradáveis e são derivados do petróleo, o que faz com que estes materiais acabem se acumulando em lixões e aterros sanitários. Em busca de solucionar este problema várias pesquisas e trabalhos foram e estão sendo realizados nesta área, e uma alternativa a estes polímeros convencionais são os compósitos poliméricos biodegradáveis.

Esta nova classe de materiais é constituída pela combinação entre polímeros biodegradáveis e fibras naturais. Os polímeros biodegradáveis são polímeros oriundos de fontes naturais e que podem ser totalmente degradados em condições específicas de solo e temperatura. Estes materiais possuem propriedades mecânicas e de processamento similares a termoplásticos convencionais, no entanto são biodegradáveis. As fibras naturais podem ser vegetais, minerais ou animais e são utilizadas desde os primórdios da humanidade para diversos fins, como sua utilização têxtil e na fabricação de papel. Um destaque maior pode ser dado as fibras naturais vegetais, devido à enorme variedade de plantas que podem ser utilizadas para a obtenção destas fibras.

As fibras vegetais podem também ser chamadas de fibras lignocelulósicas, devido ao fato de serem constituídas principalmente de lignina, hemicelulose e celulose. Sua utilização como reforço em termoplásticos convencionais já vem ocorrendo a algum tempo, isto porque as fibras vegetais possuem baixa densidade $e$ uma resistência mecânica considerável, o que faz com que sua resistência específica seja atrativa para utilização na indústria automotiva em peças não estruturais. A substituição do reforço de fibra de vidro por fibras vegetais oferece algumas vantagens como menor desgaste nos equipamentos de processamento, 
devido a menor abrasão das fibras vegetais, diminuição dos custos de fabricação do automóvel e maior eficiência, devido à menor densidade da fibra vegetal.

Para a obtenção dos compósitos poliméricos biodegradáveis vários fatores devem ser levados em conta, como a estabilidade térmica das fibras e da matriz, a toxicidade, a molhabilidade, a biodegradabilidade das duas fases e a compatibilidade entre a fibra e o polímero. Dentre estes, a compatibilidade entre as duas fases é o principal, pois o compósito apresentará boas propriedades apenas se os esforços suportados pela matriz forem transferidos de forma eficiente para as fibras. Para melhorar a interação interfacial entre fibra e matriz várias medidas podem ser tomadas, entre elas estão a adição de um agente compatibilizante, a adição de um copolímero ou o tratamento superficial da fibra vegetal. No que tange ao tratamento superficial da fibra, este pode ser realizado por ataque químico à fibra utilizando diferente tipos de reagentes, como acetilação, mercerização ou silanização. Todos estes tratamentos têm como objetivo melhorar a interface entre a matriz polimérica e a fibra vegetal. 


\subsection{OBJETIVO GERAL}

Obter compósitos biodegradáveis de PLA reforçados com fibras de curauá e estudar a incorporação da fibra de curauá na matriz de PLA e o comportamento mecânico, térmico e morfológico dos compósitos obtidos.

\subsection{OBJETIVO ESPECÍFICO}

- Promover o tratamento químico das fibras de curauá a serem utilizadas na fabricação do compósito.

- Caracterizar a morfologia, composição e propriedades térmicas das fibras de curauá.

- Obter os compósitos reforçados com a fibra de curauá.

- Estudar a influência dos teores de fibra de curauá nas propriedades mecânicas e térmicas dos compósitos.

- Determinar as propriedades mecânicas e térmicas dos compósitos preparados.

- Estudar como o tratamento químico da fibra de curauá influência nas propriedades térmicas e mecânicas dos compósitos.

- Estudar a área de ruptura dos compósitos. 


\section{REVISÃO BIBLIOGRÁFICA}

\subsection{FIBRAS NATURAIS VEGETAIS}

As fibras naturais são materiais lignocelulósicos, formados basicamente por celulose, hemicelulose e lignina. Além destes componentes também são encontrados compostos inorgânicos, carboidratos simples, resinas, gorduras e graxas. Estruturalmente, as fibras são formadas por feixes de células individuais chamadas fibrilas. Cada fibrila é formada por microfibrilas de celulose semicristalina envoltas numa matriz de hemicelulose e lignina, em teores variados (1). A composição química da fibra depende de vários fatores, entre eles as condições climáticas de plantio e a idade da planta, no entanto, em base seca todas as paredes celulares das plantas são constituídas por estes três componentes (2).

O principal componente das fibras naturais é a celulose, que é responsável pela resistência das fibras, devido ao seu alto grau de polimerização e orientação molecular. A celulose é um polímero linear cristalino formado por unidades de glicose unidas por ligações glicosídicas, conforme mostrado na Figura 1. As ligações covalentes no interior e entre as unidades de glicose conferem à celulose uma alta resistência à tração $(2,3)$. A unidade elementar da celulose é a celobiose, que apresenta várias hidroxilas e estabelecem ligações de hidrogênio intra-moleculares e intermoleculares, estas ligações são responsáveis pela característica hidrofílica da celulose.

A hemicelulose consiste de vários monossacarídeos polimerizados, que possui um alto grau de ramificação e contém vários tipos de açúcares, entre eles unidades de xilose, galactose e arabinose. Sendo um componente amorfo, as hemicelulose não conferem resistência mecânica à fibra (1).

A lignina é uma macromolécula formada por um sistema complexo, altamente aromático, reticulado, com elevada massa molar, amorfo, hidrofóbico e com ligações cruzados de tipo tridimensional, formadas a partir de unidades fenólicas (3) (4). A força de adesão entre as fibras de celulose e lignina é alta devido as ligações covalentes existentes entre as cadeias de lignina e os constituintes da celulose (1). 
a)

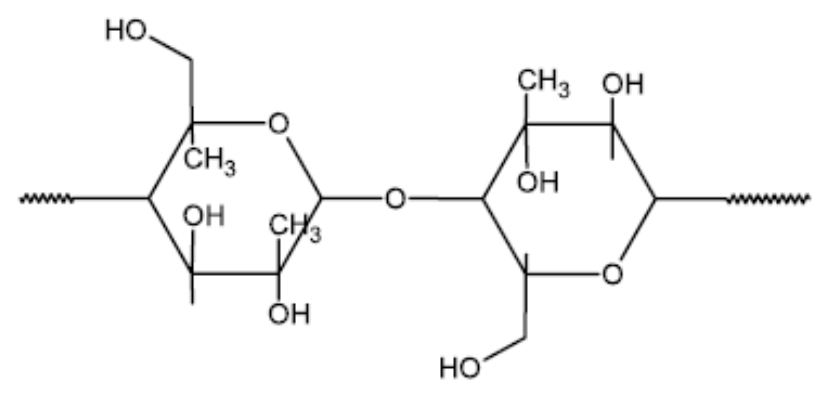

b)

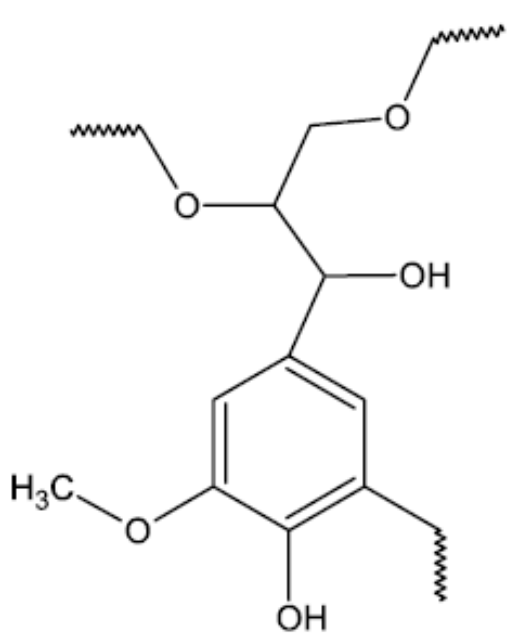

Figura 1 - Estrutura química da celulose (a) e da lignina (b). Retirado de Albinante et al. (4).

As propriedades químicas e físicas das fibras naturais são diretamente influenciadas pelas suas composições químicas. Faruk et al. (5) determinaram as composições químicas de algumas fibras naturais e alguns de seus resultados são apresentados na Tabela 1.

Tabela 1 - Composição química em massa de algumas fibras naturais.

Fibras

Bagaço de cana

Kenaf

Juta

Sisal

Abacá
Curauá
Celulose \%

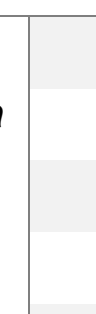

73,6

55,2

72

$$
61-71
$$

65

$56-63$
Hemicelulose \%

Lignina \%

Adaptado de Faruk et al. (5).

Dentre as vantagens na utilização das fibras naturais, estão seu peso leve, baixo custo e capacidade de renovação (2). Além de causarem menor desgaste nas ferramentas e menor irritação dérmica e respiratória quando comparadas às fibras de vidro e de carbono (6). As fibras naturais são classificadas de acordo com a sua obtenção, conforme mostra a Figura 2. 


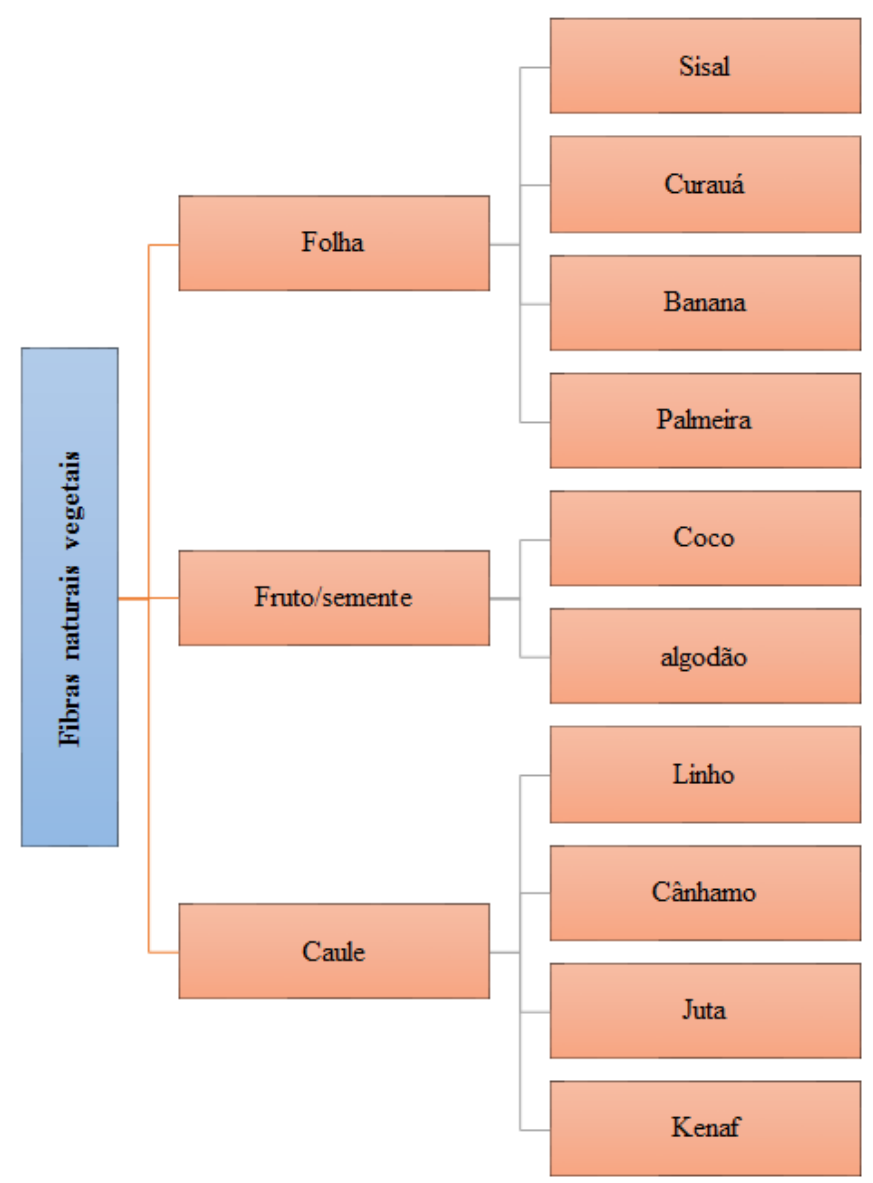

Figura 2 - Classificação das fibras naturais segundo sua origem e exemplos. Adaptado de Pandey et al. (7).

A escolha do tipo de fibra a ser utilizado depende da sua composição, propriedades e aplicação a ser destinada. Fibras de caule são muito utilizadas para a produção de papel e celulose. A juta tem sido muito utilizada em fabricação de tapetes, bolsas e cordas. A Daimler Chrysler utiliza compósitos com fibra de Abacá na proteção de piso de seus automóveis (7).

Dentre as fibras citadas, o curauá é uma planta tipicamente brasileira, natural da região amazônica. A fibra é retirada de suas folhas como fibras longas, podendo chegar até 2 metros de comprimento, a fibra de curauá é mostrada na figura 3. 


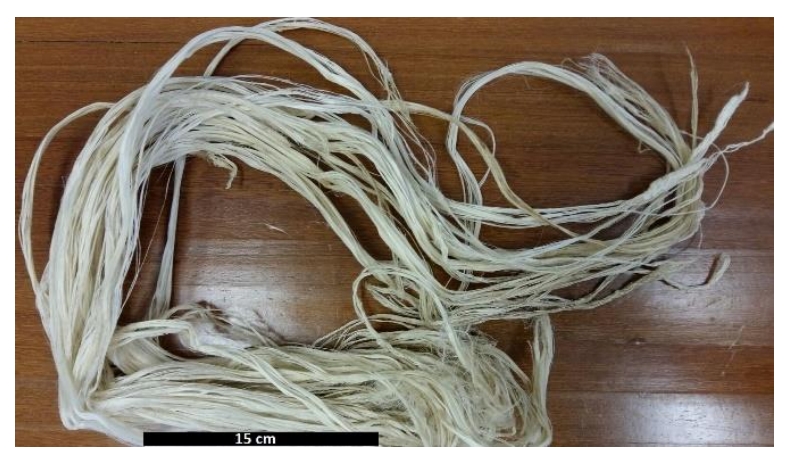

Figura 3 - Fibra de curauá.

O interesse na fibra de curauá surgiu ao notar-se que ela era utilizada pela população indígena da região, na produção de cordas, redes e linhas de pesca. As fibras de curauá tem alta resistência mecânica quando comparadas à outras fibras naturais como sisal, juta e linho, como mostrado na Tabela 2.

Tabela 2 - Comparação entre módulo de elasticidade de algumas fibras naturais com a fibra de vidro.

\begin{tabular}{|c|c|c|c|}
\hline Fibras & $\begin{array}{c}\text { Módulo de Elasticidade } \\
\text { [GPa] }\end{array}$ & $\begin{array}{c}\text { Densidade } \\
{\left[\mathrm{g} / \mathrm{cm}^{3}\right]}\end{array}$ & $\begin{array}{l}\text { Módulo de elasticidade } \\
\text { específico }\left[\mathrm{GPa} /\left(\mathrm{g} / \mathrm{cm}^{3}\right)\right]\end{array}$ \\
\hline Curauá & 26 & 1,1 & 23,6 \\
\hline Sisal & 9,4 & 1,35 & 6,9 \\
\hline Juta & 10 & 1,3 & 7,69 \\
\hline Fibra de vidro $E$ & 70 & 2,55 & 32,3 \\
\hline
\end{tabular}

Segundo Santos et al. (10), a fibra de curauá apesar de ter um módulo de elasticidade menor que a fibra de vidro apresenta um módulo de elasticidade específico de $85 \%$ do da fibra de vidro, isto devido à sua densidade ser bem menor que a densidade da fibra de vidro, o que durante a utilização do curauá permite uma redução de peso do produto final. Uma outra vantagem da fibra de curauá em relação à outras fibras naturais é que elas são inodoras, o que facilita sua aplicação em interiores de veículos (9).

Com propriedades mecânicas tão atrativas, a fibra de curauá chama atenção para seu uso na indústria automobilística (7) (11). Os compósitos de fibra de curauá 
com termoplásticos comuns, como o polipropileno, já são utilizados por indústrias automotivas como a Volkswagen. Carros desta montadora possuem o teto, a parte interna das portas e a tampa interna do compartimento de bagagens fabricados de compósitos de polipropileno reforçados com fibra de curauá. No entanto, apesar de diminuir o peso do automóvel em questão, o compósito utilizado ainda não é biodegradável (11).

\subsection{POLÍMEROS BIODEGRADÁVEIS}

A busca por materiais que possuam uma durabilidade alta e degradabilidade após o descarte alavancaram os estudos por polímeros biodegradáveis. Estes polímeros são materiais que possuem um tempo de vida curto após o descarte, sofrem degradação e desaparecem do ambiente, não resultando em acúmulo de lixo plástico em aterros sanitários. Estes polímeros podem ser produzidos por meios naturais (micro-organismos, plantas e animais) ou sintetizados quimicamente usando como matéria prima materiais biológicos (açúcares, óleos ou gorduras). A classificação destes polímeros é feita por meio de sua origem, conforme mostra a Figura 4. Os principais polímeros biodegradáveis são poliésteres baseados nos ácidos hidroxi-carbonos. Entre eles estão o polihidroxibutirato (PHB), polihidroxibutirato-co-valerato ( $\mathrm{PHBV}$ ) e poliácido láctico (PLA). Todos estes, tem em comum o fato de serem obtidos através de recursos renováveis (12). O PLA é produzido através do ácido láctico, os PHAs são produzidos através de óleos vegetais e de outros estoques de alimentação de base biológica (13) (5). 


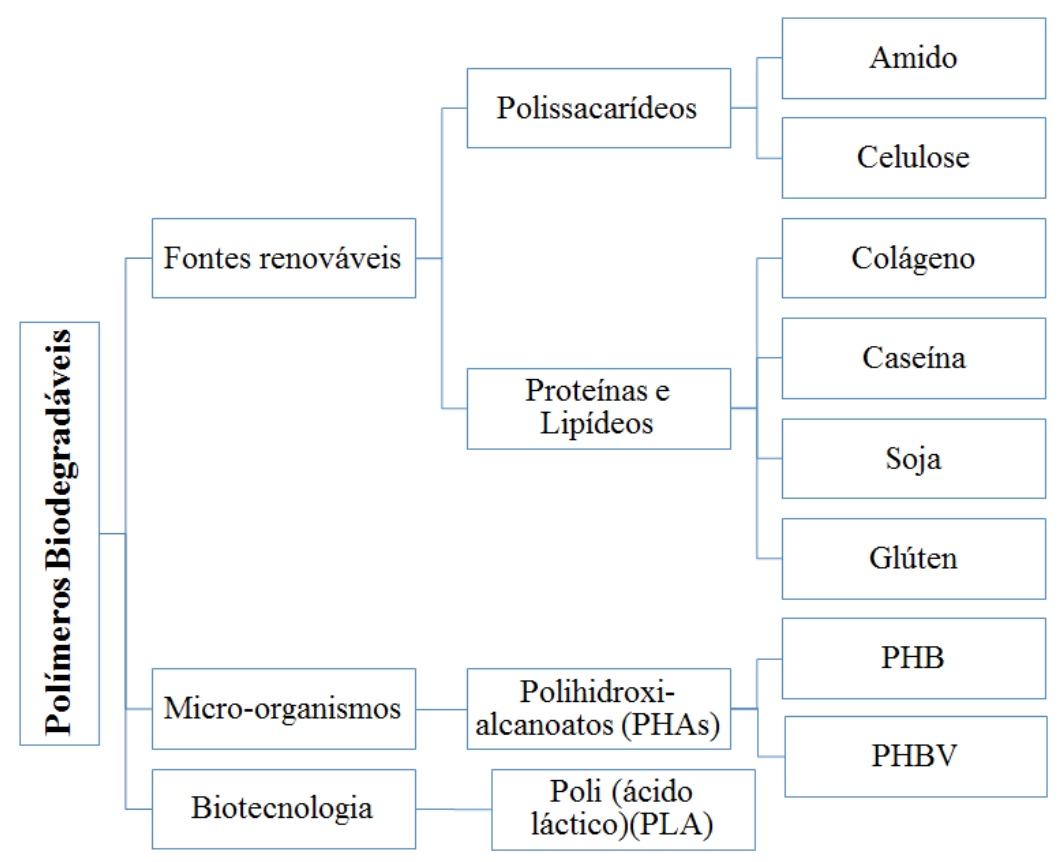

Figura 4 - Classificação dos polímeros biodegradáveis conforme sua origem. Adaptado de Brito et al. (2011)

O poliácido láctico, ou polilactato (PLA) não se refere a um único material, mas a uma família de materiais poliméricos versáteis, produzido a partir de matériasprimas agrícolas renováveis e que apresentam biodegradabilidade (14). O PLA é um poliéster que pode ser produzido por duas rotas diferentes de polimerização, policondensação do ácido lático, ou polimerização por abertura do anel do lactídeo (13) (15) (16), conforme mostrado Figura 5.

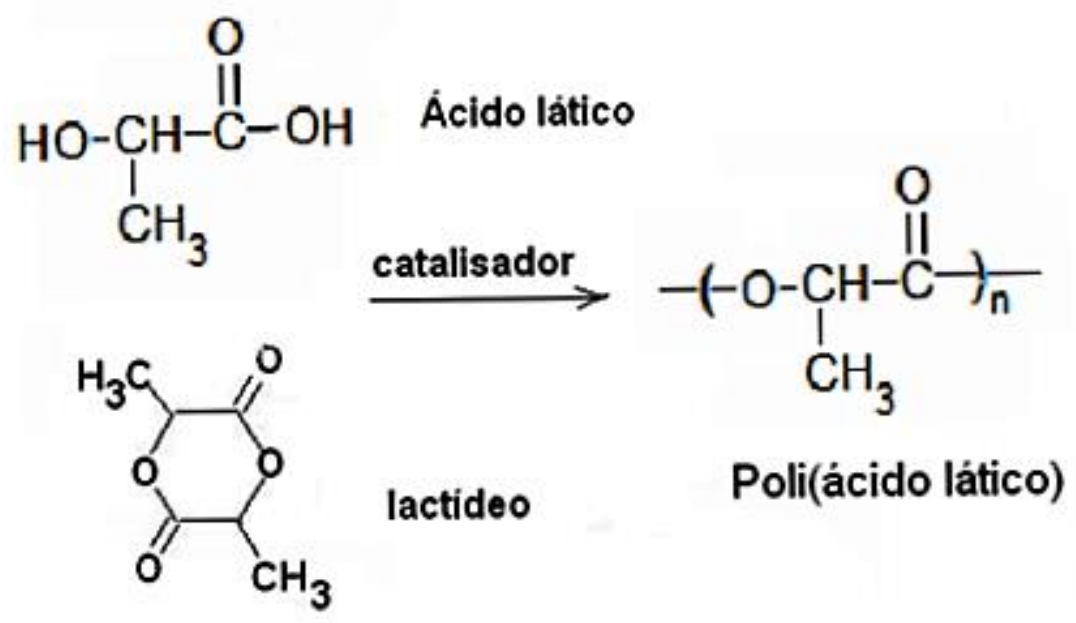

Figura 5 - Produção do PLA a partir do ácido lático e do lactídeo. 
Para a produção do polímero por meio do ácido láctico, este monômero é polimerizado formando uma cadeia polimérica linear. Os monômeros de ácido lático são produzidos pela fermentação do açúcar ou amido, presentes nos materiais renováveis, como milho e cana de açúcar. O PLA possui estrutura química conforme mostrado na Figura 6.

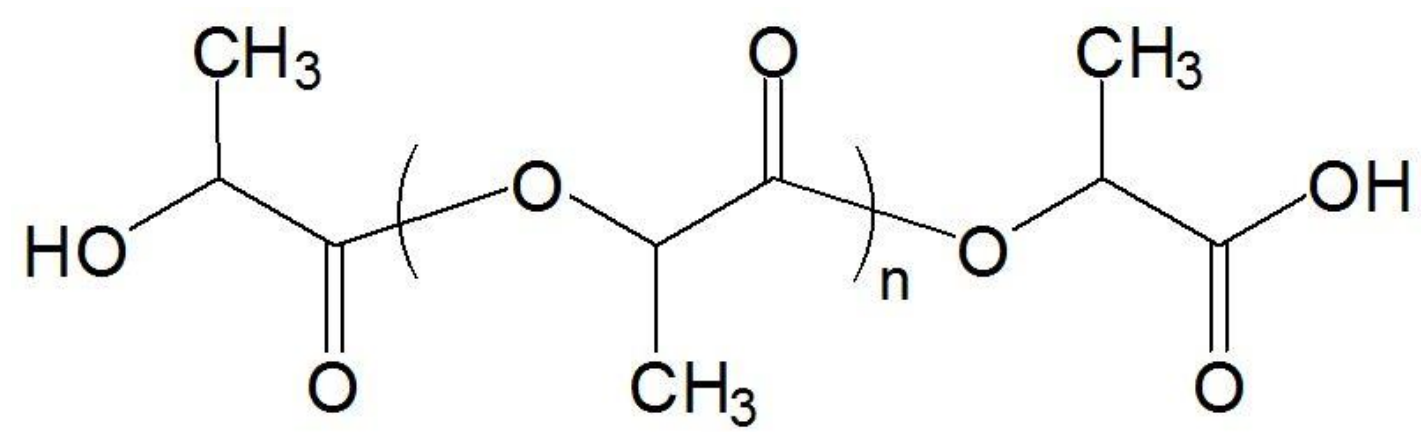

Figura 6 - Estrutura do PLA.

Apesar do polímero ser biodegradável, sua degradação não acontece no ambiente sem que as condições sejam adequadas, o que o torna atrativo para utilização. Para que ocorra a degradação o ambiente de descarte deve apresentar condições adequadas de temperatura, umidade, $\mathrm{pH}$, micro-organismos $\mathrm{e}$ disponibilidade de oxigênio (12).

O processamento do PLA pode ser feito semelhante ao de poliolefinas comuns (16). O PLA é utilizado em aplicações como sacos plásticos, copos descartáveis, placas e produtos de baixa performance. Ele apresenta propriedades interessantes para uso biomédico, como biocompatibilidade e bioabsortividade (17). Além destas características, o PLA apresenta uma elevada resistência mecânica que pode ser comparada com as de termoplásticos como o polietileno tereftalato (PET) e o polipropileno (PP). 


\subsection{COMPÓSITOS COM MATRIZ POLIMÉRICA BIODEGRADÁVEL}

Um material compósito é definido como um material composto por dois ou mais constituintes combinados numa escala macroscópica por ligações mecânicas e químicas, que são utilizados juntos para resultar em uma combinação de propriedades que não podem ser obtidas de outra maneira (18) (19) (20) (21). Os compósitos podem ser classificados segundo o mecanismo de reforço utilizado (21), conforme mostra a Figura 7.

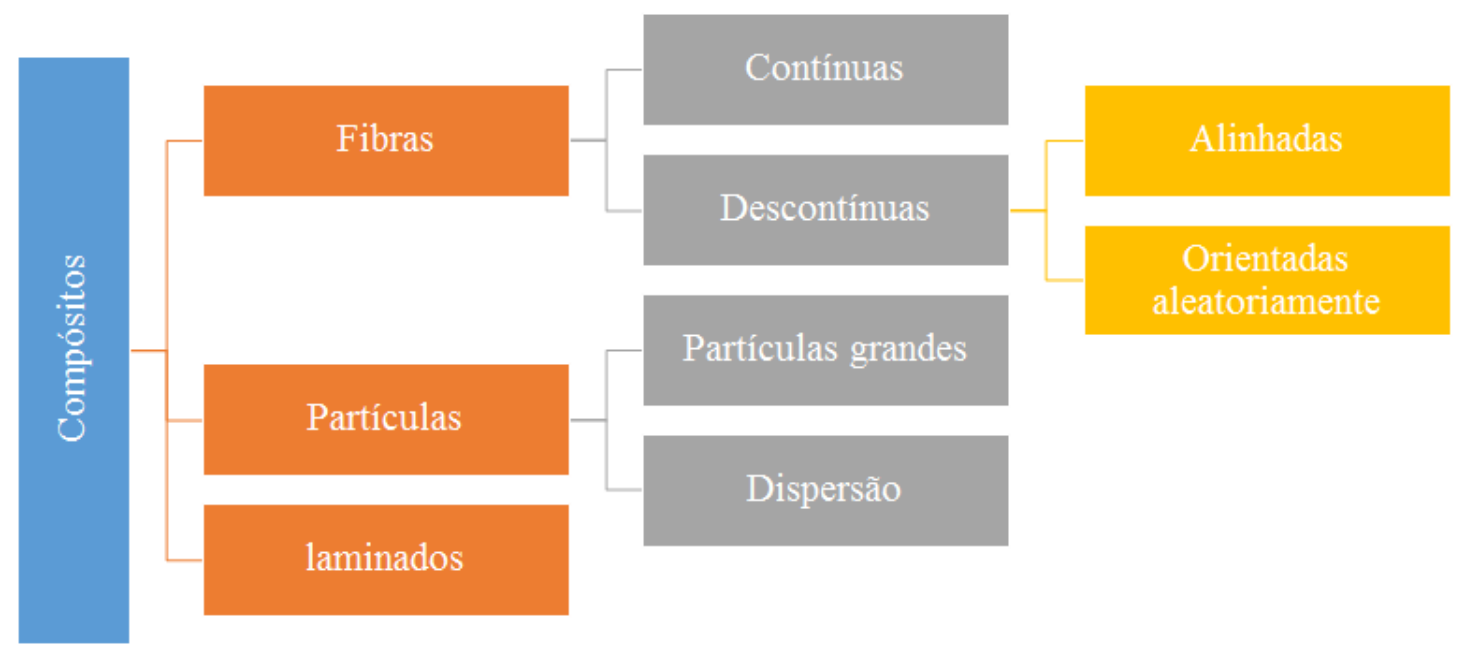

Figura 7 - Classificação dos materiais compósitos de acordo com o mecanismo de reforço utilizado. Elaborado de acordo Jones (21).

Segundo Callister (18), os compósitos reforçados com fibras são os tecnologicamente mais importantes, pois este tipo de reforço apresenta alta resistência mecânica e alta rigidez em relação ao peso. A orientação das fibras, a concentração de fibras e sua distribuição influenciam significativamente as propriedades mecânicas dos compósitos. Quanto mais uniforme a distribuição das fibras, melhores serão as propriedades dos compósitos. Compósitos reforçados com fibras alinhadas são inerentemente anisotrópicos, ou seja, suas propriedades mecânicas vão depender da direção de alinhamento da fibra. Já compósitos reforçados com fibras aleatórias podem ser considerados isotrópicos (18) (19). 
As matrizes poliméricas são utilizadas devido à sua facilidade de fabricação e custo. A matriz polimérica é a fase que determina a máxima temperatura de serviço do compósito. A matriz transmite as tensões às fibras, que resistem à força aplicada. Portanto, as fibras utilizadas como reforço devem ser resistentes, rígidas e leves (19). A matriz, como possui uma deformação na ruptura maior que a fibra tem a função de promover a ligação entre as fibras e transferir os esforços exteriores aplicados a elas, proteger as fibras de danos superficiais e separar as fibras, evitando a propagação de fissuras. A fibra tem a função de resistir aos esforços exteriores aplicados a elas (22).

O compósito biodegradável é um material compósito que tem capacidade de se biodegradar. Para que o compósito seja biodegradável, tanto sua matriz quanto o reforço devem ser biodegradáveis. Os compósitos biodegradáveis são formados com uma matriz de polímero biodegradável com reforço de fibras naturais. As fibras naturais, quando utilizadas como reforço no compósito, são utilizadas para suportar a maior parte das cargas aplicadas no material. Como as fibras normalmente tem comportamento frágil, a inserção desta na matriz polimérica não necessariamente aumenta a resistência ao impacto, contudo elas são mais resistentes e rígidas que a matriz, o que confere elevada resistência mecânica e a maior rigidez do compósito (22).

Os compósitos biodegradáveis podem ser comparados com compósitos de fibra de vidro e várias vantagens aparecem na utilização das fibras naturais, tais como baixo custo, baixa densidade e menos desgaste dos equipamentos durante 0 processamento, e a principal vantagem é a biodegradabilidade (23). Por outro lado, existem algumas limitações como a falta de compatibilidade entre a matriz e o reforço, temperaturas de processamento baixas e sazonalidade da cultura vegetal. Vários estudos têm sido realizados sobre compósitos biodegradáveis, utilizando matrizes biodegradáveis como o PHA, o PHB e o PLA e fibras naturais das mais diversas possíveis. 


\subsection{ADESÃO ENTRE REFORÇO E MATRIZ}

As fibras naturais, quando utilizadas como reforço no compósito, em muitos casos são utilizadas para suportar a maior parte das cargas aplicadas no material, para que isto ocorra deve existir uma boa interação entre a fibra e a matriz a ser utilizada no compósito. Esta interação ocorre quando há compatibilidade entre a fibra e a matriz polimérica. As principais dificuldades na fabricação dos compósitos são variabilidade das propriedades, a dispersão da fibra na matriz, a formação de bolhas durante $o$ processamento $e$ as interações entre fibra natural $e$ matriz polimérica. A matriz polimérica apresenta características apolares enquanto a fibra natural apresenta uma característica bastante polar, o que impossibilita a interação entre as duas fases. Problemas de compatibilidade podem levar a falhas nos compósitos, devido à ineficiente transferência da carga aplicada na matriz para as fibras de reforço. A interface entre fibra e matriz é usualmente avaliada por meio da microscopia eletrônica de varredura (MEV), que permite observar com alta resolução a adesão entre a fibra e a matriz.

Para aumentar a compatibilidade entre a matriz polimérica e as fibras naturais, estas normalmente são alteradas por meio de tratamentos superficiais ou por adição de compatibilizadores ou por modificação química da fibra (24) (25). Entre os tratamentos da fibra vegetal, os que mais se destacam são a mercerização, o tratamento com ácidos, com grupos silano, acetil, isocianato e peróxido (24) (4) (25). O objetivo destes tratamentos é melhorar a interface entre a fibra vegetal e a matriz polimérica. Outras modificações estudadas são as que envolvem a lavagem da fibra vegetal. A lavagem da fibra de curauá com água e hipoclorito de sódio aumentam a rugosidade da fibra de curauá, como mostrado por Spinacé et al. (8).

\subsection{TRATAMENTOS QUÍMICOS}

Os tratamentos químicos são aqueles onde se emprega um agente químico que reagirá com a fibra. Os principais são a mercerização, a acetilação e a adição de grupos silano (26) (5) (27) (28). A mercerização consiste na imersão da fibra 
vegetal em uma solução básica por determinado período de tempo (29). A acetilação é um método de tratamento que objetiva deixar a fibra vegetal com caráter mais hidrofóbico (26) (28). Este tipo de tratamento substitui os grupos hidroxila das fibras por grupos acetil, o que torna a fibra menos propensa a absorver umidade, no entanto este tipo de tratamento reduz as propriedades mecânicas das fibras (5).

O tratamento que envolve a adição de grupos silano na fibra vegetal, consiste na inserção de grupos silano com dupla funcionalidade na fibra, estes grupos possuem uma funcionalidade polar que se liga à fibra e uma funcionalidade apolar que estabelece ligações com o polímero, fazendo com que o silano atue como uma ponte de ligação entre a fibra e o polímero (5) (30) (4) (24) (31).

\subsubsection{Mercerização}

O mais popular tratamento químico utilizado em fibras vegetais é a mercerização, este processo se baseia em submeter a fibra a um tratamento alcalino (Figura 8). Este tratamento resulta na solubilização da hemicelulose e lignina presentes na fibra e na modificação da cristalinidade da celulose (4). A hemicelulose é solúvel em baixas concentrações de álcali e a lignina sofre hidrólise básica. A mercerização quebra a ligação de hidrogênio entre as cadeias de celulose e em solução aquosa a estrutura celulósica sofre inchamento. Estes dois efeitos modificam sua cristalinidade (4)(28).

\section{Fibra-OH $+\mathrm{NaOH} \rightarrow$ Fibra-O $\mathrm{O}^{-} \mathrm{Na}^{+}+\mathrm{H}_{2} \mathrm{O}$}

Figura 8 - Esquema de mercerização de uma fibra natural com hidróxido de sódio.

Neste tipo de tratamento, as fibras são imersas em uma solução básica utilizando hidróxido de sódio $(\mathrm{NaOH})$, hidróxido de lítio $(\mathrm{LiOH})$ ou hidróxido de potássio $(\mathrm{KOH})$ por um determinado tempo, o resultado do tratamento depende da concentração do álcali e do tempo utilizado no tratamento. George e colaboradores (27) mostraram que os melhores efeitos da mercerização em fibras naturais são 
obtidos com soluções com concentração entre 10-30\% de hidróxido de sódio. Fibras de juta foram mercerizadas em solução de $5 \% \mathrm{~m} / \mathrm{v}$ de $\mathrm{NaOH}$ durante 24 horas a temperatura ambiente por Rodrigues e colaboradores (32). Vários autores estudam este método de modificação química já há bastante tempo em diversas fibras naturais diferentes, como juta, linho e sisal (28). Fibras de curauá foram tratadas com solução de $\mathrm{NaOH}$ em concentrações de 10 e $15 \%$ m/v por Gomes e colaboradores (33) que mostraram que soluções concentradas de hidróxido de sódio aumentam a tensão de ruptura e a tenacidade dos compósitos finais fabricados.

\subsection{PROPRIEDADES MECÂNICAS}

As propriedades mecânicas dos materiais são de grande importância para avaliar a capacidade de utilização dos materiais sob carregamento mecânico. As principais propriedades mecânicas especificadas para polímeros são o módulo de elasticidade, o limite de escoamento e de resistência à tração (18). Os polímeros termoplásticos podem apresentar comportamento frágil ou dúctil em condições normais de temperatura, de acordo com sua temperatura de transição vítrea. Quando a temperatura de transição vítrea está acima da temperatura ambiente o polímero é rígido e seu comportamento mecânico é semelhante ao vidro. Quando a temperatura de transição vítrea do polímero está abaixo da temperatura ambiente, o polímero apresenta comportamento semelhante a borracha.

O comportamento mecânico dos compósitos apresenta um comportamento intermediário entre o comportamento da matriz e o do reforço. Quando a matriz é frágil a fibra não causa grande interferência na deformação do material, no entanto, quando a matriz é dúctil, sua deformação pode sofrer uma redução devido à inserção da fibra (34).

Alguns fatores podem influenciar diretamente as propriedades mecânicas dos materiais compósitos reforçados com matriz polimérica, entre eles podem ser citados a massa molecular do polímero e a cristalinidade. Ao se aumentar o grau de cristalinidade do material, consequentemente se aumentam sua resistência à tração e o módulo de elasticidade. Outro fator que influencia é a interface entre a matriz e o 
reforço, quando a interface é boa, há uma boa transferência da carga da matriz para o reforço, o que resulta em melhores propriedades mecânicas. Se esta interface possui falhas, se a compatibilidade entre o reforço e a matriz é pequena, então a transferência de carga pode ocorrer de forma não satisfatória, deixando as propriedades mecânicas dos compósitos iguais às da matriz puramente ou até piores.

\subsection{COMPORTAMENTO TÉRMICO DOS COMPÓSITOS}

Propriedades térmicas são entendidas como a resposta do material à aplicação de calor. Para avaliar o comportamento térmico dos compósitos técnicas de análise térmica como a análise termogravimétrica (TGA) e a calorimetria exploratória diferencial (DSC) são aplicadas. Os termoplásticos amolecem gradualmente ao se elevar a temperatura. Ao se elevar a temperatura as forças das ligações secundárias entre as cadeias moleculares se tornam mais fracas e a resistência do termoplástico diminui. Outra característica que o termoplástico apresenta é a degradação térmica, visto que o material é formado basicamente por hidrocarbonetos, ao se elevar a temperatura esses materiais sofrem degradação térmica. Devido a estas características, torna-se indispensável o conhecimento de três temperaturas específicas para os termoplásticos e seus compósitos: a temperatura de transição vítrea, a temperatura de fusão e a temperatura de degradação.

A temperatura de transição vítrea ( $\mathrm{Tg}$ ) é uma transição reversível em materiais entre um estado duro e rígido para um estado mole e borrachoso. $\mathrm{O}$ polímero alcança esta temperatura quando adquire energia suficiente para superar as barreiras de energia necessárias à rotação de ligações. O material passa de um estado cuja sua mobilidade é limitada para um estado de mobilidade, atingindo equilíbrio termodinâmico (35). A temperatura de fusão é a temperatura na qual o material passa do estado sólido para o estado líquido. Nesta temperatura ocorre a dissolução dos cristais no material, após a temperatura de fusão o material não apresenta nenhuma cristalinidade, materiais amorfos não apresentam temperatura 
de fusão. A temperatura de degradação térmica é a temperatura na qual o material degrada termicamente perdendo toda ou quase toda sua massa.

Os termoplásticos semicristalinos apresentam tanto temperatura de transição vítrea quanto temperatura de fusão. Estas grandezas podem ser determinadas por análises térmicas como TGA e DSC. Na TGA é possível determinar a temperatura de degradação do material e na DSC determina-se as temperaturas de transição vítrea e de fusão, como observado na Tabela 3. O conhecimento dessas propriedades térmicas permite avaliar como será o processamento do material. Quanto mais próximas são as temperaturas de fusão e degradação, mais difícil se torna o processamento do mesmo.

Tabela 3 - Definições sobre as análises térmicas de TGA e DSC.

Técnica

Análise termogravimétrica

\section{Princípio}

A massa da amostra é determinada em relação a um aumento controlado da temperatura.

$\begin{array}{ll}\text { Calorimetria exploratória diferencial } & \text { O fluxo de calor da amostra é } \\ & \text { determinado em relação a um aumento } \\ & \text { controlado de temperatura. O fluxo de } \\ & \text { calor da amostra é determinado } \\ & \text { comparando a amostra com um material } \\ & \text { termicamente inerte. }\end{array}$




\section{METODOLOGIA EXPERIMENTAL}

\subsection{DESCRIÇÃO DOS MATERIAIS}

As fibras de curauá utilizadas no trabalho foram cedidas pela CEAPAC, provenientes de Santarém, no estado do Pará, como fibras de curauá longas, com comprimento de $80 \mathrm{~cm}$. O polímero utilizado foi o Poliácido láctico ou polilactato (PLA) da empresa GoodFellow. O PLA foi recebido em formato de grânulos de $3 \mathrm{~mm}$, cor natural e densidade de $1,24 \mathrm{~g} / \mathrm{cm}^{3}$.

\subsection{TRATAMENTO SUPERFICIAL DA FIBRA DE CURAUÁ}

Fez-se duas rotas de tratamento superficial nas fibras de curauá, ambos os tratamentos consistiram em uma lavagem prévia da fibra e posterior mercerização. As fibras de curauá foram previamente penteadas e cortadas com $25 \mathrm{~mm}$.

Na primeira rota de tratamento, lavou-se a fibra de curauá com água na proporção $15: 1$ (água:fibra) a $80^{\circ} \mathrm{C}$ durante 2 horas. Após este período, as fibras foram lavadas em água destilada, secas em temperatura ambiente por 48 horas e em estufa por 12 horas a $60^{\circ} \mathrm{C}$. As fibras lavadas com água foram mercerizadas em solução de hidróxido de sódio $(\mathrm{NaOH})$ na concentração de $5 \% \mathrm{~m} / \mathrm{v}$. A fibra foi imersa na solução de $\mathrm{NaOH}$ na proporção de 10:1 (solução:fibra), durante 2 horas a $50^{\circ} \mathrm{C}$ com agitação. Após o tempo de reação, as fibras foram lavadas com água destilada até a neutralização do $\mathrm{pH}$, secas em temperatura ambiente por 48 horas e em estufa a $60^{\circ} \mathrm{C}$ por 12 horas.

A segunda rota de tratamento, envolveu a lavagem da fibra com hipoclorito de sódio $(\mathrm{NaClO})$ e sua posterior mercerização. As fibras in natura foram imersas sem agitação em solução de $\mathrm{NaClO}$ na concentração de $2 \%$ v/v. As fibras ficaram imersas durante 5 horas na proporção de 15:1 (solução:fibra). Após este período, elas foram lavadas em água destilada até a neutralização do $\mathrm{pH}$, secas em temperatura ambiente por 48 horas e em estufa por 12 horas a $60^{\circ} \mathrm{C}$. Após secas, as fibras 
lavadas com $\mathrm{NaClO}$ foram imersas em solução de $\mathrm{NaOH} 5 \% \mathrm{~m} / \mathrm{v}$ por 2 horas a $50^{\circ} \mathrm{C}$ com agitação. Utilizou-se a proporção 10:1 (solução:fibra). Após o tempo de mercerização, as fibras foram lavadas em água destilada até a neutralização do $\mathrm{pH}$, secas em temperatura ambiente por 48 horas e em estufa à $60^{\circ} \mathrm{C}$ por 12 horas. A Figura 9 apresenta o esquema de tratamento das fibras de curauá.

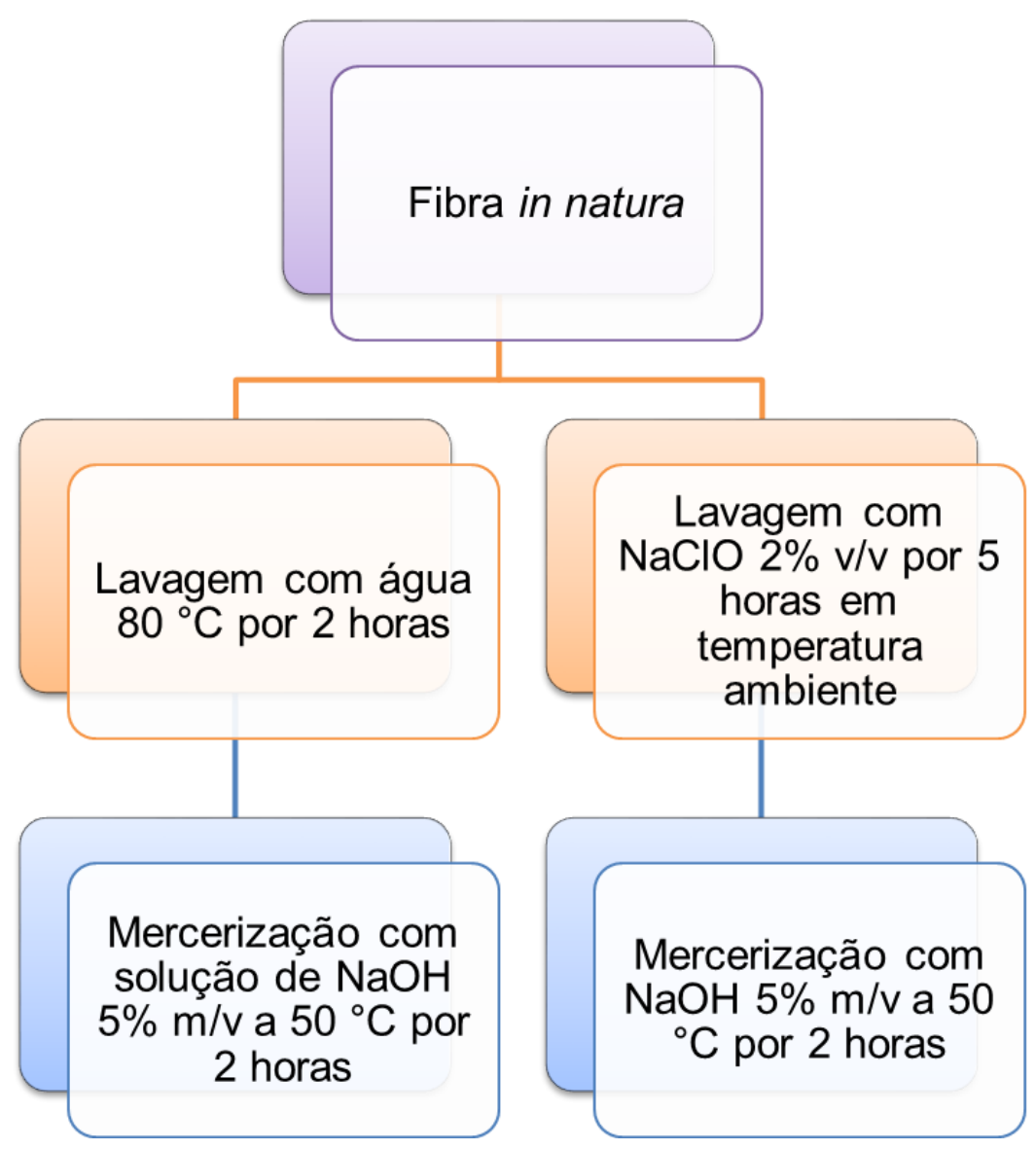

Figura 9 - Esquema de tratamento superficial das fibras de curauá

\subsection{CARACTERIZAÇÃO DA FIBRA DE CURAUÁ}

As fibras de curauá tratadas e in natura foram caracterizadas quanto à sua composição lignocelulósica, quanto ao seu comportamento térmico, comportamento morfológico e cristalinidade. 


\subsubsection{Caracterização térmica}

A caracterização térmica das fibras de curauá foi realizada por meio das técnicas de Termogravimetria (TGA) e Calorimetria Diferencial Exploratória (DSC). As análises foram realizadas no laboratório de Análise Instrumental da Faculdade do Gama, Universidade de Brasília. Cerca de $10 \mathrm{mg}$ das fibras foram colocadas em cadinhos de alumina e ensaiadas de temperatura ambiente à $600^{\circ} \mathrm{C}$, com taxa de aquecimento de $10^{\circ} \mathrm{C} / \mathrm{min}$, em atmosfera inerte com fluxo de nitrogênio $\left(\mathrm{N}_{2}\right)$ de 60 $\mathrm{mL} / \mathrm{min}$. Os gases liberados durante a análise térmica foram analisados por espectrofotometria na região do infravermelho, utilizando um equipamento de interface entre THERMO SCIENTIFIC TGA/FT-IR, conectado a um espectrofotômetro Nicolet IS10. As temperaturas utilizadas na interface para a célula e a linha de transferência de gases foram de 220 e $190^{\circ} \mathrm{C}$, respectivamente. Os espectros foram colhidos para números de onda de 4000 a $400 \mathrm{~cm}^{-1}$, com resolução de 64 scans.

\subsubsection{Caracterização lignocelulósica}

A caracterização lignocelulósica das fibras de curauá foi realizada segundo o Documento 236 - Procedimentos para análise lignocelulósica da EMBRAPA (36), que estabelece normas para a determinação dos teores de umidade, extrativos, lignina, holoceluloses e a-celulose de materiais lignocelulósicos. A caracterização lignocelulósica das fibras de curauá foi realizada para a fibra de curauá in natura, após as duas lavagens propostas e após o tratamento superficial completo da fibra, a fim de identificar como cada etapa do tratamento afeta a composição lignocelulósica da fibra de curauá.

As amostras a serem caracterizadas foram previamente moídas em moinho analítico da marca Quimis. Para a determinação da umidade a fibra é levada à estufa a $105^{\circ} \mathrm{C}$ por três horas, depois levado ao dessecador para resfriar, pesado. Depois de pesar a fibra, esta retorna à estufa por mais uma hora e repete-se o procedimento até atingir massa constante. A determinação de cinzas é feita em um 
forno mufla à $600^{\circ} \mathrm{C}$ durante 3 horas, após este período a temperatura deve cair para $200^{\circ} \mathrm{C}$ e o material ser deixado por mais 1 hora. $O$ teor de extrativos foi determinado apenas para a fibra de curauá in natura, visto que após a lavagem a fibra já perde seus extrativos. A determinação dos extrativos foi realizada em extrator soxhlet utilizando como solvente acetona p.a.. A extração ocorreu durante 4 horas, sendo estabelecidos pelo menos 24 refluxos por hora.

O teor de lignina foi determinado com solução de ácido sulfúrico com concentração de $72 \% \mathrm{~m} / \mathrm{m}$. A solução ácida foi adicionada à fibra e agitada durante 15 min, após esta agitação cuidadosa, o material foi deixado em repouso por 24 horas. Após o período de repouso adicionou-se água destilada à mistura a fim de diluir o ácido sulfúrico a $4 \%$. Colocou-se a solução sob aquecimento e refluxo por 4 horas e após resfriamento, filtrou-se a solução. A lignina retida no funil após filtração foi pesada.

O teor de holoceluloses foi determinado com uma deslignificação com clorito de sódio $\left(\mathrm{NaClO}_{2}\right)$ e ácido acético glacial durante 5 horas a $70^{\circ} \mathrm{C}$. Após este período, o material foi filtrado e a polpa celulósica proveniente foi pesada. O teor de $\alpha$ celulose foi determinado a partir da holocelulose obtida. Acrescentou-se à holocelulose uma solução de $\mathrm{NaOH}$ com concentração de $17,5 \% \mathrm{~m} / \mathrm{m}$, com o objetivo de solubilizar as parcelas amorfas de celulose e hemicelulose presentes na holocelulose. Após $10 \mathrm{~min}$ de contato com a solução de $\mathrm{NaOH}$, a polpa de $\alpha$ celulose restante foi filtrada, lavada e pesada.

\subsubsection{Caracterização Morfológica}

Para avaliar a influência do tratamento na superfície das fibras de curauá, utilizou-se da técnica de Microscopia Eletrônica de Varredura (MEV) em um microscópio JEOL modelo JSM-7001F, com tensão de aceleração de 10 a $15 \mathrm{kV}$, com tensão de aceleração de 10 a $15 \mathrm{kV}$ e aumentos de 500 e 1000x. As amostras foram metalizadas com platina. 


\subsubsection{Grau de Cristalinidade das fibras de curauá}

A cristalinidade das fibras de curauá in natura e após tratamentos foram obtidas por meio da técnica de difração de raio-x. Utilizou-se um difratômetro da marca Rigaki modelo Ultimav em modo de reflexão com um ângulo incidente de 1,54 $\AA$, radiação de CuKa, ângulo de incidência $2 \theta$ variando de 5 a $50^{\circ}$, com velocidade de varredura de $5 \% \mathrm{~min}$. O índice de cristalinidade $\left(\% \mathrm{X}_{\mathrm{C}}\right)$ foi obtido pelo método de Segal et al. (37), que contabiliza a diferença entre as intensidades do pico cristalino $\left(\mathrm{I}_{002}\right)$, cujo ângulo $2 \theta$ é $22,5^{\circ}$ e o halo amorfo $\left(\mathrm{I}_{\mathrm{am}}\right)$, cujo ângulo $2 \theta$ é igual a $18^{\circ}$, conforme mostra a Equação 1:

$\% X_{C}=\frac{I_{002}-I_{a m}}{I_{002}} \times 100$

\subsection{OBTENÇÃO DOS COMPÓSITOS}

Os compósitos de PLA reforçados com fibra de curauá após o tratamento superficial foram processados por extrusão e injeção. A extrusão foi realizada na Universidade de Caxias do Sul e a injeção na Universidade Federal do Rio Grande do Sul. Antes da mistura em extrusora das fibras com o polímero, ambos foram secos em estufa por 24 horas a $60^{\circ} \mathrm{C}$ para a eliminação da umidade presente nos materiais. As misturas foram feitas com dois teores diferentes de fibra para cada tipo de tratamento, 10 e $20 \% \mathrm{~m} / \mathrm{m}$ em relação ao polímero. Foram produzidas 6 famílias de compósitos. O polímero puro também foi extrusado e injetado.

Os compósitos foram primeiramente processados em extrusora dupla rosca corrotante interpenetrante da marca MH Equipment modelo cor 20-32 Lab, com velocidade de rosca de $200 \mathrm{rpm}$, rosca com $20 \mathrm{~mm}$ de diâmetro, L/D da rosca de 44 e perfil de temperatura variando de 170 a $210^{\circ} \mathrm{C}$. Utilizou-se ainda uma calha de refrigeração para resfriamento dos compósitos recém processados. O polímero e as fibras foram adicionados manualmente, sem ajuda de dosador e sem pré-mistura 
manual. Os compósitos resultantes foram picotados em picotador da marca Seibt. O material foi armazenado em local seco e protegido de umidade.

Após extrusado, os compósitos foram secos em estufa à $60^{\circ} \mathrm{C}$ por 24 horas para a eliminação da umidade. Os corpos de prova foram moldados por injeção em injetora Thermo Scientific Haake Mini Jet II. Os corpos de prova foram injetados à pressão de 500 bar por 10 segundos, com pressão de recalque de 450 bar por 5 segundos. As temperaturas do cilindro e do molde foram $230^{\circ} \mathrm{C}$ e $70^{\circ} \mathrm{C}$, respectivamente. Foram produzidos 7 corpos de prova de cada família de material para cada ensaio mecânico. Os corpos de prova para o ensaio de tração foram produzidos em molde fechado do tipo IV, conforme as normas ASTM D638 (38). Os corpos de prova para o ensaio de flexão foram produzidos em molde fechado conforme a norma ASTM D790 (39). Os corpos de prova para o ensaio de resistência ao impacto Izod foram produzidos conforme a norma ASTM D256 (40) em molde fechado, e fez-se o entalhe mecanicamente em entalhador da marca CEAST com profundidade de $2,4 \mathrm{~mm}$. A Figura 10 ilustra as dimensões e os formatos dos corpos de prova.

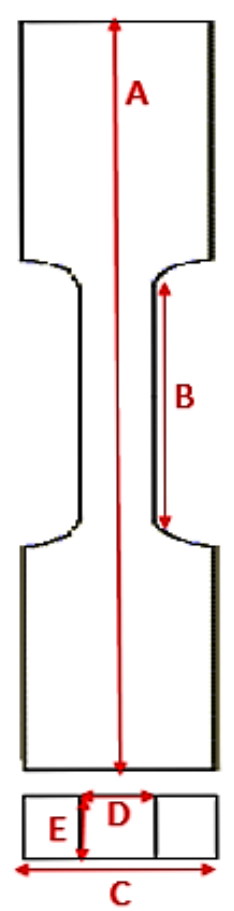

Tração

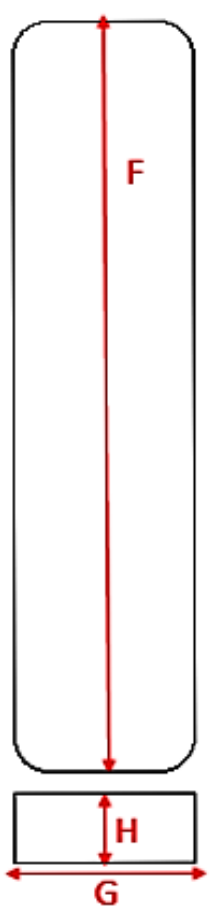

Flexão

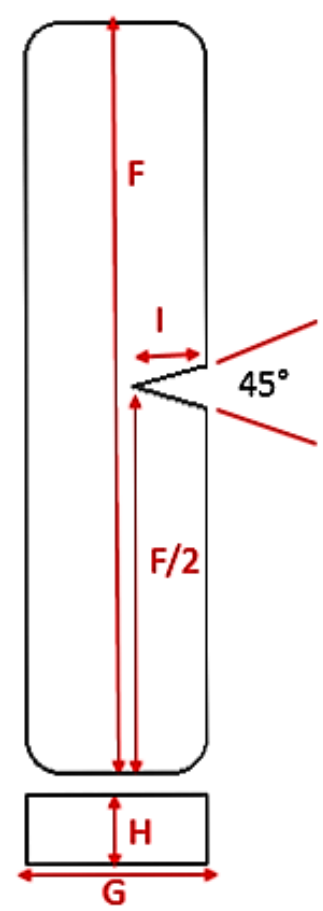

A: $62,5 \pm 0,05$

B: $9,53 \pm 0,02$

C: $9,5 \pm 0,05$

D: $3,22 \pm 0,01$

E: $3,17 \pm 0,01$

F: $62,5 \pm 0,05$

G: $12,61 \pm 0,02$

$\mathrm{H}: 3,26 \pm 0,02$

I: $2,00 \pm 0,02$

Valores em [mm].

Figura 10 - Dimensões dos corpos de prova de tração, flexão e impacto. 


\subsection{ENSAIOS MECÂNICOS}

Conforme recomendam as normas ASTM, os corpos de prova moldados, antes do ensaio, foram mantidos em ambiente climatizado a $23^{\circ} \mathrm{C}$ e umidade em $50 \%$ por 24 horas antes dos ensaios. Os ensaios mecânicos foram realizados na Universidade Federal do Rio Grande do Sul, em ambiente climatizado a $23^{\circ} \mathrm{C}$ e umidade de $50 \%$. A célula de carga utilizada no ensaio de tração e flexão foi de $5 \mathrm{kN}$, conforme recomendação para materiais que necessitam de baixa carga.

O ensaio de tração foi realizado em máquina de ensaios universal Instron 3382, com garras pneumáticas e frequência de aquisição de dados de $10 \mathrm{~Hz}$. A velocidade do ensaio foi de $1 \mathrm{~mm} / \mathrm{min}$, velocidade determinada para materiais semirígidos segundo a norma ASTM D638 (38). Do ensaio de tração obtiveram-se resultados de módulo de elasticidade, tensão na ruptura, limite de resistência à tração, deformação na ruptura e carga máxima suportada.

O ensaio de flexão foi realizado em máquina de ensaios universal Instron 3382 com acessório para flexão em três pontos, com frequência de aquisição de dados de $10 \mathrm{~Hz}$. A velocidade do ensaio é determinada conforme a norma ASTM D790 (39) por meio da Equação 2:

$$
R=\frac{Z \cdot L^{2}}{6 d}
$$

Onde R é a velocidade de ensaio ( $\mathrm{mm} / \mathrm{min})$, L é o comprimento do suporte $(\mathrm{mm})$, d é a espessura do corpo de prova $(\mathrm{mm})$ e $Z$ é uma constante que vale $0,01 \mathrm{~mm} / \mathrm{mm} / \mathrm{min}$. Para os materiais ensaiados a velocidade de ensaio foi de $1,38 \mathrm{~mm} / \mathrm{min}$ (39). Foram obtidas as seguintes informações do ensaio de flexão: módulo de elasticidade em flexão, limite de resistência à flexão, tensão na ruptura, deformação na ruptura e carga máxima suportada. A Figura 11 é apresentado um esquema do ensaio de flexão. 


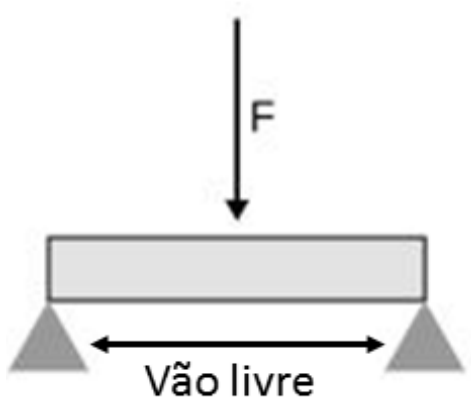

Figura 11 - Esquema do ensaio de flexão mostrando o vão utilizado para o ensaio: $51 \mathrm{~mm}$.

O ensaio de resistência ao impacto Izod foi realizado em uma máquina de ensaios CEAST Impactor II. Para a realização do ensaio utilizou-se um martelo de 2,75 J conforme recomenda a norma ASTM D256 (40) para esse tipo de material. As medições foram feitas para 7 corpos de prova de cada família e a média dos resultados foi tomada.

\subsection{CARACTERIZAÇÃO TÉRMICA DOS COMPÓSITOS}

A caracterização térmica dos compósitos foi realizada por meio das análises termogravimétricas (TGA) e análise de calorimetria diferencial exploratória (DSC). As análises foram realizadas em analisador TA Instruments SDT Q600 simultaneos, que realiza as duas análises simultaneamente. Cerca de 10 e $20 \mathrm{mg}$ dos materiais foram colocados em cadinhos de alumina e ensaiados de temperatura ambiente até $600^{\circ} \mathrm{C}$, com taxa de aquecimento de $10^{\circ} \mathrm{C} / \mathrm{min}$, em atmosfera inerte de nitrogênio $\left(\mathrm{N}_{2}\right)$ com fluxo de gás de $60 \mathrm{~mL} / \mathrm{min}$.

\subsection{CARACTERIZAÇÃO DA INTERFACE DO COMPÓSITO}

A interface entre reforço e matriz dos compósitos foi analisada por meio da técnica de Microscopia Eletrônica de Varredura (MEV) em um microscópio JEOL modelo JSM-7001F, com tensão de aceleração de 10 a $15 \mathrm{kV}$. As amostras receberam recobrimento metálico de platina. 


\section{RESULTADOS E DISCUSSÃO}

\subsection{CARACTERIZAÇÃO DA FIBRA DE CURAUÁ}

Os tratamentos superficiais das fibras de curauá tiveram como objetivo aumentar a rugosidade da fibra, para melhorar o acoplamento entre fibra e matriz, e promover a retirada de seus compostos amorfos, visto que a celulose é o único componente que confere resistência mecânica à fibra de curauá. As etapas de lavagem antes da mercerização da fibra, tiveram como objetivo retirar ácidos graxos presentes na fibra e deixar sua estrutura mais receptiva ao tratamento com a solução de hidróxido de sódio, aumentando sua área de contato e a rugosidade da mesma (8).

Cada etapa de tratamento gerou uma perda de material na fibra, o que tornou possível o cálculo do rendimento de cada etapa. A etapa de lavagem da fibra com água apresentou rendimento de $97,1 \%$ em relação à massa inicial de fibra, ao final da rota de tratamento completa, após a mercerização, este tratamento apresentou rendimento de $73 \%$ em relação à massa inicial de fibra. Isto mostrou que levando em conta a lavagem com água, a fibra não sofreu quase nenhuma modificação química, devido ao alto rendimento desta etapa, a maior perda de material ocorreu após o tratamento com $\mathrm{NaOH}$. A etapa de lavagem da fibra de curauá in natura com $\mathrm{NaClO}$ apresentou rendimento de 83,9\%, e seu rendimento após a mercerização foi de 56,9\%. Das etapas de lavagem, a que utilizou hipoclorito de sódio é a que apresentou menor rendimento, isto porque o hipoclorito de sódio teve ação mais agressiva na fibra de curauá. As fibras de curauá in natura e após os tratamentos são apresentadas na Figura 12. 

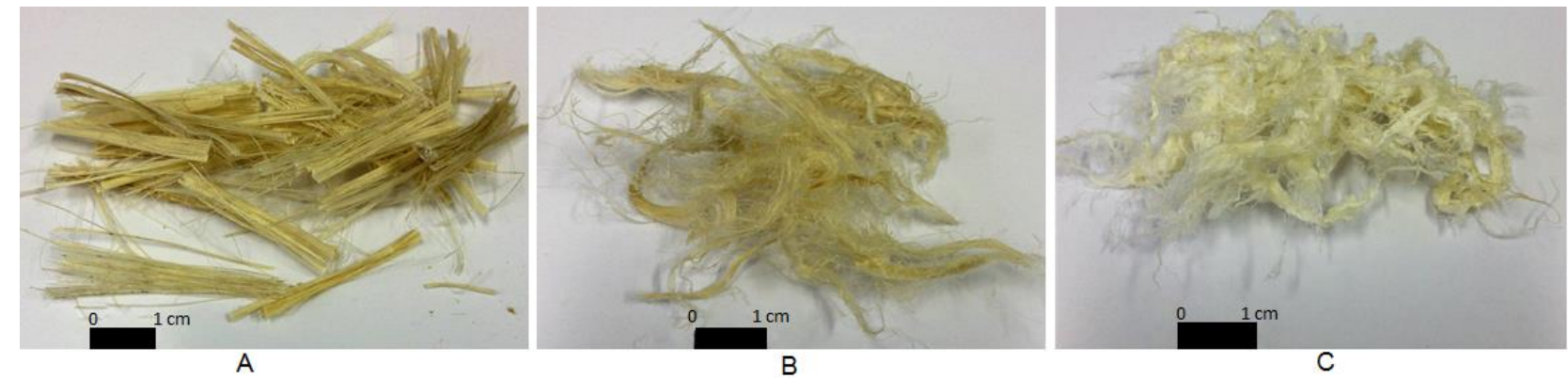

Figura 12 - Fibras de curauá in natura $(A)$, após rota de tratamento com lavagem com água e mercerização com $\mathrm{NaOH} 5 \% \mathrm{~m} / \mathrm{v}$ (B) e após rota de tratamento com lavagem com solução de NaCLO ( $2 \% \mathrm{v} / \mathrm{v})$ e mercerização com $\mathrm{NaOH} 5 \% \mathrm{~m} / \mathrm{v}(\mathrm{C})$.

Dos tratamentos superficiais testados, o que utiliza o $\mathrm{NaClO}$ apresenta 0 menor rendimento, isto porque o $\mathrm{NaClO}$ foi mais agressivo. Por conseguinte, a mercerização após a lavagem com $\mathrm{NaClO}$ apresentou também o menor rendimento. Os resultados de caracterização da morfologia da fibra de curauá ajudam a explicar este fato.

\subsubsection{Caracterização das fibras por MEV}

O estudo da morfologia das fibras de curauá in natura e tratadas foi realizado por microscopia eletrônica de varredura. Este método possibilitou a avaliação da superfície da fibra de curauá in natura e após os tratamentos superficiais. Alterações na morfologia da fibra foram importantes para prever como será o comportamento da interface no compósito. As micrografias foram obtidas para as fibras in natura, após as duas rotas de lavagem e mercerização. A Figura 13 apresenta a micrografia da fibra de curauá in natura e após a etapa de lavagem da fibra. 


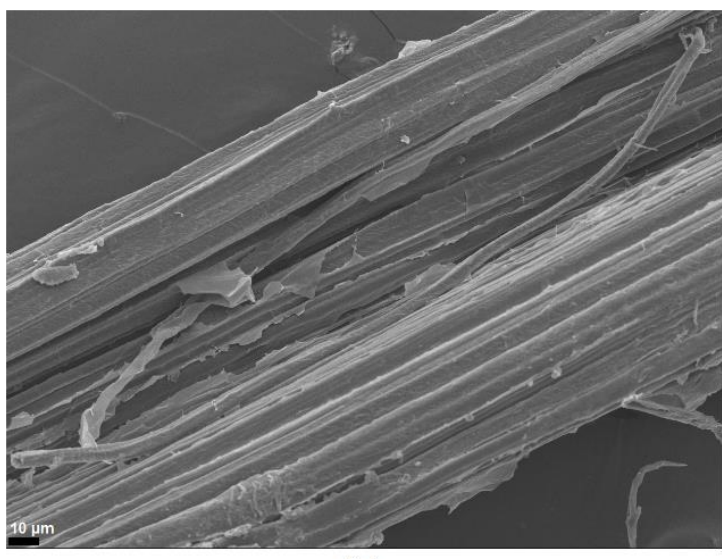

(a)

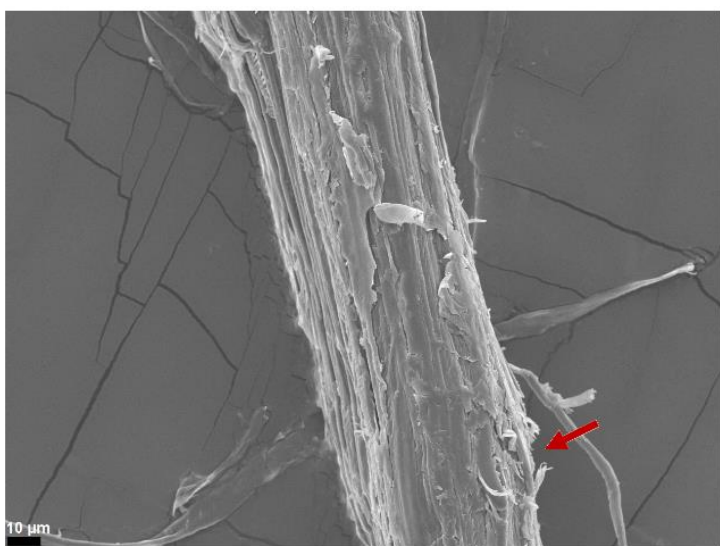

(c)

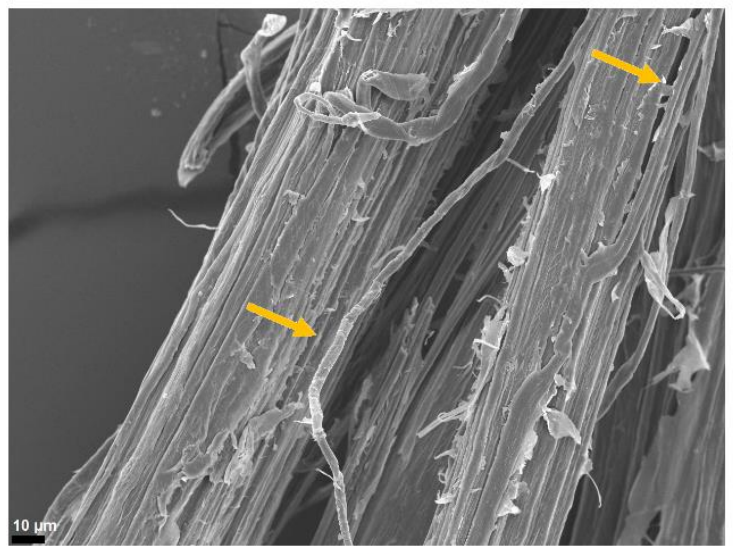

(e)

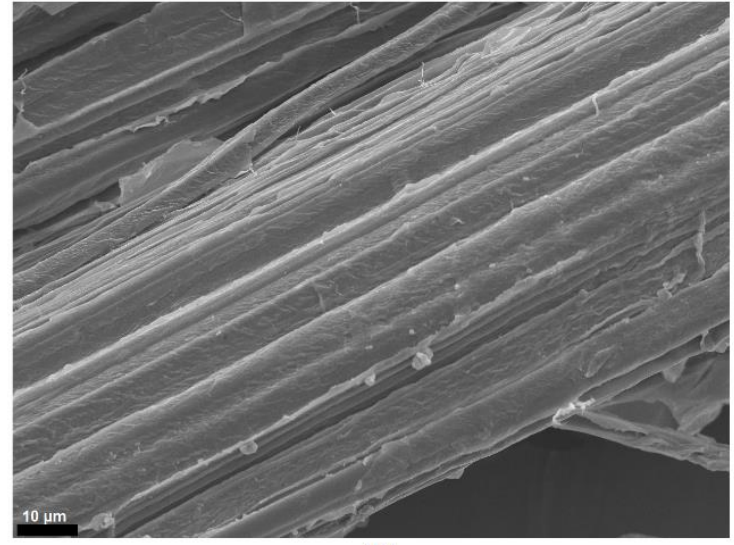

(b)

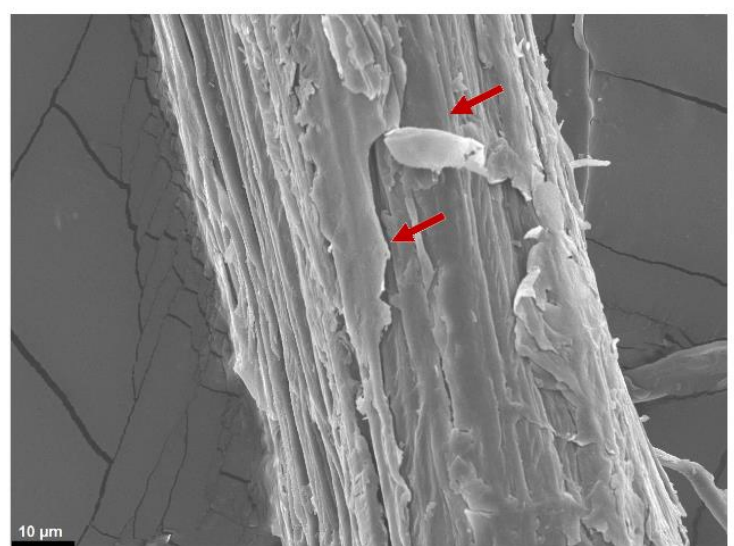

(d)

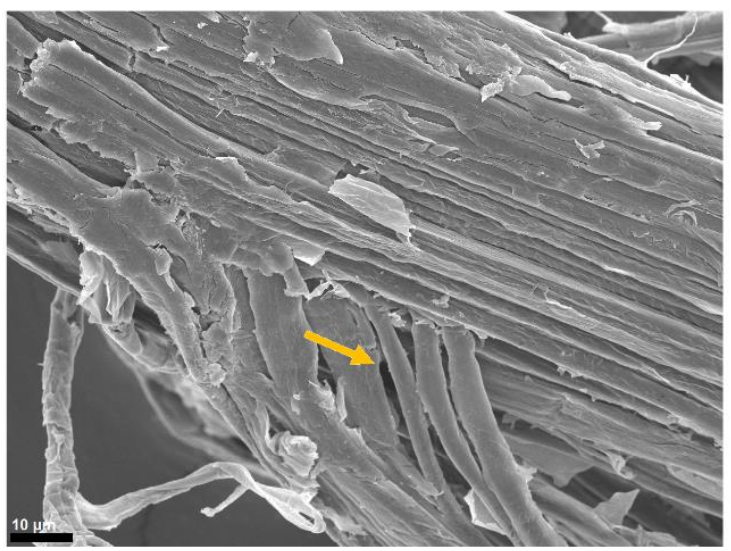

(f)

Figura 13 - Micrografias MEV do curauá in natura e após processo de lavagem. a) e b) Curauá in natura. c) e d) curauá lavado com água quente. e) e f) curauá lavado com hipoclorito de sódio.

Notou-se que a lavagem das fibras de curauá, tanto com água quente quanto com hipoclorito de sódio, aumentaram visualmente a rugosidade das fibras em relação a fibra in natura. A lavagem com água quente resultou na escamação da parede mais externa da fibra de curauá, onde se encontram ácidos graxos, resinas e ceras que podem ser retiradas com a água quente. Esta lavagem proporcionou um 
aumento da rugosidade e da área superficial da fibra, tornando mais fácil o processo de mercerização, porém, as fibrilas ainda não ficaram totalmente expostas. A fibra lavada com hipoclorito de sódio também teve este aumento de rugosidade e de área superficial, no entanto, a fibra lavada com hipoclorito de sódio sofreu mais danos que a fibra lavada com água, visto que o hipoclorito de sódio é um composto mais reativo. Como o hipoclorito de sódio tem um caráter básico, uma parcela da lignina presente nas fibras de curauá se quebrou durante a lavagem. A retirada de componente amorfo deixa as fibrilas de celulose expostas (Figura 13 e,f) e suscetíveis ao ataque do hidróxido de sódio durante a mercerização.

A mercerização da fibra com hidróxido de sódio em solução aquosa causou o inchamento da fibra de curauá e a remoção dos compostos amorfos. A remoção da lignina ocorreu pela quebra da lignina e a da hemicelulose pela dissolução da hemicelulose na solução de hidróxido de sódio. Na Figura 13 a e 13 b, observou-se a fibra de curauá mercerizada após a lavagem da fibra com água. Nestas micrografias as fibrilas da fibra de curauá estão bem visíveis e separadas. Ainda na Figura 13, mas nas micrografias c e d, é apresentada a fibra de curauá mercerizada após a lavagem com hipoclorito de sódio, as fibrilas são também facilmente vistas e estão bem separadas, no entanto estas fibrilas apresentam uma escamação. As micrografias das fibras após a mercerização são mostradas na Figura 14. 


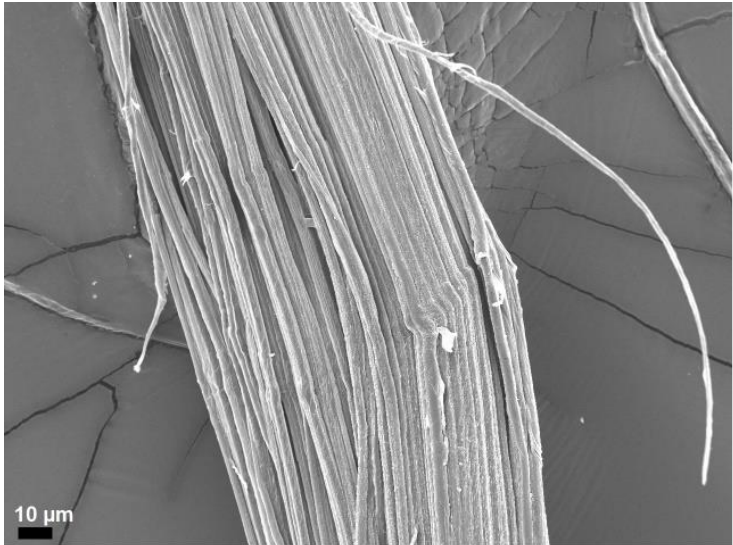

(a)

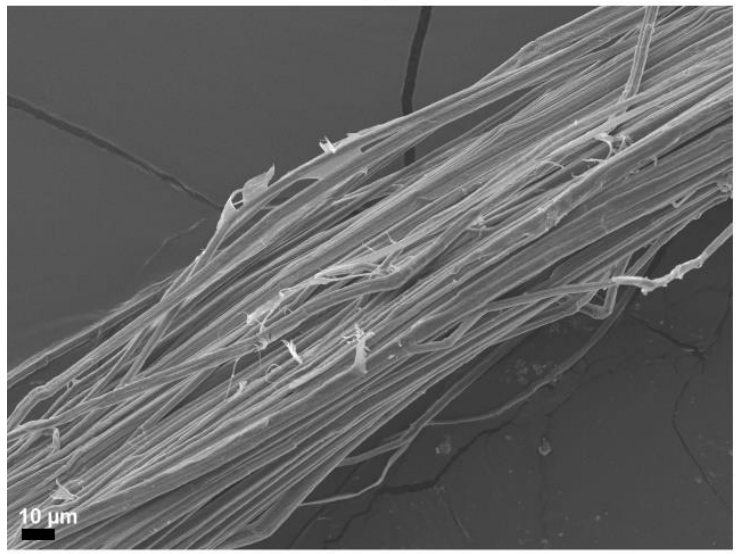

(c)

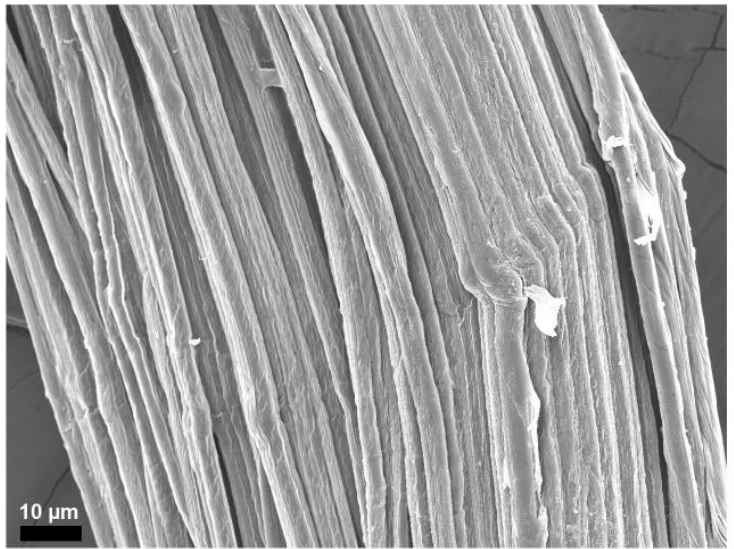

(b)

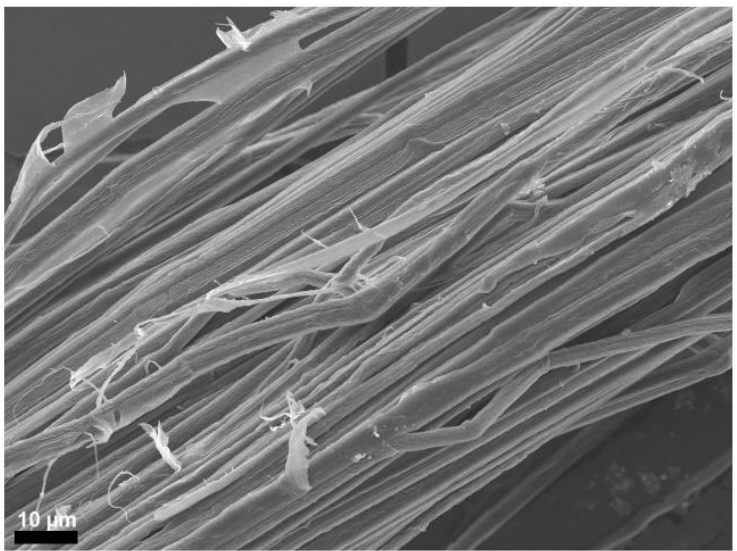

(d)

Figura 14 - Micrografias das fibras de curauá mercerizadas. a) e b) lavada com água quente e mercerizada. c) e d) lavada com hipoclorito de sódio e mercerizadas.

A lavagem da fibra com água quente antes da mercerização aumenta a rugosidade da fibra de curauá e sua área superficial, então, quando mercerizadas, toda a camada externa da fibra é retirada ficando apenas as fibrilas visíveis. A lavagem da fibra de curauá com hipoclorito de sódio, também aumenta a rugosidade e a área superficial da fibra, por outro lado, por possuir um caráter básico, o hipoclorito de sódio reagiu com a lignina e causou a quebra de uma parcela de lignina que foi retirada durante a lavagem, o que torna as fibrilas do interior da fibra mais expostas ao tratamento de $\mathrm{NaOH}$, tornando-o mais agressivo na fibra lavada com hipoclorito de sódio que na fibra lavada com água quente. Ao fazer a mercerização após a lavagem com $\mathrm{NaClO}$, como a lignina já sofreu quebra na estrutura, o $\mathrm{NaOH}$ age principalmente na hemicelulose causando sua dissolução, mas também ataca uma parcela da celulose, o que faz com que o rendimento final deste processo seja o menor. 


\subsubsection{Caracterização lignocelulósica da fibra de curauá}

Por meio da caracterização lignocelulósica da fibra, é possível observar qual componente da fibra sofreu alteração durante cada etapa do tratamento. A Tabela 4 apresenta os resultados qualitativos da caracterização lignocelulósica das fibras de curauá in natura, após lavagem e após mercerização.

Tabela 4 - Caracterização lignocelulósica das fibras de curauá in natura e tratadas.

\begin{tabular}{|c|c|c|c|c|c|c|}
\hline Amostra & Holocelulose & aCelulose & Lignina* $^{*}$ & Umidade & Cinzas & Outros $^{\star *}$ \\
\hline Curauá in natura & 76,89 & 61,87 & 6,83 & 5,80 & 0,56 & 9,92 \\
\hline $\begin{array}{l}\text { Curauá lavado com } \\
\text { água }\end{array}$ & 83,03 & 61,67 & 5,15 & 5,83 & 0,42 & 5,57 \\
\hline $\begin{array}{l}\text { Curauá lavado com } \\
\text { água e mercerizado }\end{array}$ & 80,64 & 68,46 & 6,81 & 7,56 & 0,46 & 4,53 \\
\hline $\begin{array}{l}\text { Curauá lavado com } \\
\mathrm{NaClO}\end{array}$ & 76,43 & 43,04 & 2,71 & 8,13 & 0,78 & 11,95 \\
\hline $\begin{array}{l}\text { Curauá lavado com } \\
\mathrm{NaClO} \\
\text { mercerizado }\end{array}$ & 86,68 & 71,00 & 2,71 & 7,83 & 0,71 & 2,07 \\
\hline
\end{tabular}

* Corresponde apenas a lignina insolúvel na fibra de curauá

** Corresponde aos outros componentes como lignina solúvel, extrativos e outros não detectados nas análises.

Nota-se a partir da Tabela 4 que as fibras após todas as etapas de tratamento superficial apresentaram maior quantidade de holoceluloses que as fibras in natura, a holocelulose é formada pela mistura de celulose com hemicelulose. O tratamento que envolveu a lavagem das fibras de curauá com água apresentou quase nenhuma remoção de lignina, enquanto que o tratamento que envolveu a lavagem das fibras com $\mathrm{NaClO}$ retirou quase que totalmente este componente, visto que o $\mathrm{NaClO}$ atuou como agente deslignificante na fibra, ou seja, retirou quase que completamente a lignina presente na fibra de curauá. Isto ocorreu porque a lavagem da fibra com 
água acarretou modificações nos extrativos, sem comprometer a estrutura da lignina. $\mathrm{O} \mathrm{NaClO}$, por possuir um caráter básico acabou por quebrar a lignina.

A diminuição do teor de lignina para a amostra lavada com água e mercerizada deveu-se ao fato de que a lignina na presença de hidróxido de sódio sofreu uma quebra em sua estrutura e acabou sendo solubilizada na solução de hidróxido de sódio. Como a solução de $\mathrm{NaOH}$ utilizada no tratamento é de baixa concentração, apenas essa pequena parcela de lignina pode ser solubilizada. Observou-se também, que a lavagem da fibra com $\mathrm{NaClO}$ sem a etapa de mercerização apresentou menor quantidade de a-celulose que a fibra lavada com água, isso porque o $\mathrm{NaClO}$ causou a quebra das ligações da $\alpha$-celulose, enquanto a água não afetou este composto estruturalmente, este fato foi observado pela micrografia desta fibra, visto que houve uma escamação nas fibrilas, mesmo após a etapa apenas de lavagem.

Após a etapa de mercerização, as duas rotas de tratamento mostraram maior quantidade de holocelulose que a fibra in natura, no entanto a rota de tratamento que utilizou lavagem com $\mathrm{NaClO}$ apresentou maior teor de a-celulose que a rota utilizando lavagem a água. Isso ocorreu devido ao fato que o $\mathrm{NaClO}$ apesar de causar danos a estrutura da celulose, retira quase totalmente a lignina presente na fibra, e o acréscimo da etapa de mercerização com $\mathrm{NaOH}$ retirou a parcela de hemicelulose solúvel presente na estrutura da fibra, aumentando assim o teor de $\alpha$ celulose. Como a lavagem com água não atacou a lignina nem a hemicelulose

presente na fibra, a mercerização agiu quebrando a estrutura da lignina e solubilizando a hemicelulose, o que acabou retirando também uma parcela de lignina.

\subsubsection{Grau de cristalinidade das fibras de curauá}

A a-celulose é o único componente lignocelulósico que confere cristalinidade as fibras de curauá, devido ao seu alto grau de polimerização e por ser o único componente cristalino na fibra. Além disso, o índice de cristalinidade do material está intimamente ligado com suas propriedades mecânicas (41), assim sendo, o teor de 
a-celulose está ligado com as propriedades mecânicas do material. Os difratogramas de raio-x das amostras de curauá estão apresentados na Figura 15. Observam-se três picos bem característicos, em $2 \theta=16^{\circ}, 2 \theta=22,5^{\circ}$ e $2 \theta=35^{\circ}$. Estes picos correspondem aos planos cristalográficos da celulose tipo 1 ( 00 - 0 -1), (0 0 2) e (0 4 0), respectivamente (41) (8).

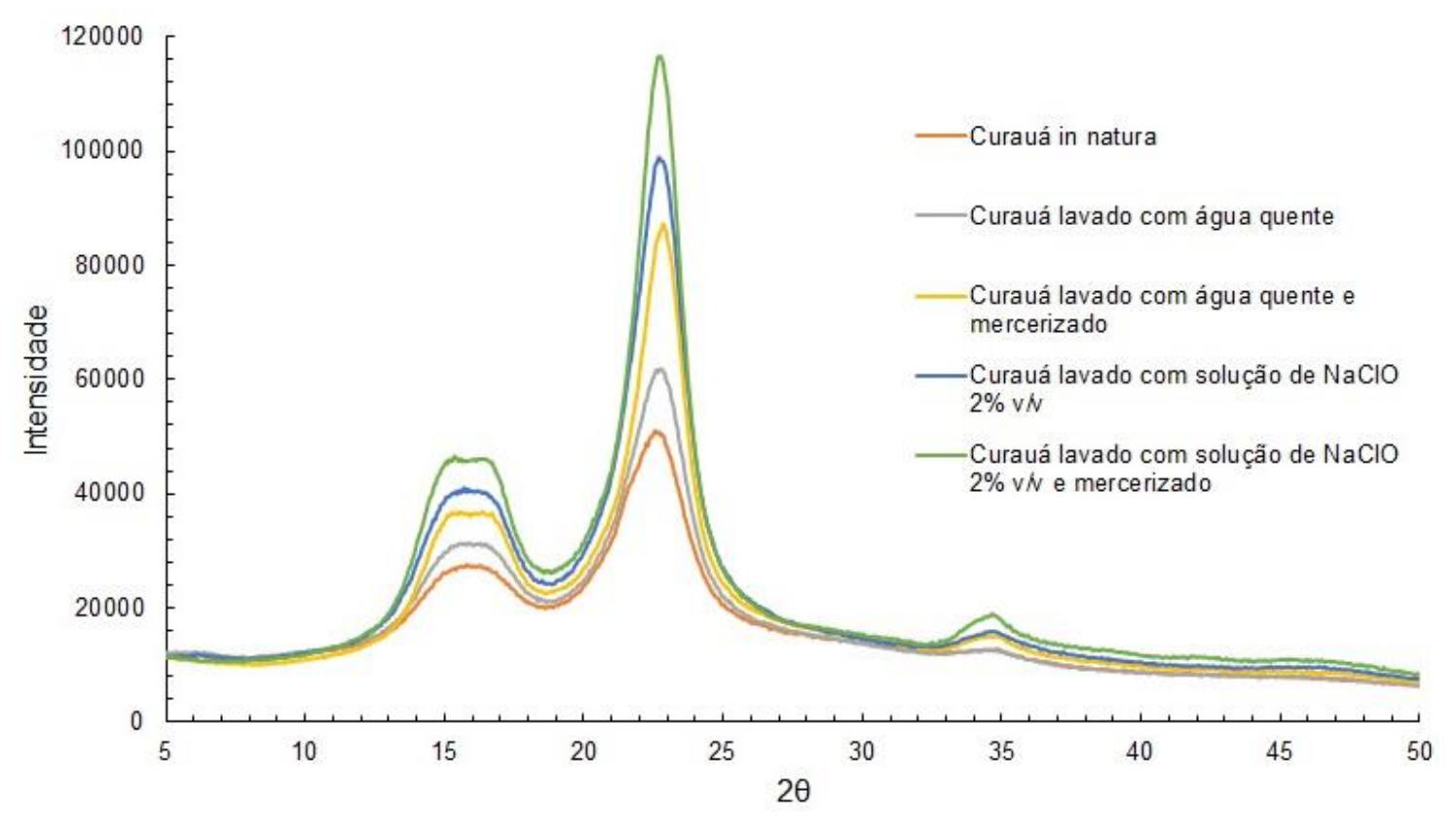

Figura 15 - Difratogramas para as amostras de fibra de curauá in natura e tratadas.

Observou-se que os difratogramas apresentaram o mesmo perfil, mudando apenas a intensidade dos picos. No entanto, nos difratogramas das amostras de fibra de curauá mercerizadas foi possível observar uma tendência em formar dois picos na região de $2 \theta$ igual a 15 e $16^{\circ}$. Quando compostos celulósicos sofrem tratamento alcalino, ocorre um rearranjo na estrutura interna da fibra formando um tipo diferente de conformação cristalina, que é evidenciado pela formação destes dois picos. Os índices de cristalinidade das amostras de fibra de curauá são mostrados na Tabela 5.

De acordo com o método de Segal, a cristalinidade não é dada apenas pela parcela cristalina do material, mas também pela diferença entre a parcela cristalina e amorfa do mesmo. No material lignocelulósico, a parcela amorfa é contabilizada pela presença de lignina e hemicelulose na estrutura da fibra. Com isto, observou-se que 
apesar das amostras de fibra de curauá mercerizadas apresentarem o maior teor de a-celulose, as amostras que apresentam o maior índice de cristalinidade foram as lavadas com $\mathrm{NaClO}$, tanto a mercerizada quanto a que sofre penas lavagem, devido aos menores teores de lignina e hemicelulose. A amostra lavada com água e mercerizada apresentou maior teor de lignina, o que fez seu índice de cristalinidade cair. A amostra apenas lavada com água, não apresentou variação no teor de $\alpha$ celulose em relação à fibra in natura, no entanto seu índice de cristalinidade foi um pouco maior que para esta fibra, devido ao seu teor de lignina ter sido um pouco menor.

Tabela 5 - Índice de cristalinidade para as fibras de curauá obtidos pelo método de Segal.

\begin{tabular}{c|c} 
Amostra & $\%$ Xc \\
\hline Curauá in natura & $58,14 \%$ \\
Curauá lavado com água & $62,32 \%$ \\
Curauá lavado com água e mercerizado & $70,07 \%$ \\
Curauá lavado com NaClO & $72,27 \%$ \\
Curauá lavado com NaClO e mercerizado & $74,56 \%$
\end{tabular}

Visto que todas as amostras apresentaram uma elevação no índice de cristalinidade, notou-se que os tratamentos superficiais na fibra de curauá foram eficientes na remoção dos constituintes amorfos das fibras. Esta remoção de hemicelulose e lignina foi observada também durante o comportamento térmico das amostras.

\subsubsection{Comportamento térmico das fibras de curauá}

Durante a pirólise de materiais lignocelulósico ocorre a degradação dos seus constituintes em diferentes temperaturas. A hemicelulose se degrada em torno de $280^{\circ} \mathrm{C}$, seguido pela celulose. Já a lignina possui reatividade muito maior que estes dois componentes, sendo degradada em um longo intervalo durante a análise, iniciando em baixas temperaturas, um pouco menores que $280^{\circ} \mathrm{C}$ e alcançando 
máxima degradação acima de $400^{\circ} \mathrm{C}$ (42). O comportamento térmico das fibras de curauá em ensaio de TGA e sua derivada estão mostrados na Figura 16 . Até $200^{\circ} \mathrm{C}$, todas as fibras apresentaram um pequeno patamar de perda de massa, isso ocorreu devido a eliminação da umidade presente no material lignocelulósico. Este patamar inicial não interferiu na estabilidade térmica das amostras.

A fibra de curauá in natura apresentou estabilidade térmica até $250^{\circ} \mathrm{C}$, a estabilidade térmica nos compostos lignocelulósicos é baseada no teor de lignina, hemicelulose e celulose que estes compostos apresentam. A celulose é a parcela mais cristalina do material, apresentando uma difícil degradação devido à sua estrutura altamente organizada, é este componente que conferiu estabilidade térmica à fibra. A hemicelulose e a lignina são compostos amorfos, que apresentaram uma reatividade alta em relação ao aumento de temperatura. A hemicelulose possui uma estrutura altamente ramificada, sendo degradada em temperaturas entre 150 a $350^{\circ} \mathrm{C}$. A lignina é uma macromolécula reticulada que possui alto número de ramificações e muitas unidades aromáticas, sendo degradada durante um grande intervalo da análise. Quanto maior o teor de estruturas cristalinas, maior foi a estabilidade térmica da amostra, portanto quanto maior os teores de hemicelulose e lignina menor foi a estabilidade térmica da amostra.

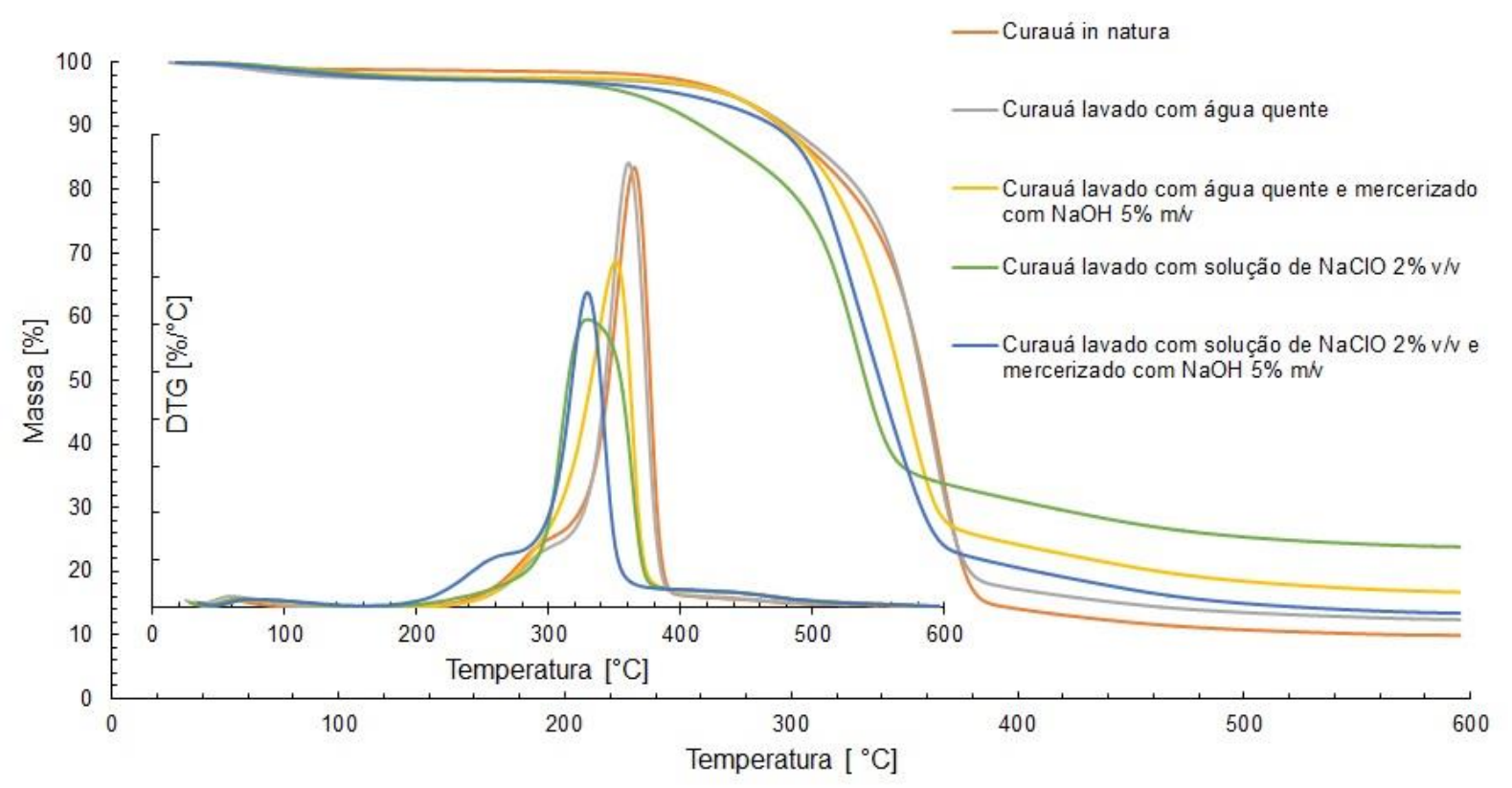

Figura 16 - Curvas TGA e DTG para as fibras de curauá in natura e tratadas. 
Ao final dos tratamentos superficiais realizados nas fibras houve um aumento na sua estabilidade térmica em torno de $10^{\circ} \mathrm{C}$ em relação à fibra in natura. No entanto, na etapa de lavagem das fibras não ocorreu aumento de estabilidade térmica. Após a etapa de lavagem, a fibra de curauá lavada com água apresentou a mesma estabilidade térmica da fibra in natura, visto que o teor de a-celulose dessas duas amostras são os mesmos. Após a lavagem da fibra de curauá com $\mathrm{NaClO}$, houve uma queda na estabilidade térmica da fibra em torno de $60^{\circ} \mathrm{C}$. Como o $\mathrm{NaClO}$ quebrou a estrutura da lignina e ainda reagiu com a celulose e hemicelulose deixando as fibrilas mais expostas, a estabilidade térmica da amostra foi reduzida, pois os carboidratos sentem mais o aumento de temperatura. As curvas DTG apresentadas mostraram que as duas amostras de fibras mercerizadas, tanto a lavada com água quanto a lavada com hipoclorito de sódio, apresentaram dois patamares de degradação, um patamar de perda de massa abaixo de $150^{\circ}$ e o outro com temperatura de pico em 350 e $330^{\circ} \mathrm{C}$, respectivamente. Esta última perda de massa é relativa à degradação da celulose presente em ambas as amostras.

As fibras de curauá in natura e lavadas com água e hipoclorito de sódio, apresentaram três patamares de perda de massa, o primeiro antes de $150^{\circ} \mathrm{C}$, o segundo relacionado à degradação da hemicelulose e o terceiro à degradação da celulose. As fibras in natura $e$ as lavadas com água tiveram o mesmo comportamento térmico, perda de umidade antes de $100^{\circ} \mathrm{C}$, perda de massa em uma temperatura de $290^{\circ} \mathrm{C}$ e outro patamar de perda com temperatura de pico entre 360 e $365^{\circ} \mathrm{C}$. A lavagem com água não alterou a estrutura da fibra de curauá a ponto de alterar seu comportamento térmico.

A fibra lavada com hipoclorito de sódio também apresentou três patamares de perda de massa, no entanto essas perdas de massa foram em temperaturas inferiores à fibra in natura, sendo a primeira perda de massa devido à evaporação da umidade, a segunda em $250^{\circ} \mathrm{C}$ e a terceira em $328^{\circ} \mathrm{C}$. Estas perdas de massa foram referentes a degradação da hemicelulose e celulose, respectivamente. A fibra de curauá, após a lavagem com hipoclorito de sódio possuiu menor teor de a-celulose que as outras, sendo assim, seu comportamento térmico foi afetado, sua estabilidade térmica foi menor e suas temperaturas de degradação térmica também. A celulose presente nesta fibra sofreu ação da temperatura mais rapidamente que 
nas outras, pois como mostrado nas micrografias de $\mathrm{MEV}$, as fibrilas de celulose já estavam expostas. Os valores encontrados para temperatura de início da degradação, temperatura de pico, resíduo e estabilidade térmica das amostras são mostrados na Tabela 6.

Tabela 6 - Estabilidade térmica, resíduos, temperatura de início de perda de massa ( $\left.T_{\text {on set }}\right)$ e temperatura de pico de perda de massa $\left(T_{\text {pico }}\right)$ para as amostras de fibra de curauá in natura e tratadas.

\begin{tabular}{|c|c|c|c|c|c|c|c|c|}
\hline \multirow{2}{*}{ Amostra } & \multirow{2}{*}{$\begin{array}{l}\text { Estabilidade } \\
\text { térmica }\left({ }^{\circ} \mathrm{C}\right)\end{array}$} & \multicolumn{2}{|c|}{$\begin{array}{c}1 \text { estágio } \\
\text { de } \\
\text { degradação }\end{array}$} & \multicolumn{2}{|c|}{$\begin{array}{l}2 \text { estágio de } \\
\text { degradação }\end{array}$} & \multicolumn{2}{|c|}{$\begin{array}{l}3 \text { estágio de } \\
\text { degradação }\end{array}$} & \multirow{2}{*}{$\begin{array}{c}\text { Resíduos } \\
\text { (\%) }\end{array}$} \\
\hline & & $\begin{array}{c}\mathrm{T}_{\text {on }} \\
\text { set } \\
\left({ }^{\circ} \mathrm{C}\right)\end{array}$ & $\begin{array}{l}\mathrm{T}_{\text {pico }} \\
\left({ }^{\circ} \mathrm{C}\right)\end{array}$ & $\begin{array}{l}\mathrm{T}_{\text {on set }} \\
\left({ }^{\circ} \mathrm{C}\right)\end{array}$ & $\begin{array}{l}\mathrm{T}_{\text {pico }} \\
\left({ }^{\circ} \mathrm{C}\right)\end{array}$ & $\begin{array}{l}\mathrm{T}_{\text {on }} \\
\text { set } \\
\left({ }^{\circ} \mathrm{C}\right)\end{array}$ & $\begin{array}{l}T_{\text {pico }} \\
\left({ }^{\circ} \mathrm{C}\right)\end{array}$ & \\
\hline $\begin{array}{c}\text { Curauá in } \\
\text { natura }\end{array}$ & 250 & 59 & 65 & 257 & 290 & 346 & 365 & 10 \\
\hline $\begin{array}{c}\text { Curauá } \\
\text { lavado com } \\
\text { água }\end{array}$ & 250 & 51 & 60 & 273 & 290 & 343 & 360 & 12 \\
\hline $\begin{array}{l}\text { Curauá } \\
\text { lavado } \\
\mathrm{NaClO}\end{array}$ & 190 & 51 & 74 & 228 & 250 & 300 & 329 & 23 \\
\hline $\begin{array}{c}\text { Curauá } \\
\text { lavado com } \\
\text { água e } \\
\text { mercerizado }\end{array}$ & 260 & 52 & 84 & 305 & 350 & - & - & 16 \\
\hline $\begin{array}{c}\text { Curauá } \\
\text { lavado com } \\
\mathrm{NaClO} \text { e } \\
\text { mercerizado }\end{array}$ & 260 & 45 & 70 & 295 & 330 & - & - & 13 \\
\hline
\end{tabular}

As fibras de curauá mercerizadas após as duas rotas de lavagem começaram a degradação térmica da celulose em temperaturas inferiores à da fibra de curauá in natura, porém, a degradação da celulose nestas duas fibras se deu de forma mais lenta, o que foi observado na largura do pico característico desta degradação para as duas fibras na curva DTG. Na fibra de curauá in natura, a estrutura da celulose foi 
protegida pelos componentes amorfos lignina e hemicelulose, após a mercerização, estes componentes sofreram quebra da estrutura e se solubilizaram na solução básica, deixando a celulose mais susceptível às variações de temperatura, no entanto, por ser bastante cristalina, a celulose resistiu bem a estas variações.

A fim identificar o que foi liberado durante a pirólise da fibra, os gases liberados durante a análise térmica foram analisados por espectrofotometria na região do infravermelho. A fibra de curauá é uma biomassa vegetal, durante sua queima são liberados basicamente gases resultantes da sua degradação térmica. Os gases provenientes da pirólise contém principalmente $\mathrm{H}_{2}, \mathrm{CO}_{2}, \mathrm{CO}, \mathrm{CH}_{4}, \mathrm{C}_{2} \mathrm{H}_{6}$, $\mathrm{C}_{2} \mathrm{H}_{4}$ e vapores de água (42) (43).

Em cada patamar de degradação é coletado um espectro referente ao gás liberado durante aquela etapa de aquecimento. O curauá in natura apresentou três estágios de degradação. Os espectros dos gases obtidos durante estes estágios são mostrados na Figura 17.

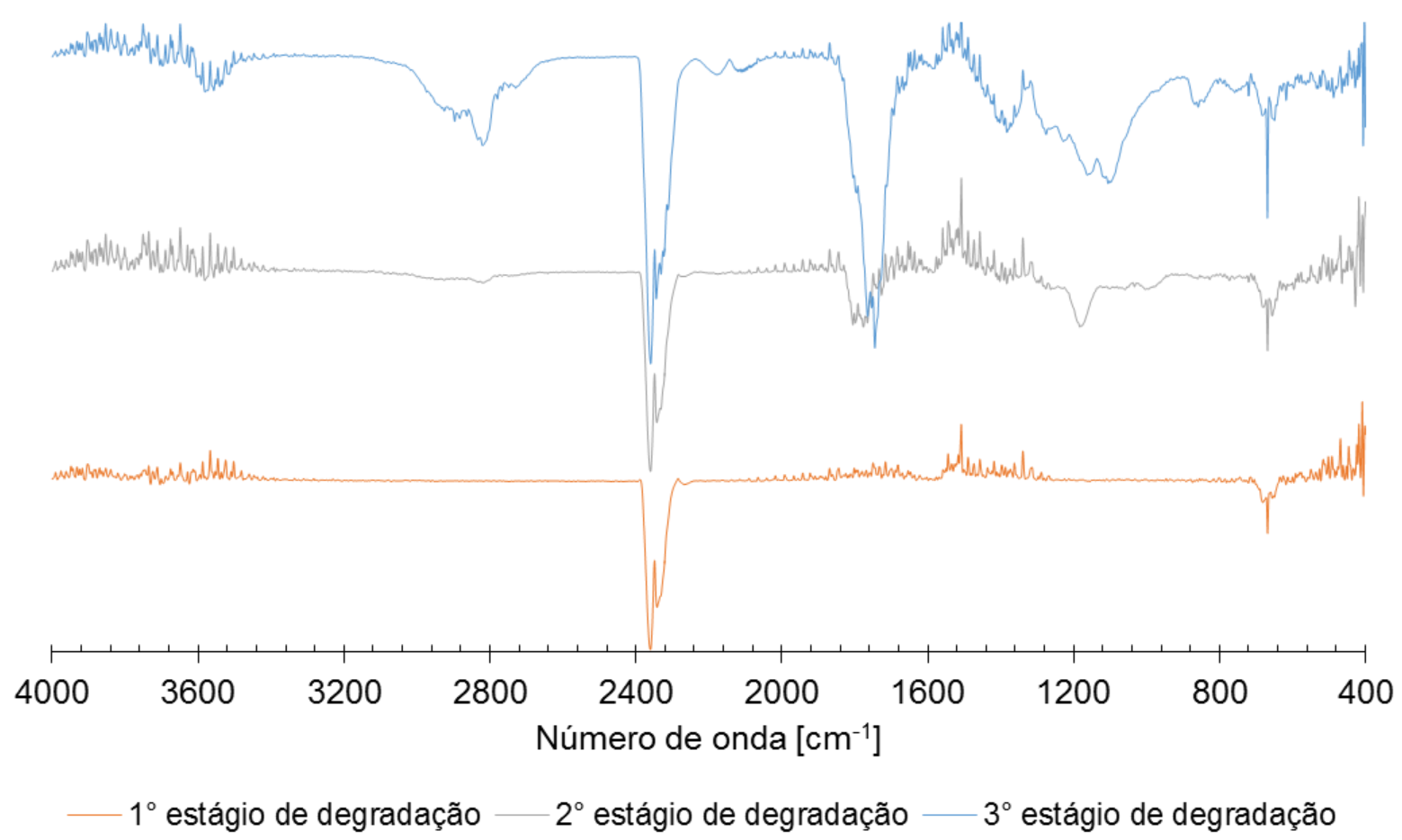

Figura 17 - Espectros dos gases liberados durante a pirólise da amostra de curauá in natura. 
O primeiro estágio de degradação apresentou liberação de $\mathrm{CO}_{2}$, caracterizado pelos picos de absorção em 2350 e $665 \mathrm{~cm}^{-1}$, e de vapores de água com banda de absorção entre 3500 e $4000 \mathrm{~cm}^{-1}$ e pelo pico em $1508 \mathrm{~cm}^{-1}$ (44). Todas as amostras apresentaram este mesmo comportamento, apresentando uma eliminação de umidade em temperaturas de até $100^{\circ} \mathrm{C}$. Durante o segundo estágio de degradação os mesmos gases liberados no primeiro ainda continuaram saindo, no entanto, a banda de absorção em $1797 \mathrm{~cm}^{-1}$ representa a vibração do grupo funcional $\mathrm{C}=\mathrm{O}$, que ocorreu principalmente pela pirólise da hemicelulose (43). O pico fraco em $1171 \mathrm{~cm}^{-1}$ ocorreu devido a absorção do grupo levoglucosano, característico da queima da celulose. No terceiro estágio de degradação continuou ocorrendo a liberação de $\mathrm{CO}_{2}$ de forma mais intensa. O pico de absorção de $2820 \mathrm{~cm}^{-1}$ diz respeito a vibração dos grupos aldeídos presentes na queima da celulose. Em $2180 \mathrm{~cm}^{-1}$ ocorreu absorção referente ao monóxido de carbono. Em $1740 \mathrm{~cm}^{-1}$ apareceram ácidos carboxílicos gerados por meio da queima da celulose e em $858 \mathrm{~cm}^{-1}$ apareceram hidroxiacetaldeidos formados a partir da pirólise da celulose (43).

Todas as amostras apresentaram os mesmos perfis de liberação de gases, sendo que os principais liberados foram $0 \mathrm{CO}_{2}$, ocorrendo durante toda a análise, vapores de água e CO. Os espectros dos gases obtidos para as outras amostras de fibra de curauá analisadas são apresentados na Figura 18. 


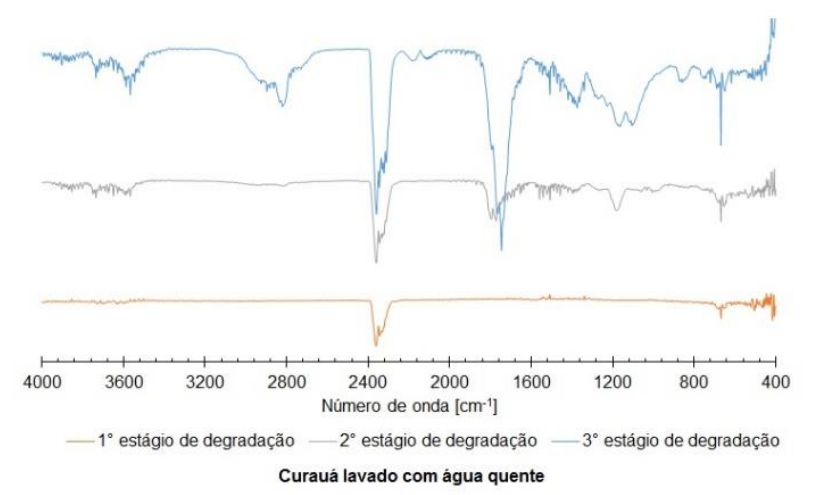

Curauá lavado com água quente

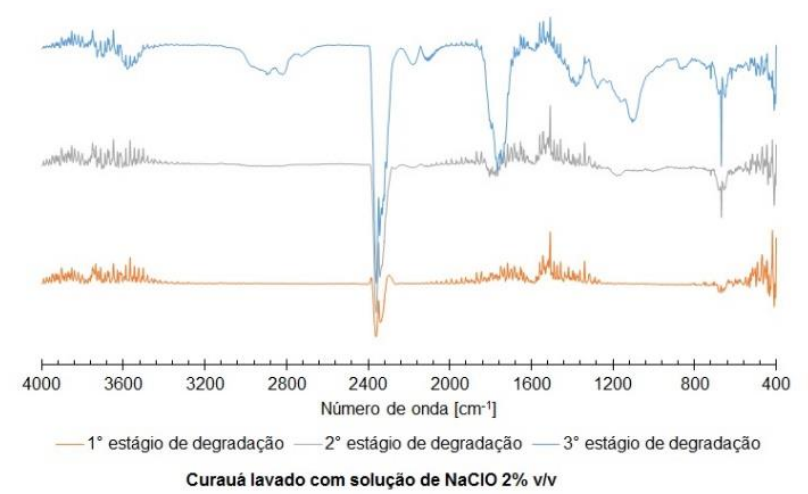

Curauá lavado com soluçäo de $\mathrm{NaClO} 2 \%$ v/v
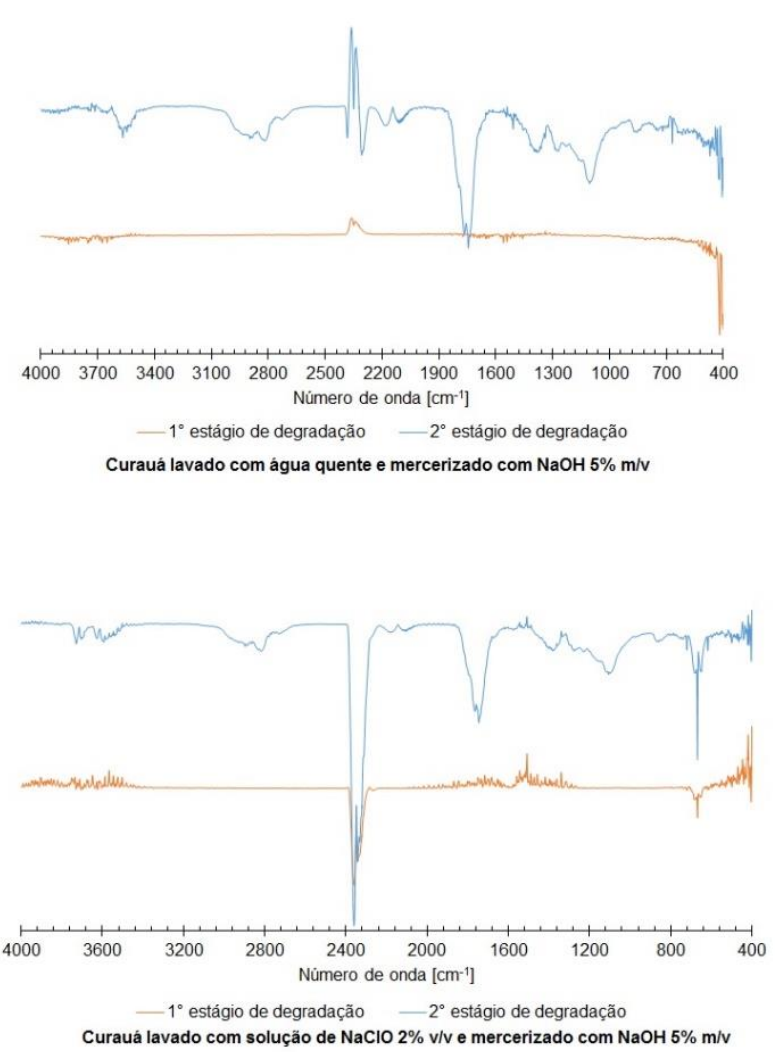

Figura 18 - Espectro dos gases liberados pela queima da fibra de curauá para as amostras tratadas.

A fibra de curauá lavada com água apresentou as mesmas características da fibra in natura, apresentando também o mesmo perfil de gases liberados. Após mercerização, a fibra apresentou apenas dois estágios de degradação, o primeiro referente à liberação de umidade e o último devido à degradação da celulose. Os picos em $2820 \mathrm{~cm}^{-1}, 2180 \mathrm{~cm}^{-1}, 1740 \mathrm{~cm}^{-1}$ e $858 \mathrm{~cm}^{-1}$ aparecem neste espectro, o que confirmou a degradação da celulose, visto que estes picos estão relacionados a vibrações de compostos presentes na celulose e durante sua degradação (43).

A fibra de curauá lavada com hipoclorito de sódio apresentou um pico um pouco mais intenso na região de $1509 \mathrm{~cm}^{-1}$ a partir do primeiro estágio de degradação, este pico foi referente a vibrações do grupo $\mathrm{C}=\mathrm{O}$ em aldeídos e ácidos presentes na hemicelulose (42). Este pico continuou durante o segundo e terceiro estágio de degradação. Quando mercerizada, esta fibra apresentou apenas dois estágios de degradação, sendo o primeiro estágio referente à liberação de umidade e de gases proveniente da queima de traços de hemicelulose e o segundo estágio referente a gases provenientes da degradação da celulose. 


\subsection{OBTENÇÃO DOS COMPÓSITOS}

Os compósitos de poliácido láctico com fibra de curauá foram fabricados com dois diferentes teores de fibra, 10 e $20 \%$ em massa. A Figura 19 mostra o aspecto dos compósitos fabricados.

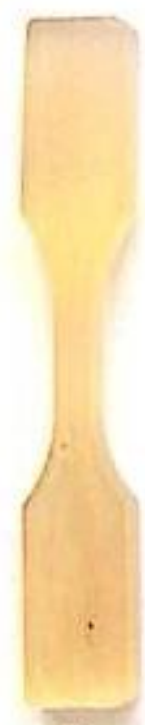

A

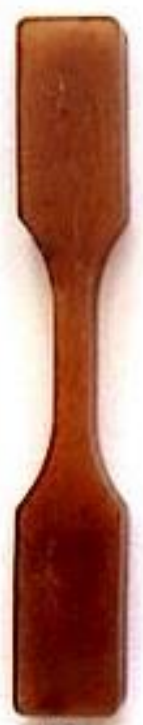

B

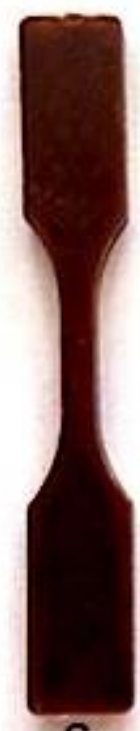

C

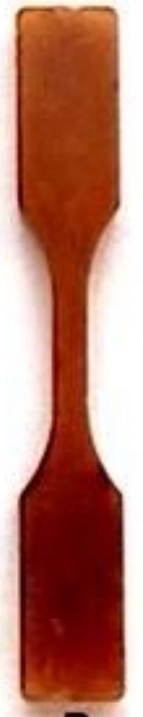

D

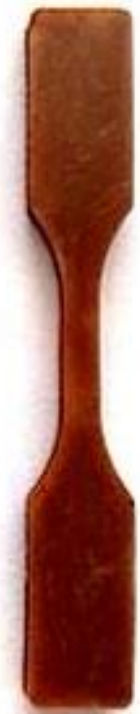

E
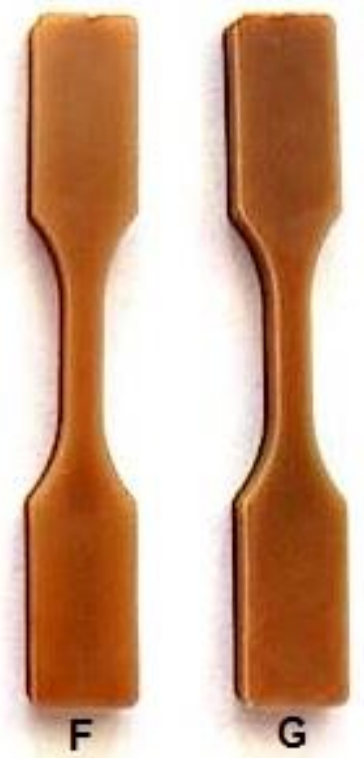

Figura 19 - Corpos de prova de tração do PLA e seus compósitos com fibra de curauá. A) PLA puro.

B) PLA/curauá in natura $10 \% \mathrm{~m} / \mathrm{m}$. c) PLA/curauá in natura $20 \% \mathrm{~m} / \mathrm{m}$. D) PLA/Curauá água- $\mathrm{NaOH}$ $10 \% \mathrm{~m} / \mathrm{m}$. E) PLA/Curauá água- $\mathrm{NaOH} 20 \% \mathrm{~m} / \mathrm{m}$. F) PLA/curauá $\mathrm{NaClO}-\mathrm{NaOH} 10 \% \mathrm{~m} / \mathrm{m} \mathrm{G}$ )

$\mathrm{PLA} /$ curauá $\mathrm{NaClO}-\mathrm{NaOH} 20 \% \mathrm{~m} / \mathrm{m}$.

\subsection{COMPORTAMENTO TÉRMICO DO COMPÓSITO}

Depois de processados, os compósitos obtidos foram caracterizados termicamente por TGA e DSC, para avaliar como a fibra interfere nas características térmicas do polilactato. O PLA puro também foi submetido as análises térmicas para comparação. A Figura 20 apresenta as curvas TGA e DTG para o PLA puro e para seus compósitos com fibra de curauá, nos diferentes teores de fibra utilizados. O PLA puro apresentou estabilidade térmica até $290^{\circ} \mathrm{C}$ e apenas um patamar de perda de massa correspondente à sua degradação, que se inicia em $290^{\circ} \mathrm{C}$ alcançando 
maior velocidade de degradação em $360^{\circ} \mathrm{C}$. Na temperatura final de ensaio, em $500^{\circ} \mathrm{C}$, o PLA puro apresentou uma pequena parcela de resíduos, em torno de 1,5\% da massa inicial.

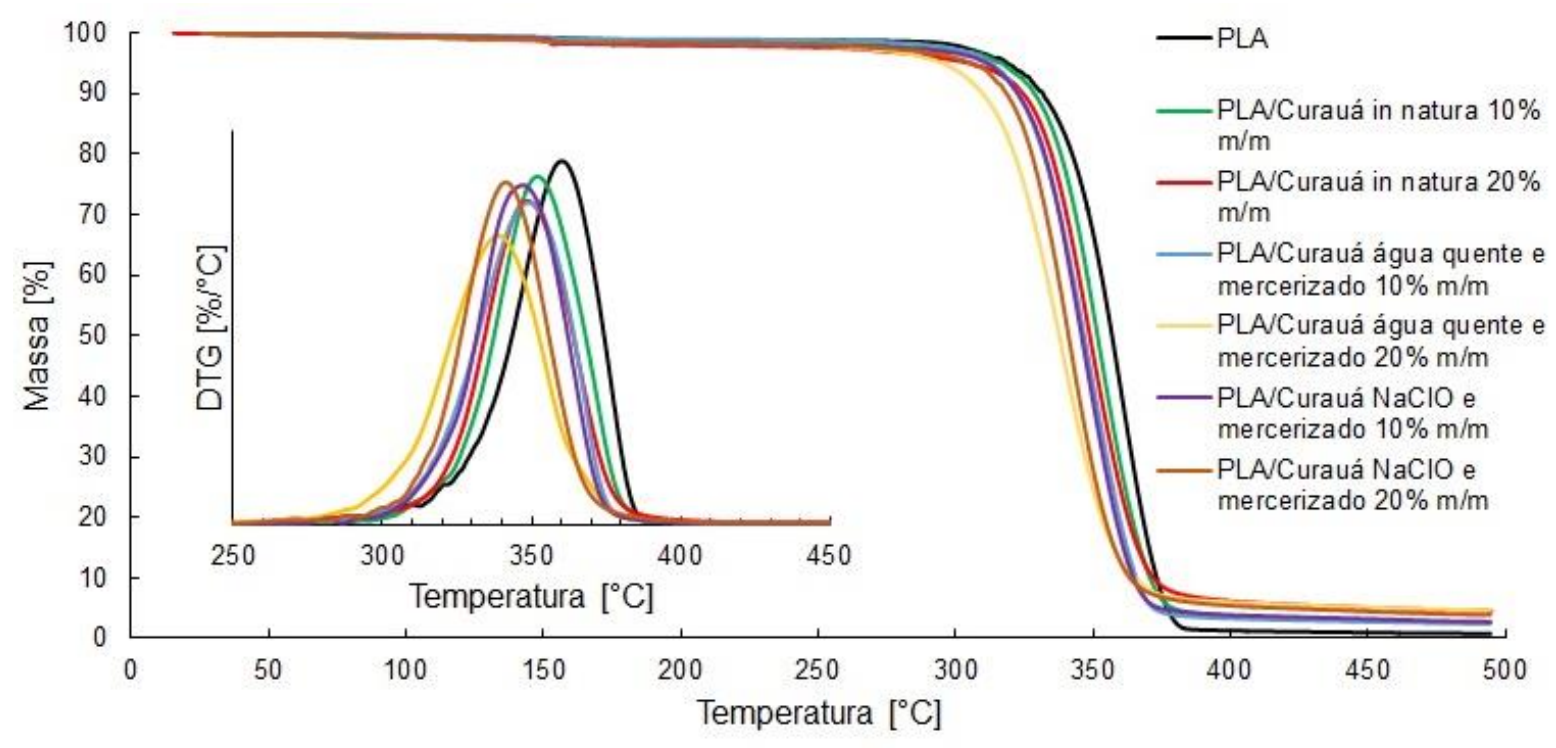

Figura 20 - Curvas TGA e DTG dos compósitos de PLA/curauá e do poliácido láctico puro.

Os compósitos de PLA/curauá apresentaram o mesmo comportamento térmico do PLA puro com apenas um patamar de degradação, no entanto, todos os compósitos apresentaram uma redução na estabilidade térmica. O compósito PLA/Curauá água quente e mercerizado $20 \% \mathrm{~m} / \mathrm{m}$ apresentou a menor estabilidade térmica, sendo estável até $280^{\circ} \mathrm{C}$. As fibras de curauá tratadas e in natura, como visto anteriormente possuem estabilidade térmica até $250^{\circ} \mathrm{C}$, já o PLA puro possui estabilidade térmica até $290^{\circ} \mathrm{C}$, os compósitos de PLA/curauá apresentaram uma redução na estabilidade térmica, porém sua estabilidade térmica ainda esteve acima da estabilidade térmica da fibra, o que sugeriu que houve uma boa interação entre a fibra e a matriz.

Da curva DTG, nota-se que o compósito PLA/Curauá água quente e mercerizado $20 \% \mathrm{~m} / \mathrm{m}$ e o PLA/Curauá $\mathrm{NaClO}$ e mercerizado $20 \% \mathrm{~m} / \mathrm{m}$ apresentaram a mesma temperatura de pico de degradação, em $340^{\circ} \mathrm{C}$, no entanto a degradação do compósito PLA/Curauá água quente e mercerizado $20 \% \mathrm{~m} / \mathrm{m}$ ocorreu mais lentamente e se iniciou em uma temperatura menor. O PLA puro 
apresentou pico de degradação em $360^{\circ} \mathrm{C}$, referente à degradação térmica deste polímero, que segundo Gupta et al. (45) é encontrada entre 350 e $370^{\circ} \mathrm{C}$. Todos os compósitos apresentaram temperatura de pico de degradação menores que o PLA puro, porém em uma faixa maior de temperatura, isto ocorreu porque a temperatura de degradação da fibra e do polímero são próximas, como a temperatura de degradação da fibra é menor, os compósitos iniciaram a degradação em temperaturas menores que o polímero puro, degradando primeiro a fibra e seguindo pela degradação do polímero, o que resultou em uma faixa de degradação maior do que para o polímero puro.

O PLA é um polímero semicristalino, devido a isso ele apresentou uma temperatura de transição vítrea, que é a temperatura onde ocorre o alívio de tensões da parcela amorfa do polímero, e uma temperatura de fusão, que é a temperatura onde ocorre a dissolução dos cristais contidos na parte cristalina do polímero. Por possuir essa parcela cristalina, para o PLA e seu compósitos foi possível obter seu grau de cristalinidade. Estes parâmetros foram obtidos por meio da análise de DSC. A curva DSC para o PLA puro e para seus compósitos com fibra de curauá estão apresentadas na Figura 21. De acordo com as curvas apresentadas pode-se observar que o PLA e seus compósitos apresentaram quatro eventos térmicos. O primeiro foi uma variação na linha base, o segundo tratou-se de um evento exotérmico correspondente a cristalização a frio do PLA, o terceiro um evento endotérmico que se tratou da fusão da parcela cristalina do polímero e o quarto um evento endotérmico referente à degradação do material. Como mostrado nas curvas DTG a degradação da fibra e do polímero ocorreram na mesma faixa de temperatura, o que ficou evidenciado no DSC do material. 


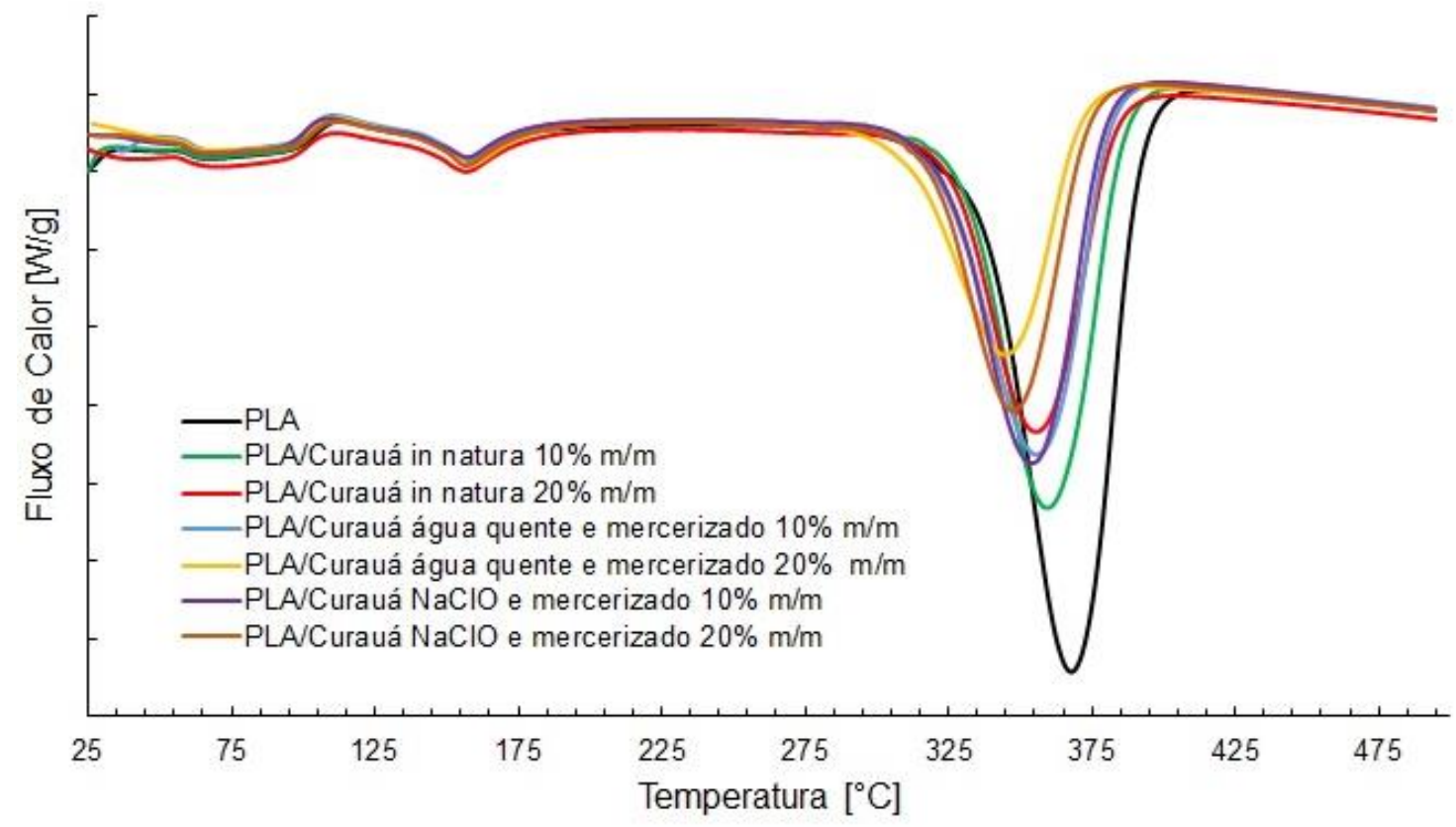

Figura 21 - Curvas de DSC do PLA puro e dos seus compósitos com fibra de curauá.

A fim de identificar os eventos térmicos principais do polímero, a Figura 22 apresenta as curvas DSC do PLA e dos seus compósitos na faixa de temperatura de 35 a $190^{\circ} \mathrm{C}$. Notou-se que o primeiro evento térmico foi um evento de segunda ordem, este evento foi caracterizado pela transição vítrea $\left(T_{g}\right)$ do PLA, que ocorreu entre 58 e $62^{\circ} \mathrm{C}$ para todas as amostras, mostrando que a inserção da fibra de curauá no compósito não alterou sua transição vítrea. Tipicamente, a temperatura de transição vítrea do PLA é encontrada entre 53 e $64^{\circ} \mathrm{C}$ (45) (46).

O segundo evento térmico foi um evento de primeira ordem, dado por um pico exotérmico, este evento ocorreu devido à cristalização a frio do PLA (47) (14). Quando o PLA é aquecido acima de sua temperatura de transição vítrea, as cadeias poliméricas apresentam uma grande mobilidade, havendo assim um rearranjo das regiões amorfas numa fase cristalina, esta cristalização é conhecida como cristalização a frio do PLA. Para os materiais analisados, a cristalização a frio ocorreu em temperaturas entre 110 e $115^{\circ} \mathrm{C}$. Sendo que o polímero puro apresentou cristalização em uma temperatura maior que seus compósitos, visto que a inserção da fibra na matriz polimérica diminuiu a mobilidade das cadeias. Esta cristalização a frio do PLA foi seguida por um evento endotérmico, a fusão do PLA, que nas amostras analisadas ocorreu com pico na temperatura de $160^{\circ} \mathrm{C}$. 


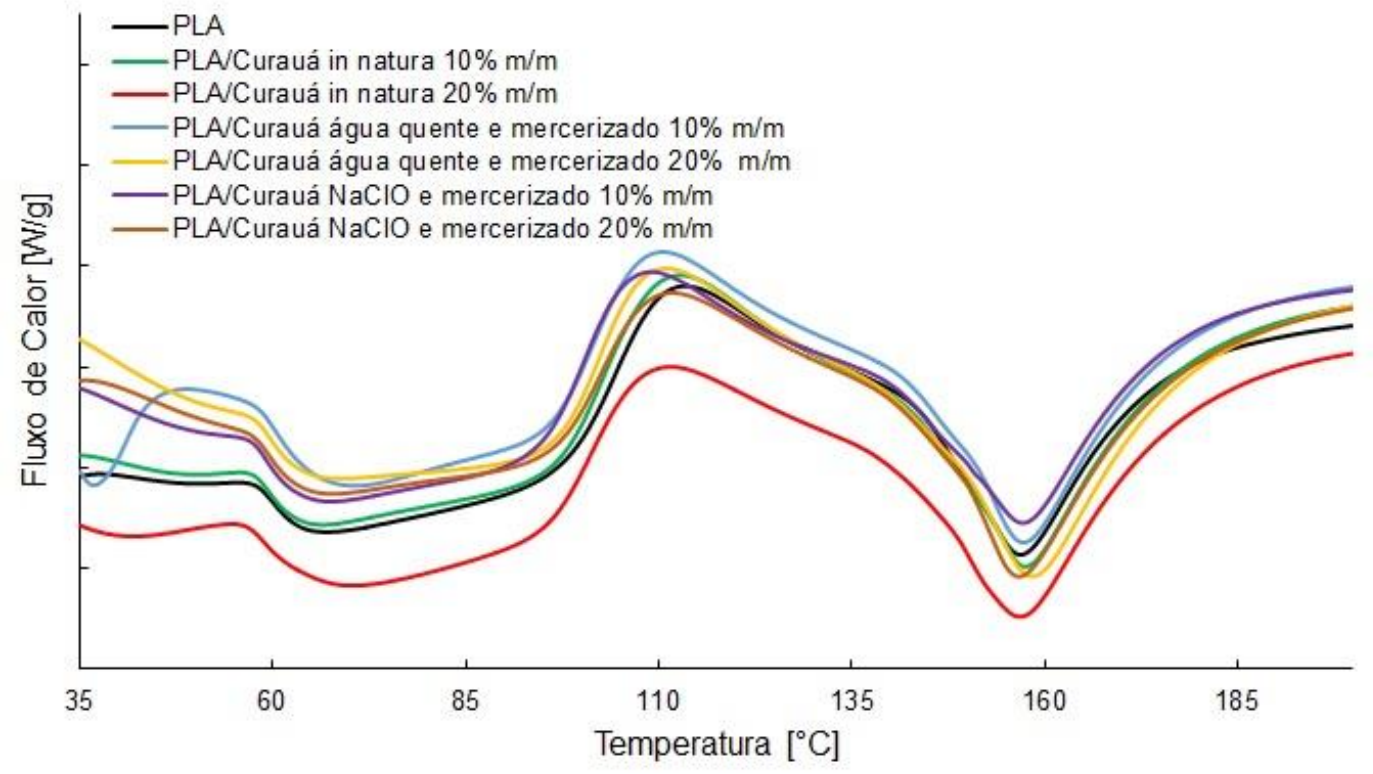

Figura 22 - Curvas DSC do PLA e de seus compósitos no intervalo de temperaturas de 35 a $190^{\circ} \mathrm{C}$.

O grau de cristalinidade do PLA foi obtido através da Equação 4:

$\% X_{C}=\frac{\Delta H_{m}-\Delta H_{C}}{w \times \Delta H_{m}^{0}}$

Onde, $\Delta \mathrm{H}_{\mathrm{m}}$ é a entalpia de fusão do PLA, $\Delta \mathrm{H}_{\mathrm{c}}$ é a entalpia de cristalização a frio, w é fração mássica do polímero no compósito e $\Delta \mathrm{H}_{\mathrm{m}}{ }^{0}$ é a entalpia de fusão para uma amostra de PLA 100\% cristalino, tomado como $93 \mathrm{~J} / \mathrm{g}$ (46). O grau de cristalinidade para o PLA puro e para seus compósitos é mostrado na Tabela 7. 
Tabela 7 - Entalpias de fusão, cristalização a frio e grau de cristalinidade para o PLA puro e para seus compósitos com fibra de curauá.

\begin{tabular}{|l|l|l|l|}
\hline Material & $\Delta \mathrm{H}_{\mathrm{c}}(\mathrm{J} / \mathrm{g})$ & $\Delta \mathrm{H}_{\mathrm{m}}(\mathrm{J} / \mathrm{g})$ & $\% \mathrm{Xc}$ \\
\hline PLA puro & 12,26 & 24,61 & 13,30 \\
\hline PLA/Curauá in natura $10 \% \mathrm{~m} / \mathrm{m}$ & 12,80 & 24,00 & 15,10 \\
\hline PLA/Curauá in natura $20 \% \mathrm{~m} / \mathrm{m}$ & 11,91 & 28,87 & 20,30 \\
\hline $\begin{array}{l}\text { PLA/Curauá água quente e mercerizado } \\
10 \% \mathrm{~m} / \mathrm{m}\end{array}$ & 13,23 & 26,59 & 18,00 \\
\hline $\begin{array}{l}\text { PLA/Curauá água quente e mercerizado } \\
20 \% \mathrm{~m} / \mathrm{m}\end{array}$ & 14,02 & 36,68 & 27,10 \\
\hline $\begin{array}{l}\mathrm{PLA} / \text { Curauá NaClO e mercerizado 10\% } \\
\mathrm{m} / \mathrm{m}\end{array}$ & 13,14 & 24,76 & 15,60 \\
\hline $\begin{array}{l}\mathrm{PLA} / \text { Curauá NaClO e mercerizado 20\% } \\
\mathrm{m} / \mathrm{m}\end{array}$ & 12,78 & 29,32 & 19,80 \\
\hline
\end{tabular}

O grau de cristalinidade de todos os compósitos foi maior em relação ao polímero puro, isto porque as fibras apresentaram uma cristalinidade alta, intensificando assim a formação de cristais no polímero, o que aumentou sua cristalinidade. O PLA puro apresentou cristalinidade de 13\%, de acordo com Gupta, Revagade e Hilborn (45) o grau de cristalinidade do PLA pode variar de 0 a $37 \%$. A maior cristalinidade foi obtida no compósito PLA/Curauá água quente e mercerizado $20 \% \mathrm{~m} / \mathrm{m}$, que apresentou $27,1 \%$ de cristalinidade. Quanto maior o teor de fibras no polímero, maior foi o grau de cristalinidade, o que evidenciou a influência da fibra neste índice.

\subsection{DETERMINAÇÃO DO ÍNDICE DE FLUIDEZ}

$O$ índice de fluidez (MFI - Melt Flow Index) é um parâmetro inversamente proporcional à viscosidade do material fundido. A determinação deste parâmetro é feita medindo a vazão por extrusão do polímero sob pressão e temperaturas específicas. Esta propriedade é dependente de parâmetros como peso molecular e ramificações no material, e pode ser usado como uma forma de avaliação indireta do 
peso molecular dos termoplásticos. Um valor alto de MFI indica que o polímero apresenta baixo peso molecular (48). Os resultados da determinação do MFI dos materiais ensaiados são apresentados na Figura 23.

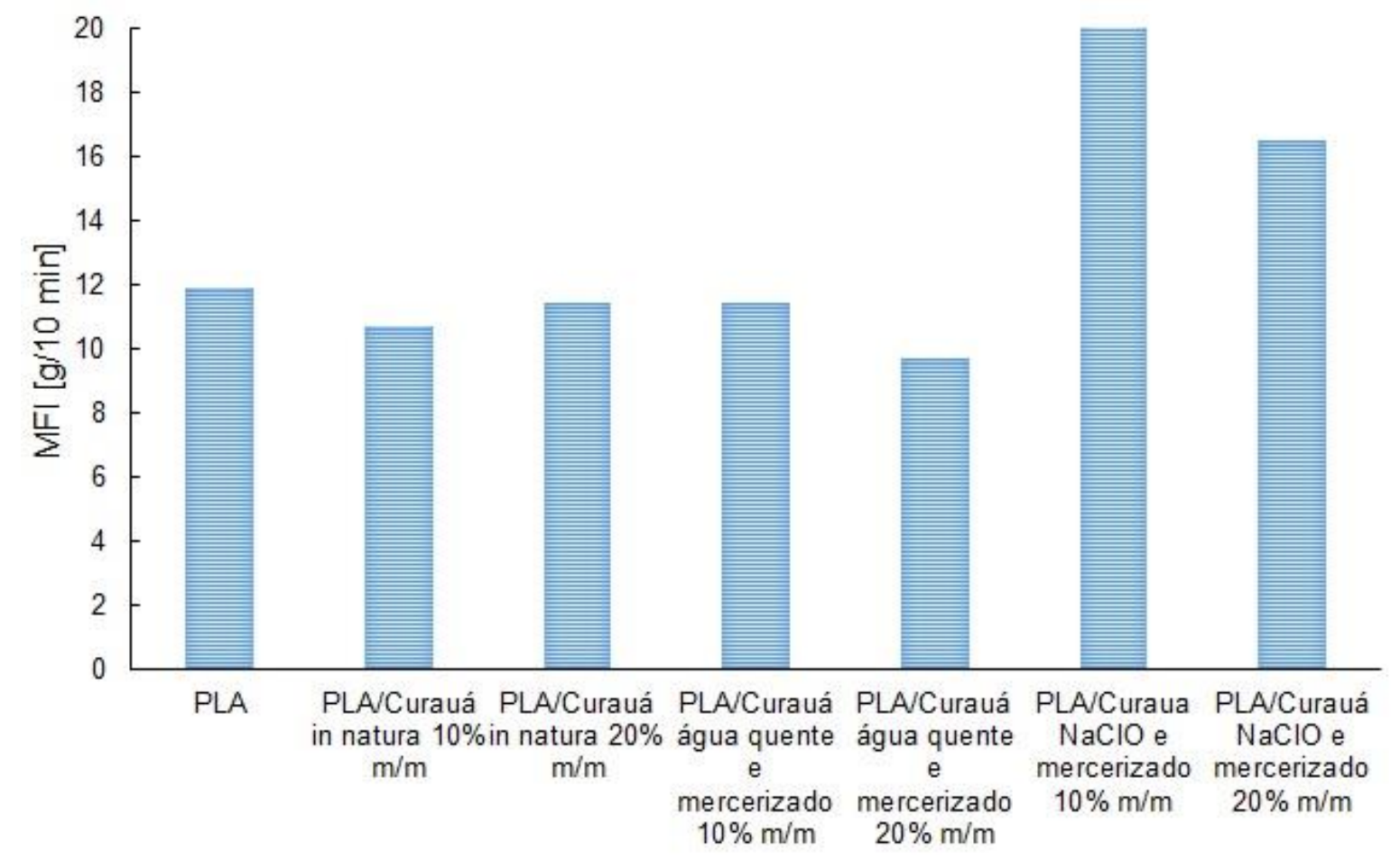

Figura 23 - Índice de fluidez para as amostras de PLA puro e seus compósitos com fibra de curauá.

Nota-se a partir da tabela que os compósitos de PLA/Curauá in natura $10 \mathrm{e}$ $20 \% \mathrm{~m} / \mathrm{m}$ e PLA/Curauá água quente e mercerizado 10 e $20 \% \mathrm{~m} / \mathrm{m}$ apresentaram MFI menores que o PLA puro, isto porque a inserção da fibra aumentou a viscosidade do polímero, o que fez com que o mesmo apresentasse um baixo MFI. Já os compósitos com fibras lavadas com NaCLO apresentaram valores de MFI superiores ao PLA puro, mostrando que estes compósitos apresentaram um peso molecular menor que o PLA puro. As fibras de curauá quando foram tratadas com o $\mathrm{NaClO}$ e $\circ \mathrm{NaOH}$ apresentaram uma maior quantidade de componentes hidroxila $(\mathrm{OH})$, que se ligaram ao polímero, facilitando a fluidez e diminuindo seu peso molecular. 


\subsection{ENSAIOS MECÂNICOS}

As propriedades mecânicas do PLA e de seus compósitos podem ser caracterizadas pelo modo com que estes materiais respondem às solicitações mecânicas aplicadas.

\subsubsection{Ensaio de tração}

Polímeros normalmente não apresentam comportamentos elásticos, e sim comportamento viscoelástico. No PLA, a Tg é em torno de $60^{\circ} \mathrm{C}$, durante o ensaio de tração este material encontrou-se no estado vítreo, ou seja, abaixo da $\mathrm{Tg}$, isto conferiu ao polímero uma resposta elástica às solicitações mecânicas, sua componente viscosa existe, mas sua contribuição é minoritária, o que torna o polímero rígido e frágil (49). A Figura 24 apresenta as curvas tensão versus deformação do PLA puro e de seus compósitos. Da curva, observa-se que o PLA apresentou um comportamento frágil, pois não houve um patamar de escoamento visível e suas deformações chegaram a somente a 1,5\% em relação ao comprimento inicial. Todos os compósitos de PLA/curauá apresentaram um comportamento ainda mais frágil que o polímero puro, isto ocorreu devido a inserção da fibra de curauá na matriz polimérica, o que aumentou a cristalinidade do polímero e aumentou sua fragilidade.

A partir da Figura 24 foi possível calcular o módulo de elasticidade do PLA puro e de seus compósitos. Para polímeros vítreos o módulo de elasticidade foi calculado obedecendo à lei de Hooke em deformações de até 0,2\% (34). O módulo de elasticidade dos materiais ensaiados é apresentado na Figura 25. 


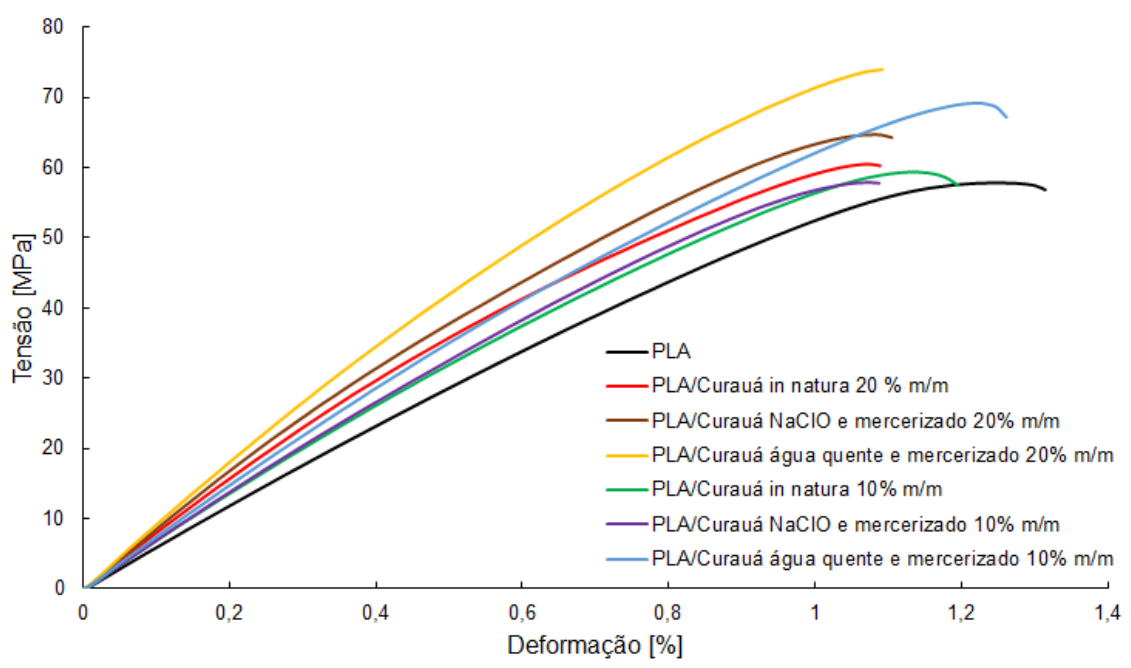

Figura 24 - Comportamento tensão vs deformação em tração para o PLA e para os seus compósitos com fibras de curauá.

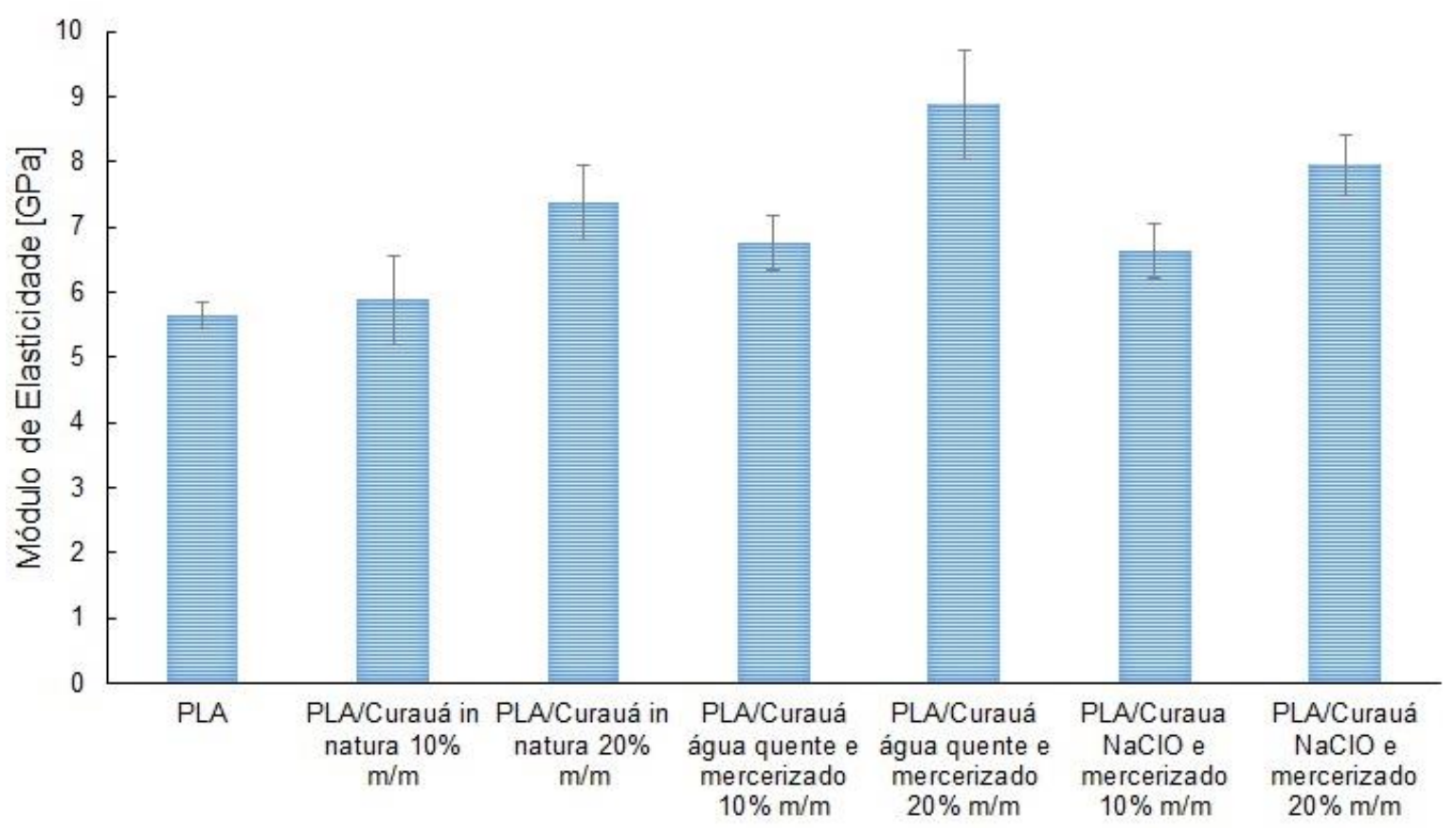

Figura 25 - Módulo de elasticidade em tração para o PLA e para seus compósitos com fibra de curauá.

De acordo com a Figura 25, com o aumento do teor de fibra no compósito ocorreu um aumento no módulo de elasticidade dos mesmos, este aumento ocorreu devido à maior quantidade de reforço que é adicionada à matriz de PLA. Segundo Spinacé (8) as fibras de curauá apresentam um módulo de elasticidade de cerca de $19 \mathrm{GPa}$ e um limite de resistência à tração de $509 \mathrm{MPa}$. Este alto módulo de 
elasticidade da fibra foi refletido no módulo de elasticidade dos compósitos, quanto maior o teor de reforço de fibra de curauá, maior foi o módulo de elasticidade encontrado. Um outro parâmetro que influenciou diretamente o módulo de elasticidade do polímero foi o seu grau de cristalinidade, quanto maior o grau de cristalinidade, maior será o módulo de elasticidade do polímero. O compósito PLA/Curauá água quente e mercerizado $20 \% \mathrm{~m} / \mathrm{m}$ apresentou o maior grau de cristalinidade dentre os materiais ensaiados, e foi também o que apresentou o maior módulo de elasticidade, sendo o mais rígido dentre os materiais ensaiados.

Os limites de resistência a tração do PLA puro e dos compósitos são mostrados na Figura 26. Assim como no módulo de elasticidade, o aumento do teor do reforço de fibras no compósito proporcionou aumento no limite de resistência à tração. A fibra possui uma resistência à tração muito maior que o polímero puro, quando foi inserida no compósito, este apresentou um ganho em resistência mecânica e uma perda em deformação.

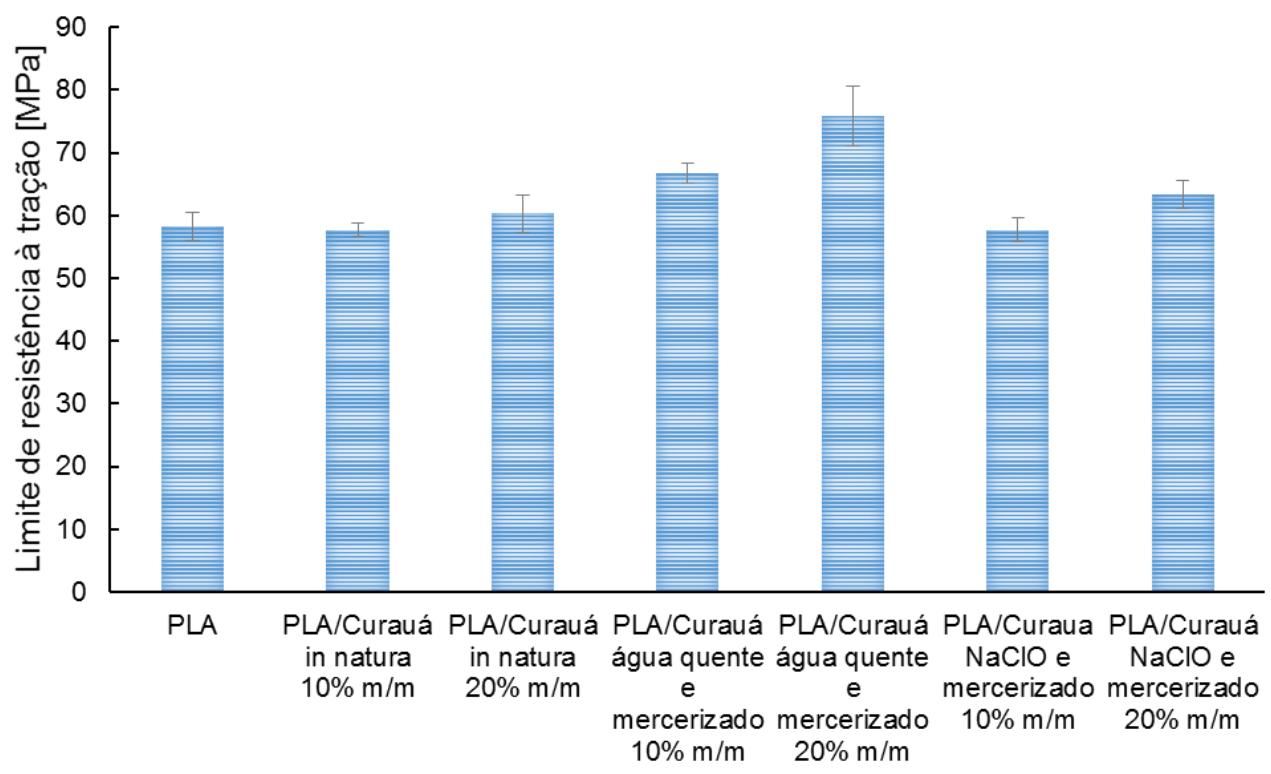

Figura 26 - Limite de resistência à tração dos compósitos de PLA/fibra de curauá.

Tanto as fibras tratadas quanto as fibras de curauá in natura adquiriram um aumento no módulo de elasticidade e na resistência à tração dos compósitos de curauá, este aumento foi mais intensificado para os compósitos com teores de $20 \%$ de fibra na matriz polimérica. Nos compósitos com este teor de fibra, o PLA/Curauá 
in natura $20 \% \mathrm{~m} / \mathrm{m}$ apresentou um aumento de $30 \%$ no módulo de elasticidade em relação ao PLA puro, porém o melhor resultado obtido foi para o compósito PLA/Curauá água e mercerizado $20 \% \mathrm{~m} / \mathrm{m}$, que apresentou um aumento de $57 \%$ em seu módulo de elasticidade. A rota de tratamento das fibras que utilizou o $\mathrm{NaClO}$, apresentou para o módulo de elasticidade um aumento um pouco maior que a fibra in natura, mas menor que a fibra tratada pela rota utilizando água, isto ocorreu devido ao NaCLO ter degradado a celulose, tornando-a menos rígida e menos resistente que a celulose obtida pela rota utilizando apenas água. O $\mathrm{NaClO}$ se mostrou como um agente muito agressivo à fibra de curauá, aumentando a cristalinidade da fibra de curauá, mas diminuindo a cristalinidade do compósito formado.

O aumento no módulo de elasticidade dos compósitos foi traduzido como um aumento na rigidez do material. Quanto maior o módulo de elasticidade, mais rígido será o compósito (18). Esta característica foi evidenciada durante o ensaio, observando o comportamento sob tração do compósito PLA/Curauá água quente e mercerizado $20 \% \mathrm{~m} / \mathrm{m}$ percebeu-se que ele apresentou maior resistência à tração e menor deformação, sendo dentre os materiais ensaiados o mais rígido. Os valores de módulo de elasticidade e resistência à tração estão disponíveis na Tabela 1 do Anexo 1.

\subsubsection{Ensaio de flexão}

Durante o ensaio de flexão o PLA e os compósitos apresentaram, assim como no ensaio de tração, um comportamento frágil. Esta fragilidade ocorreu devido ao estado vítreo em que o polímero se encontrava durante a realização do ensaio. Os comportamentos tensão vs deformação em flexão do polímero e dos compósitos são apresentados na Figura 27. 


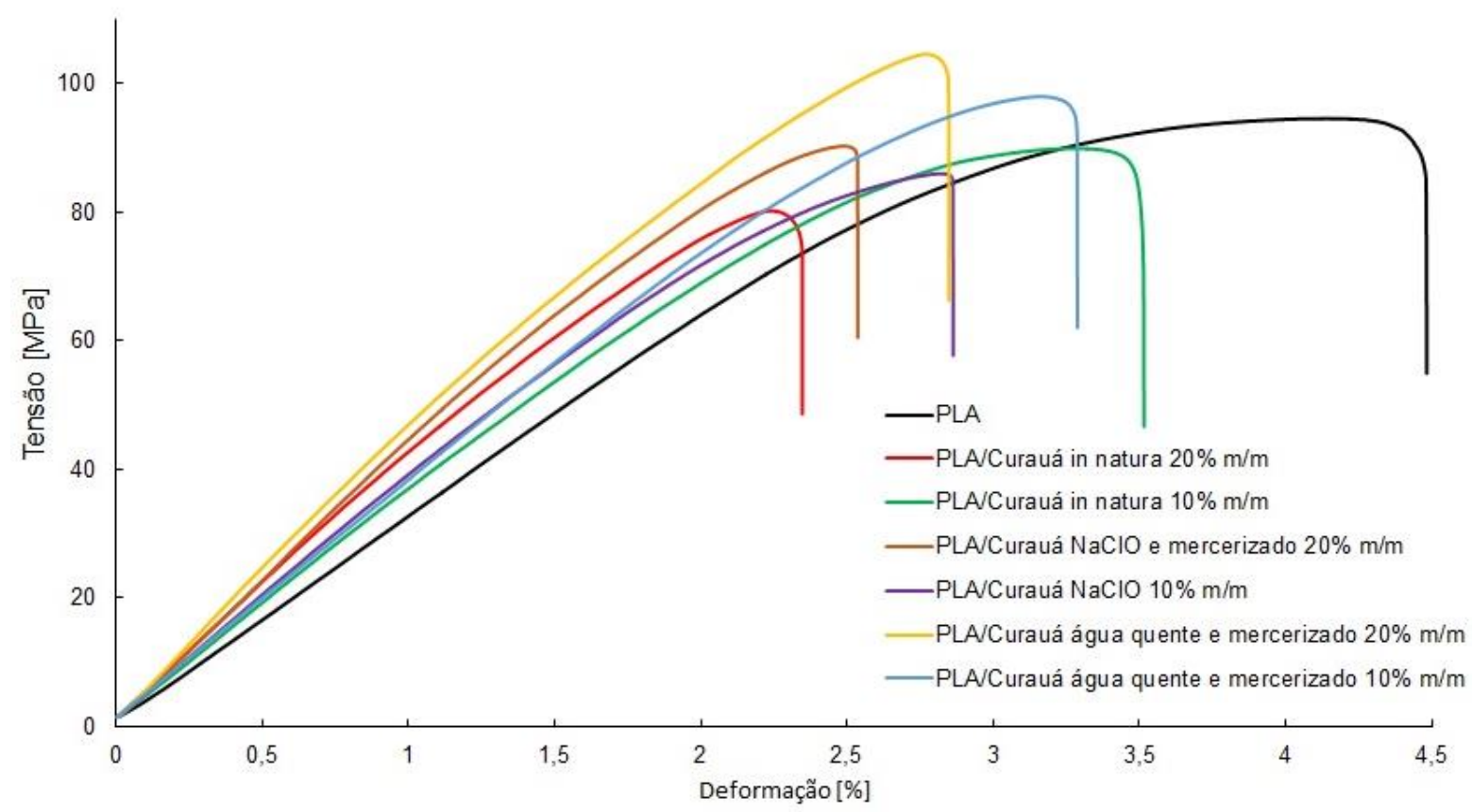

Figura 27 - Comportamento tensão vs deformação em flexão para o PLA e compósitos de PLA/fibra de curauá.

Assim como no ensaio de tração, os compósitos com teor de $20 \%$ de fibras apresentaram maior rigidez, o que foi evidenciado pelo aumento no módulo de elasticidade mostrado na Figura 28, sendo que o compósito mais rígido foi o PLA/Curauá água quente e mercerizado $20 \% \mathrm{~m} / \mathrm{m}$. Isto ocorreu devido ao maior grau de cristalinidade do compósito.

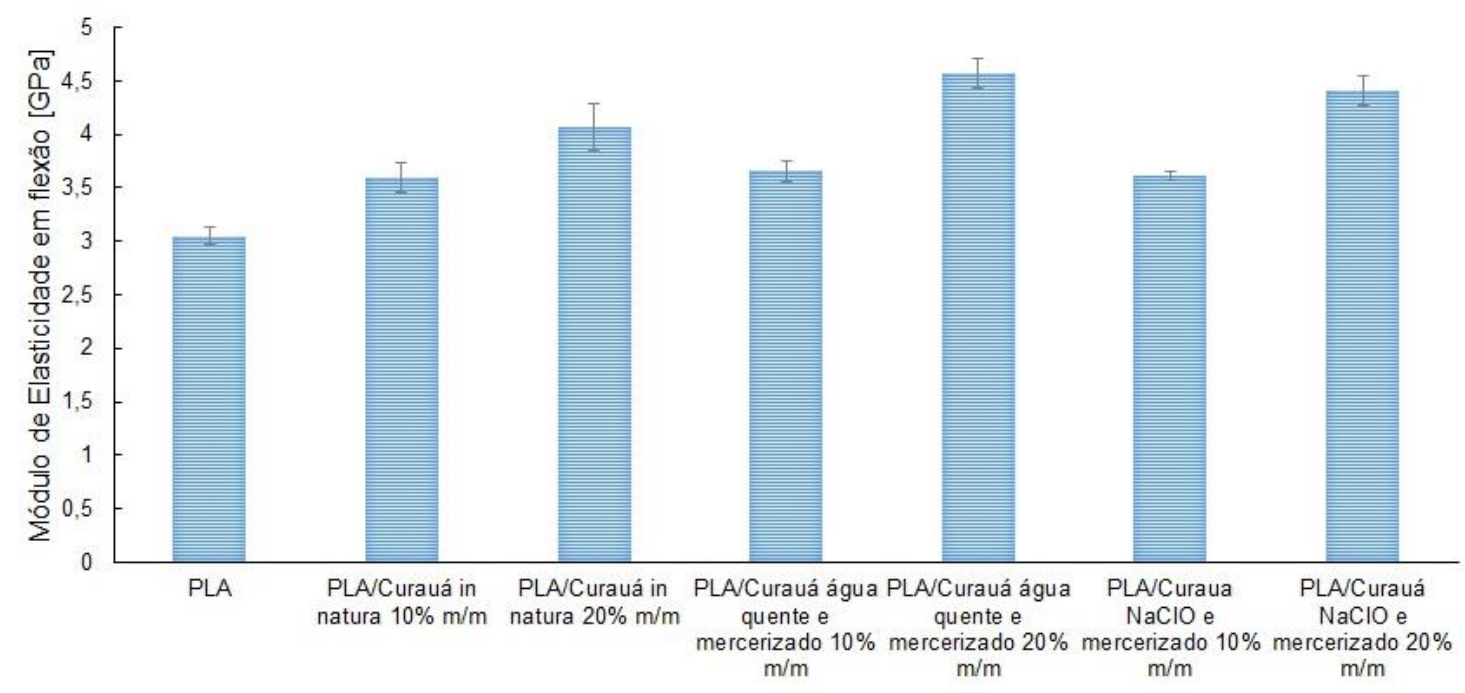

Figura 28 - módulo de elasticidade em flexão para o PLA e compósitos de PLA/fibra de curauá 
O aumento no módulo de elasticidade em flexão do compósito PLA/CA 20\% foi de $50 \%$ em relação ao polímero puro. Os resultados de limite de resistência à flexão são apresentados na Figura 29.

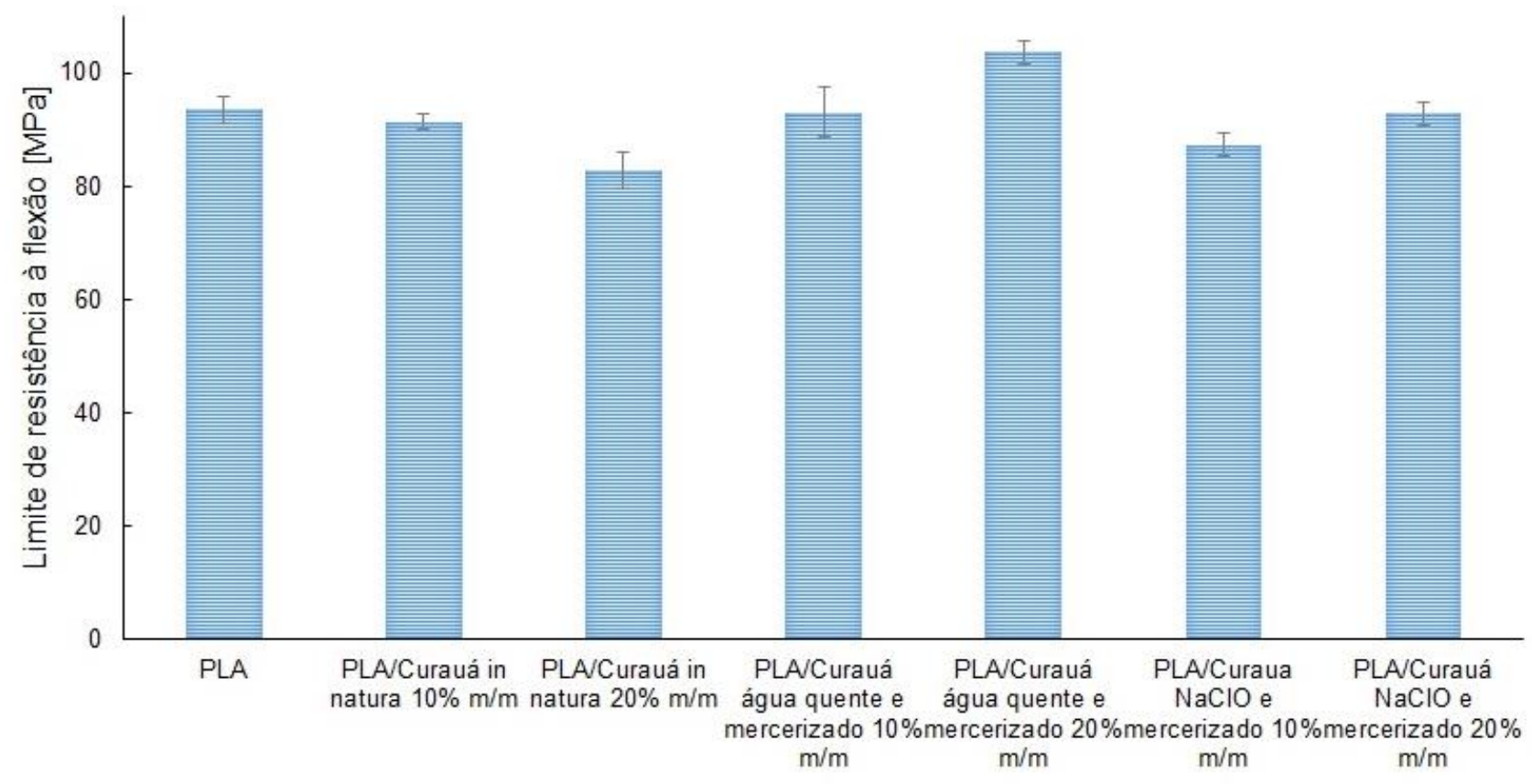

Figura 29 - Limite de resistência à flexão para o PLA e compósitos de PLA/fibra de curauá.

A inserção da fibra na matriz polimérica não acarretou em um aumento no limite de resistência à flexão dos compósitos. Os únicos compósitos que apresentaram aumento nesses valores foram os compósitos reforçados com as fibras de curauá tratadas pela rota utilizando a água. Isto mostrou que essa rota de tratamento foi a que proporcionou maior acoplamento entre a fibra e a matriz polimérica, melhorando assim a adesão entre a fibra e a matriz. Esta maior adesão proporcionou uma transferência de carga maior da matriz para o reforço, aumentando sua resistência à flexão. Os valores de módulo de elasticidade e resistência à flexão estão disponíveis na Tabela 2 do Anexo 1. 


\subsubsection{Ensaio de resistência ao impacto Izod.}

O teste de impacto Izod é utilizado para medir a energia absorvida durante o impacto, ou a tenacidade ao entalhe. O entalhe durante o teste serve como concentrador de tensão, fazendo com que o impacto sofrido gere uma fratura que siga a orientação do entalhe previamente feito. A carga é aplicada como um golpe de impacto gerado por um pêndulo que é liberado de uma altura fixa, após atingir a amostra gera uma fratura que segue o entalhe e o pêndulo continua a oscilar até uma altura menor que a inicial. A energia absorvida pela amostra é computada. Os valores de resistência ao impacto Izod são mostrados na Figura 30.

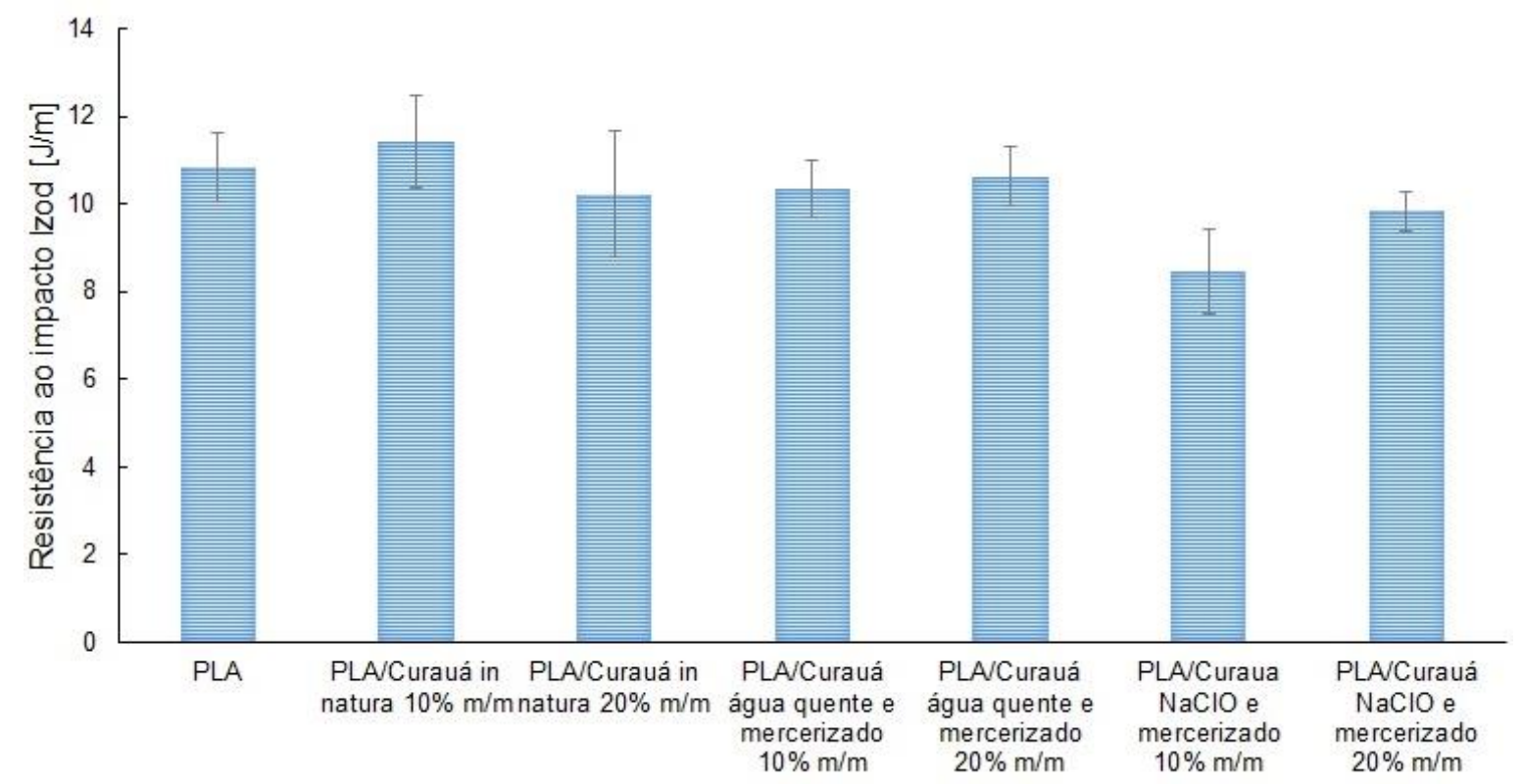

Figura 30 - Resistência ao impacto Izod para o PLA e para os compósitos de PLA/fibra de curauá.

Nota-se a partir da Figura 30 que a inserção da fibra não apresentou nenhuma tendência de aumento à resistência ao impacto. A resistência ao impacto do PLA puro foi de 10,8 ( $\pm 0,7) \mathrm{J} / \mathrm{m}$. Os compósitos de PLA/curauá apresentaram a resistência ao impacto igual ao PLA puro, dentro da faixa de erro calculado, somente o compósito PLA/Curauá $\mathrm{NaClO}$ e mercerizado $10 \% \mathrm{~m} / \mathrm{m}$ apresentou uma resistência ao impacto bem menor que o PLA puro. A resistência ao impacto menor pode ser explicada devido à má adesão da fibra de curauá na matriz de PLA, o que 
não resultou numa boa transferência de carga da matriz para a fibra. Todos os compósitos apresentaram fratura frágil, o que ficou evidenciado pela rápida propagação da trinca, sem que houvessem deformações apreciáveis. Os valores de resistência ao impacto para termoplásticos normalmente são baixos, devido ao fato da carga ser aplicada instantaneamente (19). Os valores de resistência ao impacto Izod estão disponíveis na Tabela 3 do Anexo 1.

\subsection{CARACTERIZAÇÃO DA REGIÃO DA FRATURA}

Estudou-se a região da fratura em tração dos compósitos por Microscopia eletrônica de varredura. A Figura 30 apresenta as micrografias da região da fratura para os compósitos de PLA/fibra de curauá com aumentos de 100 vezes. Com este aumento foi possível avaliar a dispersão da fibra no compósito. Notou-se que a fibra in natura não apresentou boa dispersão na matriz de PLA, para os dois compósitos fabricados, observou-se também que a fibra se uniu a matriz não em forma de fibrila de celulose, já que os componentes amorfos presentes na fibra in natura não permitiram o desfibrilamento da fibra de curauá.

Os compósitos com fibra de curauá lavada com água e mercerizada apresentaram melhor dispersão na matriz de PLA em relação a fibra in natura, houve também uma maior desfibrilação da fibra de curauá. Os compósitos de fibra de curauá lavada com hipoclorito de sódio e mercerizada apresentaram a melhor dispersão da fibra no compósito, ocorreu um grande desfibrilamento e as fibras se apresentaram bem mais espalhadas nas micrografias observadas. 

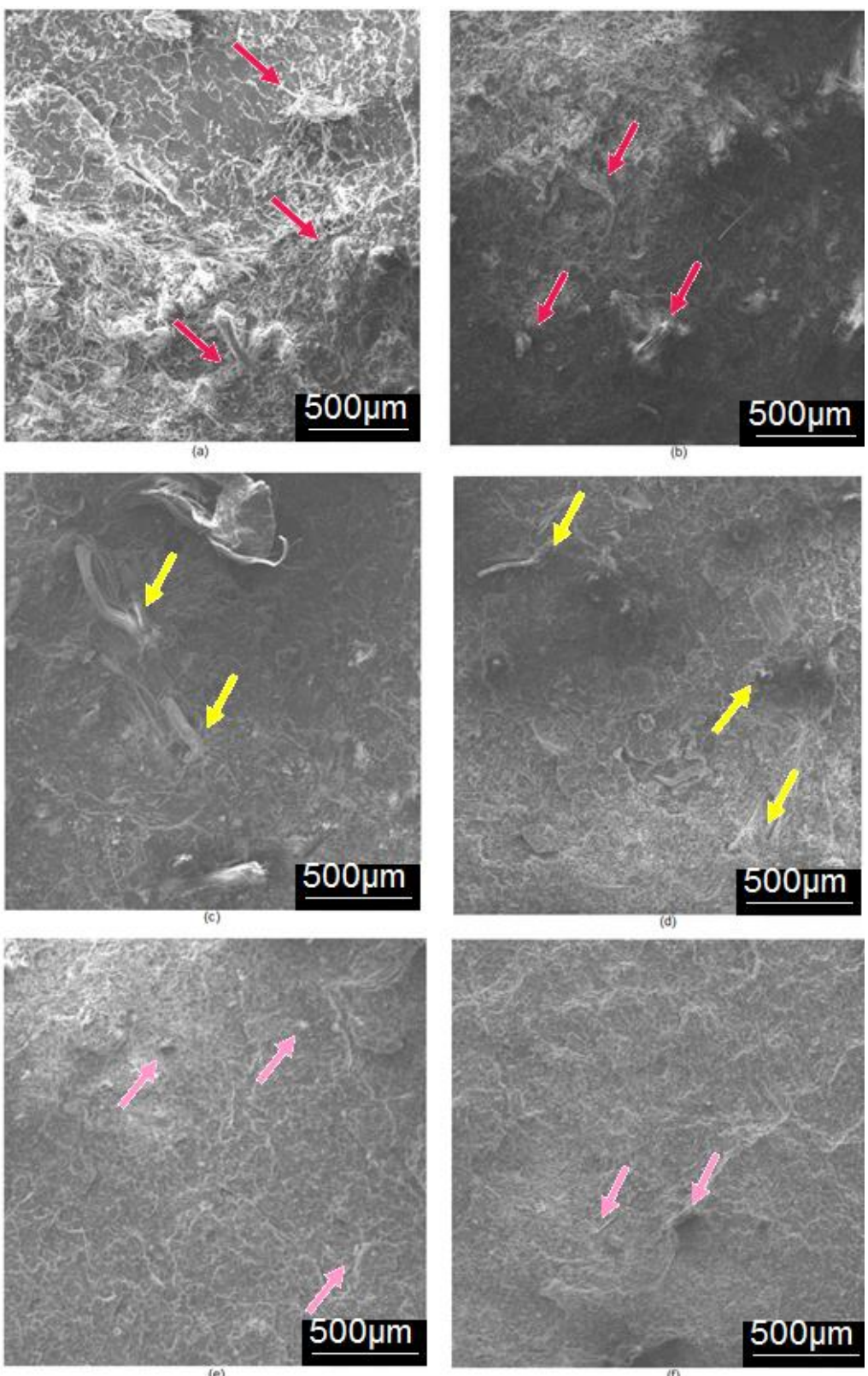

Figura 31 - Região fraturada do corpo de prova do ensaio de tração para os compósitos de PLA/fibra de curauá. a) PLA/Curauá in natura $10 \% \mathrm{~m} / \mathrm{m}$, b) PLA/Curauá in natura $20 \% \mathrm{~m} / \mathrm{m}$, c) PLA/Curauá água quente e mercerizado $10 \% \mathrm{~m} / \mathrm{m}$, d) PLA/Curauá água quente e mercerizado $20 \% \mathrm{~m} / \mathrm{m}$, e) PLA/Curauá $\mathrm{NaClO}$ e mercerizado $10 \% \mathrm{~m} / \mathrm{m}$ e f) PLA/Curauá $\mathrm{NaClO}$ e mercerizado $20 \% \mathrm{~m} / \mathrm{m}$.

A Figura 32 apresenta as micrografias na região de fratura dos corpos de prova ensaiados em tração, estas micrografias foram obtidas em aumentos de 1000 vezes. 


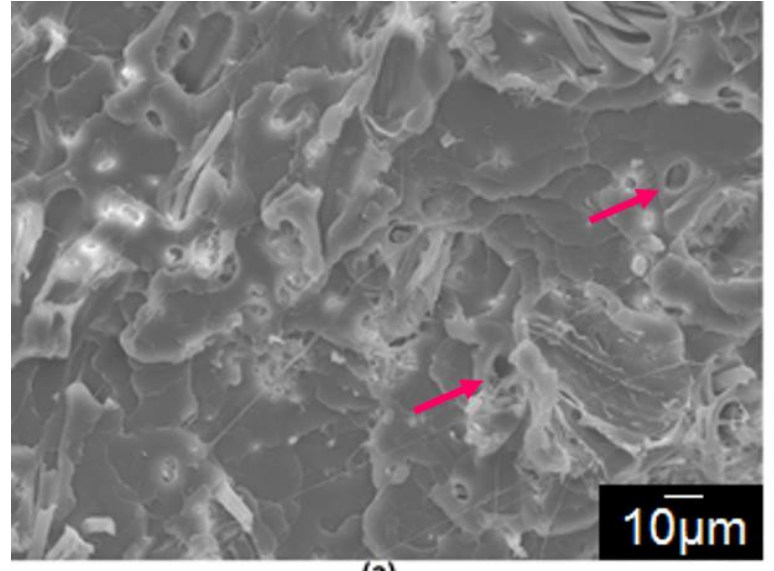

(a)

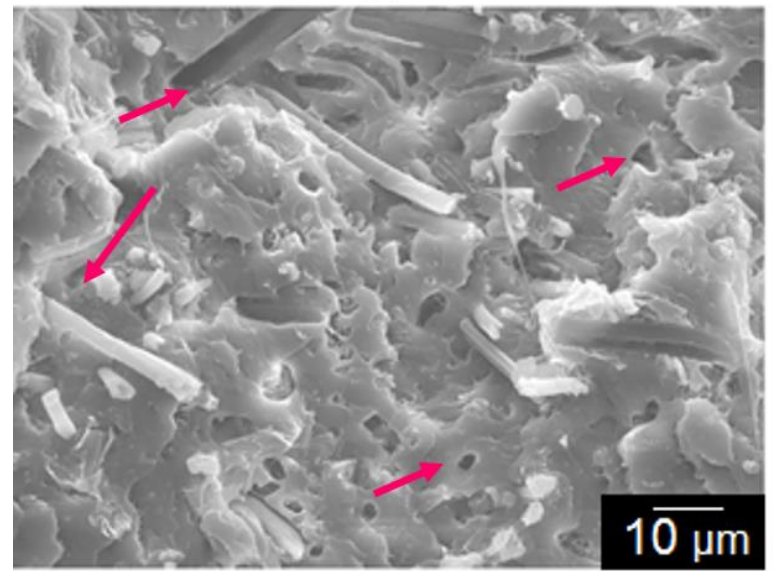

(c)

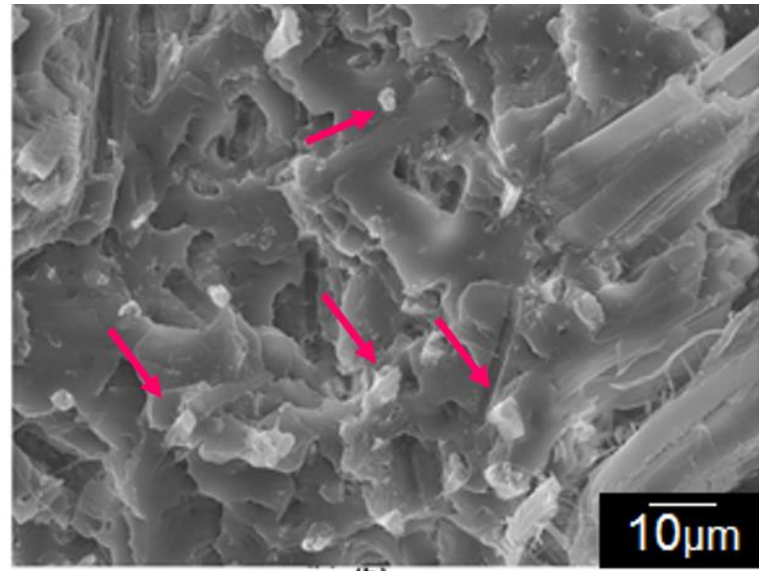

(b)

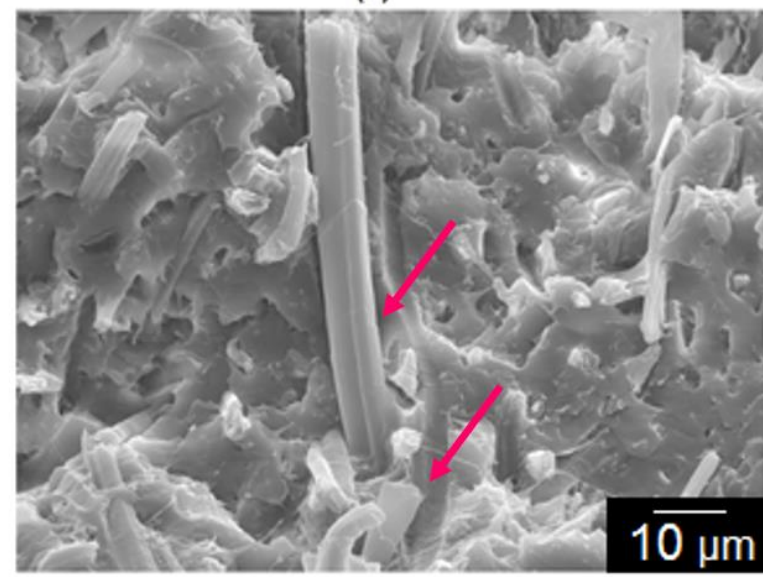

(d)

Figura 32 - Micrografias da seção de ruptura dos corpos de tração para os compósitos mercerizados. a) PLA/Curauá água quente e mercerizada $10 \% \mathrm{~m} / \mathrm{m}$, b) PLA/Curauá água quente e mercerizada $20 \% \mathrm{~m} / \mathrm{m}$, c) PLA/Curauá NaClO e mercerizada $10 \% \mathrm{~m} / \mathrm{m}$ e d) PLA/Curauá $\mathrm{NaClO}$ e mercerizada $20 \% \mathrm{~m} / \mathrm{m}$.

Nas micrografias a) e b) da Figura 32 observou-se que a maioria das fibras de curauá presentes na região estudada se romperam juntamente com a matriz de PLA, apresentando pouco descolamento entre a fibra e a matriz. Esta quebra da fibra juntamente com a matriz evidenciou a boa adesão que a mercerização precedida da rota de lavagem com água quente proporcionou ao compósito. Nos ensaios mecânicos de tração, o compósito PLA/Curauá água quente e mercerizado $20 \% \mathrm{~m} / \mathrm{m}$ apresentou os melhores resultados, isto porque a fibra de curauá utilizada para a produção deste compósito apresentou a melhor adesão, o que permitiu à matriz transferir os esforços recebidos durante o ensaio para a fibra. O compósito com teor de fibras de $20 \%$ em massa apresentou melhores resultados pois esta quantidade de fibras conseguiu suportar os esforços transferidos pela matriz sem que houvesse perda em propriedade mecânica. 
As fibras de curauá mercerizadas e lavadas com solução de hipoclorito de sódio apresentaram uma boa dispersão das fibras no compósito, no entanto a adesão entre a fibra e a matriz foi pequena. Por meio das micrografias $c$ e $d$ da Figura 32, observou-se que houve um grande descolamento da fibra na matriz de PLA. Estas falhas de descolamento mostraram que a matriz não conseguiu transferir os esforços para as fibras de reforço, causando o rompimento da matriz e o descolamento da fibra. Várias falhas pull out foram observadas para estes compósitos, estas falhas foram responsáveis pelo comportamento mecânico inferior destes compósitos quando submetidos aos ensaios de tração. 


\section{CONCLUSÕES}

Das fibras de curauá caracterizadas, notou-se que a lavagem com água aumenta a rugosidade da fibra, no entanto não retira os componentes estruturais da fibra de curauá.

A lavagem da fibra com $\mathrm{NaClO}$ retira componentes estruturais da fibra de curauá, fazendo com que a mercerização na fibra lavada com $\mathrm{NaClO}$ retire ainda mais componentes estruturais, deixando-a mais quebradiça.

O comportamento térmico dos compósitos foi semelhante ao comportamento térmico do PLA, não houve grande perda de estabilidade térmica devido à introdução da fibra de curauá e não houve inserção de patamares de degradação diferentes do polímero puro. Os compósitos de PLA/Curauá apresentaram maior grau de cristalinidade que o polímero puro, devido ao grau cristalinidade das fibras de curauá.

O compósito PLA/Curauá lavado com água e mercerizado com $20 \%$ em massa de fibra apresentou maiores propriedades mecânicas em tração e flexão em relação ao compósito puro, maior cristalinidade e melhor adesão interfacial. 


\section{PROPOSTAS PARA TRABALHOS FUTUROS}

Os resultados obtidos forneceram informações importantes para uma inicial caracterização dos compósitos de PLA reforçados com fibra de curauá, no entanto para um estudo mais completo recomenda-se a realização de ensaio de análise dinâmico mecânica (DMA) para a caracterização mecânica dos compósitos frente ao aumento da temperatura.

Testes de sensibilidade à radiação ultravioleta também serão de grande importância para a caracterização dos compósitos.

Outro ensaio importante para a total caracterização do compósito é o teste de biodegradabilidade. Este teste mostrará e comprovará o caráter renovável e sustentável dos compósitos obtidos, além de prever a durabilidade dos compósitos. 


\section{ANEXO 1}

Tabela 1 - Valores médios das propriedades mecânicas obtidos a partir do ensaio de tração.

\begin{tabular}{|l|c|c|c|}
\hline & $\begin{array}{c}\text { Módulo de } \\
\text { elasticidade [MPa] }\end{array}$ & $\begin{array}{c}\text { Limite de } \\
\text { resistência à } \\
\text { tração [MPa] }\end{array}$ & $\begin{array}{c}\text { Deformação } \\
\text { [\%] }\end{array}$ \\
\hline PLA & $5,64 \pm 0,21$ & $58,21 \pm 2,19$ & $1,84 \pm 0,26$ \\
\hline $\begin{array}{l}\text { PLA/Curauá in } \\
\text { natura 10\% m/m }\end{array}$ & $5,88 \pm 0,68$ & $57,69 \pm 1,09$ & $1,38 \pm 0,21$ \\
\hline $\begin{array}{l}\text { PLA/Curauá in } \\
\text { natura 20\% m/m }\end{array}$ & $7,37 \pm 0,57$ & $60,28 \pm 3,00$ & $1,07 \pm 0,12$ \\
\hline $\begin{array}{l}\text { PLA/Curauá água } \\
\text { quente e } \\
\text { mercerizado 10\% } \\
\text { m/m }\end{array}$ & $6,76 \pm 0,42$ & $66,7 \pm 1,66$ & $1,28 \pm 0,06$ \\
\hline $\begin{array}{l}\text { PLA/Curauá água } \\
\text { quente e } \\
\text { mercerizado 20\% } \\
\text { m/m }\end{array}$ & $8,88 \pm 0,84$ & $75,78 \pm 4,73$ & $1,14 \pm 0,21$ \\
\hline $\begin{array}{l}\text { PLA/Curauá } \\
\text { NaClO e } \\
\text { mercerizado 10\% } \\
\text { m/m }\end{array}$ & $6,63 \pm 0,40$ & $57,69 \pm 1,86$ & $1,19 \pm 0,10$ \\
\hline $\begin{array}{l}\text { PLA/Curauá } \\
\text { NaClO } \\
\text { mercerizado 20\% } \\
\mathrm{m} / \mathrm{m}\end{array}$ & $7,95 \pm 0,46$ & $63,40 \pm 2,25$ & $1,13 \pm 0,09$ \\
\hline
\end{tabular}

Tabela 2 - Valores médios das propriedades mecânicas obtidos a partir do ensaio de flexão.

\begin{tabular}{|c|c|c|c|}
\hline PLA & $\begin{array}{c}\text { Módulo de } \\
\text { elasticidade [MPa] }\end{array}$ & $\begin{array}{c}\text { Limite de } \\
\text { resistência [MPa] }\end{array}$ & $\begin{array}{c}\text { Elongação } \\
\text { máxima [mm] }\end{array}$ \\
\hline $\begin{array}{c}\mathrm{PLA} / \text { Curauá in } \\
\text { natura 10\% m/m }\end{array}$ & $3,05 \pm 0,08$ & $93,53 \pm 2,41$ & $4,43 \pm 0,19$ \\
\hline $\begin{array}{c}\mathrm{PLA} / \text { Curauá in } \\
\text { natura 20\% m/m }\end{array}$ & $4,07 \pm 0,22$ & $91,38 \pm 1,42$ & $3,41 \pm 0,2$ \\
\hline $\begin{array}{c}\mathrm{PLA} / \text { Curauá água } \\
\text { quente e } \\
\text { mercerizado 10\% } \\
\mathrm{m} / \mathrm{m}\end{array}$ & $3,66 \pm 0,10$ & $93,14 \pm 4,28$ & $2,35 \pm 0,10$ \\
\hline $\begin{array}{c}\mathrm{PLA} / \text { Curauá água } \\
\text { quente e } \\
\text { mercerizado 20\% } \\
\mathrm{m} / \mathrm{m}\end{array}$ & $4,57 \pm 0,14$ & $103,66 \pm 1,99$ & $2,05 \pm 0,20$ \\
\hline $\begin{array}{c}\mathrm{PLA} / \mathrm{Curauá} \\
\mathrm{NaClO} \text { e } \\
\text { mercerizado 10\% } \\
\mathrm{m} / \mathrm{m}\end{array}$ & $3,61 \pm 0,04$ & $87,34 \pm 1,94$ & $2,90 \pm 0,12$ \\
\hline $\begin{array}{c}\mathrm{PLA} / \mathrm{Curauá} \\
\mathrm{NaClO}\end{array}$ & $4,42 \pm 0,14$ & $92,8 \pm 2,00$ & $2,52 \pm 0,10$ \\
$\begin{array}{c}\mathrm{mercerizado} \mathrm{20 \%} \\
\mathrm{m} / \mathrm{m}\end{array}$ & & \\
\hline
\end{tabular}


Tabela 3 - Valores médios das propriedades mecânicas obtidos no ensaio de resistência ao impacto Izod.

\begin{tabular}{|l|c|}
\hline & $\begin{array}{c}\text { Resistência ao } \\
\text { impacto Izod [J/m] }\end{array}$ \\
\hline PLA & $10,82 \pm 0,78$ \\
\hline $\begin{array}{l}\text { PLA/Curauá in } \\
\text { natura } 10 \% \mathrm{~m} / \mathrm{m}\end{array}$ & $11,42 \pm 1,04$ \\
\hline $\begin{array}{l}\text { PLA/Curauá in } \\
\text { natura 20\% m/m }\end{array}$ & $10,23 \pm 1,44$ \\
\hline $\begin{array}{l}\text { PLA/Curauá água } \\
\text { quente e } \\
\text { mercerizado 10\% } \\
\text { m/m }\end{array}$ & $10,34 \pm 0,63$ \\
\hline $\begin{array}{l}\text { PLA/Curauá água } \\
\text { quente e } \\
\text { mercerizado 20\% } \\
\text { m/m }\end{array}$ & $10,64 \pm 0,66$ \\
\hline $\begin{array}{l}\text { PLA/Curauá } \\
\text { NaClO e } \\
\text { mercerizado 10\% } \\
\text { m/m }\end{array}$ & $8,44 \pm 0,97$ \\
\hline $\begin{array}{l}\text { PLA/Curauá } \\
\text { NaClO } \\
\text { mercerizado 20\% } \\
\text { m/m }\end{array}$ & $9,84 \pm 0,45$ \\
\hline
\end{tabular}




\section{BIBLIOGRAFIA}

1. Silva, R.V., Aquino, E. M. F. Curaua Fiber: A New Alternative to Polymeric Composites. J Reinf Plast Compos. 2008;27(1):103-12.

2. Komuraiah, A., Kumar, N. S., Prasad, B. D. Chemical Composition of Natural Fibers and its Influence on their Mechanical Properties. Mech Compos Mater. 2014;50(3):359-76.

3. Smith, W.F., Hashemi, J. Fundamentos de Engenharia e Ciências dos Materiais. 5 ed. McGraw-Hill; 2012. 734 p.

4. Albinante, S. R., Beatriz, É., Vasques, A., Lea, L., Visconte, Y. Revisão. 2013;36(1):114-22.

5. Faruk, O., Bledzki, A. K., Fink, H., Sain, M. Progress in Polymer Science Biocomposites reinforced with natural fibers : 2000 - 2010. Prog Polym Sci. 2012;37(11):1552-96.

6. Silva, R., Haraguchi, S. K., Muniz, E. C., Rubira, A. F. Aplicações de fibras lignocelulósicas na química de polímeros e em compósitos. Quim Nova. 2009;32(3):661-71.

7. Pandey, J. K., Ahn, S. H., Lee, C. S., Mohanty, A. K., Misra, M. Recent advances in the application of natural fiber based composites. Macromol Mater Eng. 2010;295(11):975-89.

8. Spinacé, M. A. S., Lambert, C. S., Fermoselli, K. K. G., De Paoli, M. A. Characterization of lignocellulosic curaua fibres. Carbohydr Polym. 2009;77(1):47-53.

9. Zah, R., Hischier, R., Leão, A. L., Braun I. Curaua fibers in the automobile industry - a sustainability assessment. J Clean Prod. 2007;15(11-12):1032-40.

10. Santos, P. A., Spinacé, M. A. S., Fermoselli, K. K. G., De Paoli, M. A. Efeito da forma de processamento e do tratamento da fibra de curauá nas propriedades de compósitos com poliamida-6. Polímeros. 2009;19:31-9.

11. Ereno, D. Fibra para toda obra. Pesqui Fapesp. 2004;104:70-5.

12. Falcone, D. M. B., Agnelli, J. A. M., De Faria, L. I. L. Panorama setorial e 
perspectivas na área de polímeros biodegradáveis. Polimeros. 2007;17(1):5-9.

13. Rasal, R. M., Janorkar, A. V., Hirt DE. Poly(lactic acid) modifications. Prog Polym Sci. 2010;35(3):338-56.

14. Saeidlou, S., Huneault, M. A., Li, H., Park, C. B. Poly(lactic acid) crystallization. Prog Polym Sci. 2012;37(12):1657-77.

15. Raquez, J. M., Habibi, Y., Murariu, M., Dubois, P. Polylactide (PLA)-based nanocomposites. Prog Polym Sci. 2013;38(10-11):1504-42.

16. Mathew, A. P., Oksman, K. Sain, M. Mechanical properties of biodegradable composites from poly lactic acid (PLA) and microcrystalline cellulose (MCC). J Appl Polym Sci. 2005;97(5):2014-25.

17. De Fatima, V. Marques, M., Melo, R. P., Da S. Araujo, R., Do N. Lunz, J., De O. Aguiar, V. Improvement of mechanical properties of natural fiberpolypropylene composites using successive alkaline treatments. J Appl Polym Sci. 2015;132(12):1-12.

18. Callister, W. D. Ciência e Engenharia de Materiais uma introdução. 7 ed. LTC; 2008.

19. Askeland D. R., Phulé, P. P. Ciência e Engenharia dos Materiais. 1 ed. Cengage Learning; 2011.

20. Chou, T. W., Kelly, A. Mechanical-Properties of Composites. Annu Rev Mater Sci. 1980;10:229-59.

21. Jones, R. M. Mechanics of Composite Materials. 2 ed. Taylor \& Francis Group; 1999.

22. Romão, C. M. N. Estudo do comportamento mecânico de materiais compósitos de matriz polimérica reforçados com fibras naturais. 2003.

23. Mano, B., Araujo, J. R., De Paoli, M-A., Waldman, W. R., Spinace, M. A. Mechanical properties, morphology and thermal degradation of a biocomposite of polypropylene and curaua fibers: coupling agent effect. Polímeros Ciência e Tecnol. 2013;23(2):161-8.

24. Abdelmouleh, M., Boufi, S. SCIENCE AND Short natural-fibre reinforced 
polyethylene and natural rubber composites : Effect of silane coupling agents and fibres loading. 2007;67:1627-39.

25. Huda, M. S., Drzal, L. T., Mohanty, A. K., Misra, M. Effect of fiber surfacetreatments on the properties of laminated biocomposites from poly(lactic acid) (PLA) and kenaf fibers. Compos Sci Technol. 2008;68(2):424-32.

26. Kalia, S., Kaith, B. S., Kaur, I. Pretreatments of Natural Fibers and their Application as Reinforcing Material in Polymer Composites - A Review. 2009;

27. George, J., Sreekala, M. S., Thomas, S., George, J., Sreekala, M. S., Thomas S. A Review on Interface Modification and Characterization of Natural Fiber Reinforced Plastic Composites. 2001;41(9).

28. Li, X., Tabil, G. L., Panigrahi, S. Chemical Treatments of Natural Fiber for Use in Natural Fiber-Reinforced Composites : A Review. 2007;25-33.

29. Gomes, A., Goda, K., Ohgi, J. Effects of Alkali Treatment to Reinforcement on Tensile Properties of Curaua Fiber Green Composites. JSME Int J Ser A. 2004;47:541-6.

30. Xie, Y., Hill, C. A. S., Xiao, Z., Militz, H., Mai, C. Composites : Part A Silane coupling agents used for natural fiber / polymer composites : A review. Compos Part A. 2010;41(7):806-19.

31. Gonzalez, D., Santos, V., Parajo, J. C. Silane-treated lignocellulosic fibers as reinforcement material in polylactic acid biocomposites. J Thermoplast Compos Mater. 2011;25(8):1005-22.

32. Rodrigues, J., Souza, J. A., Fujiyama, R. Compósitos poliméricos reforçados com fibras naturais da Amazônia fabricados por infusão. Rev Mater. 2015;20(4):946-60.

33. Gomes, A., Matsuo, T., Goda, K., Ohgi, J. Development and effect of alkali treatment on tensile properties of curaua fiber green composites. Compos Part A Appl Sci Manuf. 2007;38(8):1811-20.

34. Canevarolo Jr, S. V. Ciência dos Polímeros. 3 ed. Artliber; 2010. 280 p.

35. De Paiva, J. M. F., Frollini, E. Unmodified and modified surface sisal fibers as 
reinforcement of phenolic and lignophenolic matrices composites: Thermal analyses of fibers and composites. Macromol Mater Eng. 2006;291(4):405-17.

36. Morais, J. P. S., Rosa, M. F., Marconcini, J. M. Procedimentos para análise lignocelulósica. 2010.

37. Xu, F., Shi, Y., Wang, D. X-ray scattering studies of lignocellulosic biomass : A review. Carbohydr Polym. 2017;94(2):904-17.

38. ASTM D638 Norma. Standard Test Method for Tensile Properties of Plastics. Annu B ASTM Stand. 2004;1-15.

39. The American Society for Testing and Materials PM. Standard Test Methods for Flexural Properties of Unreinforced and Reinforced Plastics and Electrical Insulating Materials 1. 2002;1-12.

40. ASTM International. ASTM D256 - Standard Test Methods for Determining the Izod Pendulum Impact Resistance of Plastics. Annu B ASTM Stand. 2010;120.

41. Sena Neto, A. R., Araujo, M. A. M., Souza, F. V. D., Mattoso, L. H. C., Marconcini, J. M. Characterization and comparative evaluation of thermal, structural, chemical, mechanical and morphological properties of six pineapple leaf fiber varieties for use in composites. Ind Crops Prod. 2013;43(1):529-37.

42. Yang, H., Yan, R., Chen, H., Lee, D. H., Zheng, C. Characteristics of hemicellulose, cellulose and lignin pyrolysis. Fuel. 2007;86(12-13):1781-8.

43. Liu, Q., Zhong, Z., Wang, S., Luo, Z. Interactions of biomass components during pyrolysis: A TG-FTIR study. J Anal Appl Pyrolysis. 2011;90(2):213-8.

44. Singh, S., Wu, C., Williams, P. T. Journal of Analytical and Applied Pyrolysis Pyrolysis of waste materials using TGA-MS and TGA-FTIR as complementary characterisation techniques. J Anal Appl Pyrolysis. 2012;94:99-107.

45. Gupta, B., Revagade, N., Hilborn, J. Poly(lactic acid) fiber: An overview. Prog Polym Sci. 2007;32(4):455-82.

46. Lim, L-T., Auras, R., Rubino, M. Processing technologies for poly(lactic acid). Prog Polym Sci. 2008;33(8):820-52. 
47. Fortunati, E., Armentano, I., Zhou, Q., Puglia, D., Terenzi, A., Berglund, L. A. Microstructure and nonisothermal cold crystallization of PLA composites based on silver nanoparticles and nanocrystalline cellulose. Polym Degrad Stab. 2012;97(10):2027-36.

48. Lodi, P. C. Aspecto de degradação de geomembranas poliméricas de polietileno de alta densidade (PEAD) e de poli (cloreto de vinila) (PVC). Tese de doutorado. Universidade de São Paulo; 2003.

49. Ochi, S. Mechanical properties of kenaf fibers and kenaf/PLA composites. Mech Mater. 2008;40(4-5):446-52. 